\title{
The comparative osteology of Plesiochelys bigleri n. sp., a new coastal marine turtle from the Late Jurassic of Porrentruy (Switzerland)
}

\author{
Christian Püntener ${ }^{\text {Corresp., } 1}$ ， Jérémy Anquetin ${ }^{2,3}$, Jean-Paul Billon-Bruyat ${ }^{1}$ \\ ${ }^{1}$ Section d'archéologie et paléontologie, Office de la culture, République et Canton du Jura, Porrentruy, Switzerland \\ 2 JURASSICA Museum, Porrentruy, Switzerland \\ 3 Department of Geosciences, University of Fribourg, Fribourg, Switzerland \\ Corresponding Author: Christian Püntener \\ Email address: christian.puntener@jura.ch
}

Background. During the Late Jurassic several groups of eucryptodiran turtles inhabited the shallow epicontinental seas of Western Europe. Plesiochelyidae are an important part of this first radiation of crown group turtles into coastal marine ecosystems. Fossils of Plesiochelyidae occur in many European localities, and are especially abundant in the Kimmeridgian layers of the Swiss Jura Mountains (Solothurn and Porrentruy). In the mid 19th century, the quarries of Solothurn (NW Switzerland) already provided a large amount of fossil turtles, most notably Plesiochelys etalloni, the best-known plesiochelyid species. Recent excavations in the Porrentruy area (NW Switzerland) revealed new fossils of Plesiochelys, including numerous well-preserved shells with associated cranial and postcranial material.

Methods/Results. Out of 80 shells referred to Plesiochelys, 41 are assigned to a new species, PI. bigleri n. sp., including a skull-shell association. We furthermore refer 15 shells to Pl. etalloni, and 24 shells to Plesiochelys sp. Anatomical comparisons show that PI. bigleri can clearly be differentiated from PI. etalloni by cranial features. The shell anatomy and the appendicular skeleton of PI. bigleri and PI. etalloni are very similar. However, a statistical analysis demonstrates that the thickness of neural bones allows to separate the two species based on incomplete material. This study furthermore illustrates the extent of intraspecific variation in the shell anatomy of PI. bigleri and PI. etalloni. 
1 The comparative osteology of Plesiochelys bigleri n. sp., a new coastal marine turtle from

2 the Late Jurassic of Porrentruy (Switzerland)

3

4 Christian Püntener ${ }^{1}$, Jérémy Anquetin², ${ }^{2}$, Jean-Paul Billon-Bruyat ${ }^{1}$

5

$6{ }^{1}$ Section d'archéologie et paléontologie, Office de la culture, République et Canton du Jura,

7 Porrentruy, Switzerland

$8 \quad 2$ JURASSICA Museum, Porrentruy, Switzerland

$9 \quad{ }^{3}$ Department of Geosciences, University of Fribourg, Fribourg, Switzerland

10

11 Corresponding Author:

12 Christian Püntener

13

14 Email address: christian.puntener@jura.ch 
15 ABSTRACT

16 Background. During the Late Jurassic several groups of eucryptodiran turtles inhabited the

17 shallow epicontinental seas of Western Europe. Plesiochelyidae are an important part of this first

18 radiation of crown group turtles into coastal marine ecosystems. Fossils of Plesiochelyidae occur in many European localities, and are especially abundant in the Kimmeridgian layers of the Swiss Jura Mountains (Solothurn and Porrentruy). In the mid 19th century, the quarries of Solothurn (NW Switzerland) already provided a large amount of fossil turtles, most notably Plesiochelys etalloni, the best-known plesiochelyid species. Recent excavations in the Porrentruy area (NW Switzerland) revealed new fossils of Plesiochelys, including numerous well-preserved shells with associated cranial and postcranial material.

Methods/Results. Out of 80 shells referred to Plesiochelys, 41 are assigned to a new species, $P l$. bigleri $\mathrm{n}$. sp., including a skull-shell association. We furthermore refer 15 shells to Pl. etalloni, and 24 shells to Plesiochelys sp. Anatomical comparisons show that Pl. bigleri can clearly be differentiated from $P l$. etalloni by cranial features. The shell anatomy and the appendicular skeleton of $P l$. bigleri and $P l$. etalloni are very similar. However, a statistical analysis demonstrates that the thickness of neural bones allows to separate the two species based on incomplete material. This study furthermore illustrates the extent of intraspecific variation in the shell anatomy of $P l$. bigleri and $P$. etalloni. 


\section{INTRODUCTION}

The first radiation of crown-group turtles into marine environments occurred in Western Europe during the Late Jurassic. At that time, several groups of basal pan-cryptodiran turtles, traditionally referred to the families Plesiochelyidae Baur, 1888, Thalassemydidae Zittel, 1889, and Eurysternidae Dollo, 1886, colonized coastal ecosystems from restricted lagoons to more open seaways. These turtles eventually disappeared at the Jurassic-Cretaceous boundary following major sea-level changes that restricted their habitats (e.g., Bardet, 1994; Bardet, 1995; Bardet et al., 2014), although some phylogenetic analyses suggest that eurysternids may have survived into the Cretaceous in the form of Sandownidae or even Protostegidae (e.g., Joyce, 2007).

Plesiochelyids are relatively large coastal marine turtles known from the Late Jurassic of Switzerland, France, Germany, England, Spain, and Portugal. They are notably characterized by a fully ossified carapace and a series of derived basicranial features (Gaffney, 1975a; Gaffney, 1976; Anquetin, Püntener \& Billon-Bruyat, 2015). Plesiochelys etalloni (Pictet \& Humbert, 1857 ) is undoubtedly the best known plesiochelyid turtle, thanks notably to numerous specimens found in Solothurn, Switzerland (Rütimeyer, 1873; Bräm, 1965; Gaffney, 1975a; Gaffney, 1976; Anquetin, Püntener \& Billon-Bruyat, 2014; Anquetin, Püntener \& Billon-Bruyat, 2015).

Plesiochelys etalloni is known by both skulls and shells from the Kimmeridgian of the Swiss and French Jura Mountains, southern England, and northwestern Germany (Pictet \& Humbert, 1857; Rütimeyer, 1873; Bräm, 1965; Karl et al., 2007; Anquetin, Deschamps \& Claude, 2014, Anquetin, Püntener \& Billon-Bruyat, 2014; Anquetin, Püntener \& Billon-Bruyat, 2015; Anquetin \& Chapman, 2016). Plesiochelys planiceps (Owen, 1842), the only other valid species in the genus, is known only from a single specimen (cranium, mandibule, and remains of the hyoids 
and cervical vertebrae) from the Tithonian of the Isle of Portland, UK. The cranium of $P l$.

planiceps differs in many aspects from that of Pl. etalloni (Anquetin, Püntener \& Billon-Bruyat, 2015).

In the present study we describe new material of Plesiochelys from the Kimmeridgian of Porrentruy, Canton Jura, Switzerland. The new specimens were found by the Paleontology A16 project, which rescued the paleontological material discovered during the construction of the A16 Transjurane highway. These excavations yielded a great number of fossil vertebrates from Kimmeridgian layers, notably including dinosaur trackways (Marty \& Hug, 2003; Marty et al., 2007; Marty, 2008; Marty \& Billon-Bruyat, 2009) and numerous coastal marine turtles (BillonBruyat, 2005a). The rich and diverse turtle fauna from Porrentruy notably includes different species of Plesiochelyidae and Thalassemydidae (see Geological setting) (Püntener et al., 2014; Anquetin, Püntener \& Billon-Bruyat, 2015; Püntener, Anquetin \& Billon-Bruyat, 2015).

As in Solothurn, Plesiochelys is by far the most common turtle taxon in the Kimmeridgian of Porrentruy. Slightly more than 100 relatively complete, but mostly disarticulated shells were discovered during the excavations, out of which 80 can be referred to Plesiochelys. Among these shells, 41 are herein assigned to a new species, Plesiochelys bigleri $\mathrm{n}$. sp. We furthermore refer 15 shells to Plesiochelys etalloni, and 24 shells to Plesiochelys sp. This material is described in detail herein. The shell of $P l$. bigleri shows only minor anatomical differences with that of $P l$. etalloni, but cranial anatomy clearly distinguishes the two species. Two skulls, one associated with a shell and the other found isolated, are known for Pl. bigleri. A statistical analysis confirms that the thickness of neural bones allows to separate the two species and to tentatively identify otherwise indeterminate specimens. Based on abundant shell material, the intraspecific variations in both species are discussed in details. Finally, we fully describe and illustrate elements of the 
appendicular skeleton, which are otherwise rarely described in the literature, hoping that this will facilitate future comparisons.

\section{MATERIAL AND METHODS}

\section{Material}

The present study is based on a collection of 80 relatively complete, but mostly disarticulated shells (Table 1), most of which were found in a single stratigraphical layer in the Porrentruy region (see Geological setting, below). Forty-one shells are referred to a new species, Plesiochelys bigleri $\mathrm{n}$. sp. One of these specimens (MJSN TCH007-252) is a skull-shell association, which we designate as the holotype of the new species. An isolated cranium (MJSN TCH006-1451) is also referred to this new species and designated as its paratype.

Fifteen out of the 80 aforementioned shells are identified as Plesiochelys etalloni. The identification of the remaining 24 shells is uncertain because they lack diagnostic features. These specimens are therefore referred to Plesiochelys sp. However, a tentative identification of some of these specimens is provided herein based on the statistical analysis of neural bone thickness (see below).

\section{Geological setting}

All of the specimens were collected between 2001 and 2011 near the small town of Courtedoux, along the A16 Transjurane highway in the Ajoie Region, Canton of Jura, NW Switzerland (Fig. 1). The majority of the specimens come from the Lower Virgula Marls (Reuchenette Formation, Chevenez Member; Comment et al., 2015) of the sites of Bois de Sylleux (BSY; 47²4'52.22"N 
$\left.1027^{\circ} 01^{\prime} 21.99 " \mathrm{E}\right)$, Sur Combe Ronde (SCR; 47²4'00.3"N 701'35.98"E), and Tchâfouè (TCH; $10347^{\circ} 24^{\prime} 14.01^{\prime \prime} \mathrm{N} 7^{\circ} 01^{\prime} 21.57^{\prime \prime} \mathrm{E}$ ) (Fig. 2). These sites yielded a rich and diverse coastal marine

104 105 106 107 108 assemblage, including invertebrates (bivalves, gastropods, cephalopods, crustaceans, and echinoderms), vertebrates (chondrichthyans, osteichthyans, turtles, crocodilians, and pterosaurs), and wood remains (e.g., Billon-Bruyat, 2005a; Billon-Bruyat, 2005b; Marty \& Billon-Bruyat, 2009; Philippe et al., 2010; Schaefer, 2012; Comment et al., 2015; Koppka, 2015; Leuzinger et al., 2015).

Plesiochelys is the dominating turtle taxon in the Lower Virgula Marls. Other taxa occur only in small numbers, including Tropidemys langii Rütimeyer, 1873, Portlandemys gracilis Anquetin, Püntener \& Billon-Bruyat, 2015, Thalassemys hugii Rütimeyer, 1873, and Thalassemys bruntrutana Püntener, Anquetin \& Billon-Bruyat, 2015 (Püntener et al., 2014; Anquetin, Püntener \& Billon-Bruyat, 2015; Püntener, Anquetin \& Billon Bruyat, 2015). The Lower Virgula Marls are dated from the Eudoxus ammonite zone (early late Kimmeridgian; Comment et al., 2015) and are therefore slightly older than the Solothurn Turtle Limestone, which forms the uppermost member of the Reuchenette Formation and is dated from the Autissiodorensis ammonite zone (Meyer, 1994; Comment, Ayer \& Becker, 2011). One specimen of Plesiochelys bigleri (MJSN CRT007-2) has been discovered within the dinosaur track-bearing tidal laminites of the Crat site (CRT; 47²3'55.8"N 701'43.65"E; Fig. 2) (Billon-Bruyat et al., 2012). These laminites represent the lowermost layers of the Corbis Limestones and are dated from the Cymodoce ammonite zone (late early Kimmeridgian; Comment et al., 2015). Two other specimens of Plesiochelys bigleri (MJSN VTT006-299 and MJSN VTT006-579) are stratigraphically slightly older and come from the Banné Marls of the 
124 Vâ Tche Tchâ site (VTT; 47²5'10.13"N 701'04.44"E; Cymodoce ammonite zone; Fig. 2),

125 where Tropidemys langii is the dominating turtle taxon (Püntener et al., 2014).

Most turtle shells from Porrentruy have been discovered in a state of partial disarticulation, which contrasts with the mostly articulated shells found in Solothurn. The latter were apparently rapidly incorporated in a calcareous mud, while the turtle remains from Porrentruy remained for a longer period on top of the sediment before being completely buried. This is confirmed by the common presence of incrusting bivalves (oysters) on the bone remains from Porrentruy. However, disturbance by predators or water movements was relatively limited since disarticulated elements were usually found relatively close together (Fig. 3).

\section{Anatomical comparisons}

As far as the cranium is concerned, Plesiochelys bigleri was compared to all plesiochelyids for which that part of the skeleton is known: Plesiochelys etalloni (NMB 435, NMS 8738, NMS 8739, NMS 8740, NMS 9145, NMS 40870, NMS 40871, NHMUK R3370), Plesiochelys planiceps (OUMNH J.1582), Portlandemys mcdowelli Gaffney, 1975a (NHMUK R2914, NHMUK R3164), and Portlandemys gracilis (MJSN BSY009-708). When pertinent, comparisons were also extended to PIMUZ A/III 514, a skull-shell association from the Tithonian of the Isle of Oléron (Department of Charente-Maritime, France) initially referred to Thalassemys moseri Bräm, 1965 by Rieppel (1980), but which was recently designated as the holotype of a new taxon, Jurassichelon oleronensis Pérez-García, 2015. All of these specimens have been studied first hand by the second author. The reader is referred to the primary literature describing these specimens (Parsons \& Williams, 1961; Gaffney, 1975a; Gaffney, 1976; Rieppel, 1980; Anquetin, Püntener \& Billon-Bruyat, 2015; Anquetin \& Chapman, 2016). Anatomical 
147 descriptions in the present study follow the nomenclature established by Gaffney $(1972,1979)$ as 148 updated by Rabi et al. (2013).

Anatomical descriptions of shell material follow the nomenclature established by Zangerl (1969). Shell and non-shell postcranial material of Pl. bigleri was compared, when pertinent, to plesiochelyids (Plesichelys etalloni, Tropidemys langii, and Craspedochelys jaccardi) and thalassemydids (Thalassemys bruntrutana and Thalassemys hugii).

\section{Statistical analysis}

The length and thickness of 119 neurals 2 to 5 pertaining to 43 selected specimens from Porrentruy (25 Plesiochelys bigleri, 8 Plesiochelys etalloni, and 10 Plesiochelys sp.) were measured in order to test the hypothesis that neural bones are significantly thinner in Pl. bigleri relative to $P l$. etalloni (see Table $\mathrm{S} 1$ ). Length was measured as the maximal length on the dorsal surface of the neural bone. Thickness was measured on the left and right sides and approximately at the mid-length of each neural bone (see below). The mean of these two measurements was used as the thickness value for each individual neural bone (Table S1). Measurements were taken using a digital Vernier caliper by a single operator (CP).

Neural shape can be relatively variable within a single individual. For example, one neural can be disproportionately shorter, longer, thinner, or thicker in a given neural series. Specimens exhibiting extreme divergences from the common condition were not measured. For specimens included in this analysis, the mean neural length and mean neural thickness were computed for each individual, which had the effect of smoothing intra-individual discrepancies. The analyzed dataset therefore consists of the mean neural length, mean neural thickness, and corresponding length/thickness ratio measured for the 43 included specimens (see below). 
The statistical analysis was run using PAST 3.14 (Hammer, Harper \& Ryan, 2001). Length and thickness were plotted in a 2D space, whereas length, thickness, and length/thickness ratio were tested for equal medians using a non-parametric Mann-Whitney test (with Monte Carlo permutations). A discriminant analysis was also performed on the length and thickness measurements and used to tentatively identify indeterminate specimens (Plesiochelys sp.; see below).

\section{D Models}

3D models of the holotype (MJSN TCH007-252) and paratype (MJSN TCH006-1451) crania have been computed with the photogrammetry software Agisoft Photoscan 1.0.4 Standard Edition using sets of high-quality photographs of the specimens. We followed the procedures recently described by Mallison \& Wings (2014). These models are provided herein as 3D PDFs (reduced resolution; to be opened with Adobe Acrobat): MJSN TCH007-252 (Fig. S1), and MJSN TCH006-1451 (Fig. S2). Scaled and textured high-resolution meshes in PLY format are also available freely on figshare (http://figshare.com/authors/J_r_my_Anquetin/651097).

A 3D surface scan of the pelvis preserved with specimen MJSN BSY006-307 was produced with an Artec Space Spider scanner (Artec Group, Luxembourg; http://www.artec3d.com) and reconstructed with Artec Studio 10, the native scanner software. The textured 3D mesh in PLY format is freely available on figshare (http://figshare.com/authors/J_r_my_Anquetin/651097).

\section{Nomenclatural act}


192 The electronic version of this article in Portable Document Format (PDF) will represent a

193 published work according to the International Commission on Zoological Nomenclature (ICZN),

194 and hence the new name contained in the electronic version is effectively published under that

195 Code from the electronic edition alone. This published work and the nomenclatural act it

196

197

198

199

200

201

202

203

204

205

206

207

208

209

210

211

212

213

214

contains have been registered in ZooBank, the online registration system for the ICZN. The

ZooBank LSIDs (Life Science Identifiers) can be resolved and the associated information viewed through any standard web browser by appending the LSID to the prefix http://zoobank.org/. The LSID for this publication is: urn:1sid:zoobank.org:pub:C5AE9DE8-9911-4CFD-AD0965850C35BDEC. The online version of this work is archived and available from the following digital repositories: PeerJ, PubMed Central and CLOCKSS.

\section{SYSTEMATIC PALEONTOLOGY}

TESTUDINES Batsch, 1788

PAN-CRYPTODIRA Joyce, Parham \& Gauthier, 2004

EUCRYPTODIRA Gaffney, 1975c

PLESIOCHELYIDAE Baur, 1888

Plesiochelys Rütimeyer, 1873

Type species. Plesiochelys solodurensis Rütimeyer, 1873

Included valid species. Plesiochelys planiceps (Owen, 1842); Plesiochelys etalloni (Pictet \& Humbert, 1857); Plesiochelys bigleri n. sp.

Referred material and range. Kimmeridgian of Switzerland, France, Germany, and England

(Pictet \& Humbert, 1857; Maack, 1869; Rütimeyer, 1873; Oertel, 1924; Bräm, 1965; Karl et al., 2007; Anquetin, Deschamps \& Claude, 2014; Anquetin, Püntener \& Billon-Bruyat, 2014; 
215 Anquetin, Püntener \& Billon-Bruyat, 2015; Anquetin \& Chapman, 2016), and Tithonian of

216 England (Owen, 1842; Gaffney 1975a; Gaffney, 1976; Anquetin, Püntener \& Billon-Bruyat,

217 2015). Indeterminate specimens are also signalled from the Kimmeridgian-Tithonian of Portugal

218 (Pérez-García et al., 2008) and late Tithonian of Spain (Pérez-García, Scheyer \& Murelaga, 219 2013).

220 Diagnosis. See Anquetin, Püntener \& Billon-Bruyat (2014, 2015).

221

222

223

224

225

226

227

228

229

230

231

232

233

234

235

236

237

\section{Plesiochelys etalloni (Pictet \& Humbert, 1857)}

Synonymy. Emys Etalloni Pictet \& Humbert, 1857 (original description); Stylemys hannoverana

Maack, 1869 (subjective synonymy); Plesiochelys langii Rütimeyer, 1873 (subjective

synonymy); Plesiochelys sanctaeverenae Rütimeyer, 1873 (subjective synonymy); Plesiochelys

solodurensis Rütimeyer, 1873 (subjective synonymy); Plesiochelys solodurensis var.

langenbergensis Oertel, 1924 (subjective synonymy).

Type material. MAJ 2005-11-1, a shell missing a large part of the carapace medially.

Illustrations of type. Pictet \& Humbert (1857: plates I-III); Anquetin, Deschamps \& Claude

(2014: Figs. 1 and 2, S2); Anquetin, Püntener \& Billon-Bruyat (2014: Figs. 2A-2D).

Type horizon and locality. "Forêt de Lect"' (Lect is a small village) near Moirans-en-Montagne

(Department of Jura, France), Late Jurassic. See Anquetin, Deschamps \& Claude (2014) for details.

Referred material and range. Kimmeridgian of Oker and Hannover, Lower Saxony, Germany

(Maack, 1869; Oertel, 1924; Karl et al., 2007); Kimmeridgian of Solothurn, Canton of Solothurn, and Glovelier and Porrentruy, Canton of Jura, Switzerland (Rütimeyer, 1873; Bräm, 1965;

Gaffney, 1975a; Gaffney, 1976; Anquetin, Deschamps \& Claude, 2014; Anquetin, Püntener \& 
238 Billon-Bruyat, 2014; Anquetin, Püntener \& Billon-Bruyat, 2015; Table 1); Kimmeridgian of

239 England, UK (Anquetin \& Chapman, 2016).

240

241

242

243

244

245

246

247

248

249

250

251

252

253

254 255

256

257

258

259

Emended diagnosis. Plesiochelys etalloni differs from other Plesiochelys spp. in a more

extensive flooring of the cavum acustico-jugulare by the pterygoid, the complete ossification of

the pila prootica, and a narrow, slit-like foramen nervi trigemini. In addition, Plesiochelys

etalloni differs from Plesiochelys planiceps in a smaller size, a lower lingual ridge on the

maxilla, a narrower distance between the lingual ridges of the maxilla at the level of the

pterygoid-vomer suture, a more rounded foramen palatinum posterius, a parietal-quadrate contact

posterior to the foramen nervi trigemini, a less developed processus trochlearis oticum, a

superficial canalis caroticus internus often remaining partly open ventrally, a reduced

contribution of the exoccipital to the condylus occipitalis, and the anterior portion of the lingual

ridge on the dentary curving medially, and from Plesiochelys bigleri in a higher temporal skull

roof, a deeper pterygoid fossa, a more developed processus trochlearis oticum, an anterior

foramen nervi abducentis opening more posteriorly relative to the base of the processus

clinoideus, foramina anterius canalis carotici cerebralis opening almost vertically below the

dorsum sellae and usually more closely set, a processus paroccipitalis extending mainly

posteriorly, an increased neural and costal bone thickness, the presence of epiplastral bulbs, and a more rounded or pointed anterior margin of the anterior plastral lobe.

Plesiochelys bigleri sp. nov.

urn:1sid:zoobank.org:act:9A8EF46E-7DAA-4F5B-B727-58C559BA503C

Figs. 3-8, 9A-B, 10-15 
Etymology. This species is dedicated to Pierre Bigler (Villars-sur-Fontenais, Canton of Jura, Switzerland) who so skillfully prepared many of the fossil turtles from the Paleontology A16 collection, including the holotype specimen.

Holotype. MJSN TCH007-252, near complete disarticulated carapace, epiplastra, entoplastron, hypoplastra, and right xiphiplastron; posterior part of skull; proximal part of right scapular process; proximal parts of both humeri; one radius; one ulna; both ilia with acetabulum (Figs. 4, 7, 11, and 12).

Type locality and horizon. Tchâfoué (TCH), Courtedoux, near Porrentruy, Canton of Jura, Switzerland. Lower Virgula Marls, Chevenez Member, Reuchenette Formation, late Kimmeridgian, Late Jurassic (Comment, Ayer \& Becker, 2011; Comment et al., 2015). Paratype. MJSN TCH006-1451, an isolated partial cranium (Figs. 5 and 6). Referred material and range. Late early and early late Kimmeridgian of Porrentruy, Canton of Jura, Switzerland (See Table 1).

Diagnosis. Plesiochelys bigleri differs from other Plesiochelys spp. in a lower temporal skull roof, a shallower pterygoid fossa, a reduced processus trochlearis oticum, a more rounded foramen nervi trigemini, an anterior foramen nervi abducentis opening anteromedially to the base of the processus clinoideus, and foramina anterius canalis carotici cerebralis opening more anteriorly relative to the level of the dorsum sellae. In addition, Plesiochelys bigleri differs from Plesiochelys planiceps in a smaller size, a lower lingual ridge on the maxilla, a parietal-quadrate contact posterior to the foramen nervi trigemini, a less developed processus trochlearis oticum, a superficial canalis caroticus internus that may have remained partly open ventrally, and a reduced contribution of the exoccipital to the condylus occipitalis, and from Plesiochelys etalloni in a less extensive flooring of the cavum acustico-jugulare by the pterygoid, the absence of 
283 284 285 286

complete ossification of the pila prootica, a processus paroccipitalis extending posterolaterally, a reduced neural and costal bone thickness, absent or poorly developed epiplastral bulbs, and a more quadrangular anterior margin of the anterior plastral lobe.

Remarks. The better part of the 42 specimens referred to Plesiochelys bigleri will be amply illustrated in the forthcoming "Catalogues du patrimoine paléontologique jurassien", which document the numerous discoveries made by the Paleontology A16 team. Hence, the present study concentrates on illustrating the most significant specimens only.

\section{Referred material. Early late Kimmeridgian of Porrentruy, Canton of Jura, Switzerland (See} Table 1).

Remarks. Twenty-four shells among the 80 studied herein lack sufficient diagnostic characters to be clearly identified as either Plesiochelys bigleri or Plesiochelys etalloni. This is no surprise considering how close these two species are in terms of shell anatomy. These 24 indeterminate specimens are therefore provisionally referred to Plesiochelys sp. Ten of these indeterminate specimens are however tentatively identified herein based on a statistical analysis of neural bone thickness (see below).

\section{DESCRIPTION OF PLESIOCHELYS BIGLERI}

\section{Cranium}


General description. The cranium of Plesiochelys bigleri is known from two specimens. The first one is the holotype specimen (MJSN TCH007-252) and consists of the posterior part of a skull (Fig. 4) associated with a relatively complete shell and some limb and girdle elements. The parts of the skull anterior to the pterygoids (including the nasal, palatal, and orbital regions) and the lateral part of the left otic chamber are missing. For this reason, the following bones are missing from that specimen: nasal, prefrontal, frontal, postorbital, premaxilla, maxilla, vomer, and palatine. Post-mortem deformation is minor, but the basicranium is partly disarticulated along the basisphenoid-pterygoid suture. The preservation of this specimen is not optimal. The skull was initially heavily encrusted by ferruginous mineralizations. Although most of these mineralizations were skillfully removed during preparation, sutures remain rather difficult to see in this specimen. The length of the skull as measured from the pterygoid-vomer suture to the stem of the condylus occipitalis (the condyle itself is missing) is $38.5 \mathrm{~mm}$, whereas the width at the level of the condyli mandibularis is $60.6 \mathrm{~mm}$ (Table 2).

The second specimen (MJSN TCH006-1451) is an isolated, partial skull missing all of the skull roof, the ethmoid region, the orbital area, the anterior part of the snout, and most of the palate (Fig. 5). As a result, the following bones are missing from that specimen: nasal, prefrontal, frontal, postorbital, and premaxilla. The skull has been severely flattened dorsoventrally during fossilization. Crushing forces were not oriented exactly dorsoventrally and resulted in a slight lean toward the right hand side, mostly apparent in posterior view (Figs. 5E-5F). As preserved, the skull is $59.8 \mathrm{~mm}$ in length from the anteriormost part of the maxilla to the condylus occipitalis (34.4 mm from pterygoid-vomer suture to condylus occipitalis; see Table 2). The width taken at the level of the condyli mandibularis is $60 \mathrm{~mm}$. MJSN TCH006-1451 is therefore slightly smaller than the holotype specimen (Table 2). Compared to other plesiochelyids, MJSN 
328 TCH006-1451 is about the same size as NMS 8738 and NMS 9145, both referred to Plesiochelys

329

330

331

332

333

334

335

336

337

etalloni, but it is much smaller than OUMNH J.1582, the holotype skull of Plesiochelys planiceps (Anquetin, Püntener \& Billon-Bruyat, 2015: table 1).

Parietal. The parietals are best preserved in the holotype specimen (MJSN TCH007-252), but fragments of the ventral part of the processus inferior parietalis are preserved on the right hand side of the paratype specimen (MJSN TCH006-1451). The parietals form the posterior part of the skull roof and meet one another medially (Fig. 4). The anterior and lateral contacts of the parietals are not preserved. Most of the posterior margin of each parietal is natural. The temporal skull roof is relatively low compared to other Plesiochelys spp. The upper temporal emargination largely exposes the foramen stapedio-temporale in dorsal view, but does not extend as far anteriorly as to expose the processus trochlearis oticum. This is similar to the condition in $P l$. etalloni (NMB 435, NMS 40870). The development of the upper temporal emargination is not well known in other plesiochelyids. The preservation of the dorsal surface of the parietals in the holotype (MJSN TCH007-252) does not allow to identify scute sulci with confidence.

As usual in plesiochelyids (Anquetin, Püntener \& Billon-Bruyat, 2015), the anterior braincase wall formed mostly by the processus inferior parietalis is shorter than in most turtles as a result of the great development of the foramen interorbitale. As preserved, the ventral contacts of the parietal in $\mathrm{Pl}$. bigleri are as follows: epipterygoid and pterygoid anterior to the foramen nervi trigemini; pterygoid, quadrate and prootic posterior to the foramen nervi trigemini; and supraoccipital posteroventrally (Figs. 4I-4L). The parietal forms the dorsal half of the anterior margin of the foramen nervi trigemini. There, the parietal and pterygoid have a broad contact that excludes the epipterygoid from the margin of that foramen. The posterior margin of the 
351 foramen nervi trigemini is formed entirely by a posteroventral process of the parietal that reaches

352 the quadrate and prevents a contact between the pterygoid and prootic. This configuration of the

353 region of the foramen nervi trigemini is characteristic of plesiochelyids (except for the parietal-

354 quadrate contact that is absent in Pl.planiceps) and Jurassichelon oleronensis (Anquetin,

355 Püntener \& Billon-Bruyat, 2015). In Pl. bigleri, the foramen nervi trigemini is somewhat more

356 rounded than in other plesiochelyids, in which the foramen is usually taller than wide and oval in

357 shape. In most specimens of Pl. etalloni (NMB 435, NMS 8738, NMS 40870, NMS 40871,

358 NHMUK R3370), the foramen nervi trigemini is very narrow and forms a slit-like opening.

359

360

361

362

363

364

365

366

367

368

369

370

371

372

373

Jugal. In the holotype specimen (MJSN TCH007-252), the anterior part of the right jugal is preserved as an isolated fragment. A small flake of bone (probably from the maxilla) is still attached to the ventromedial margin of the isolated jugal. In the paratype specimen (MJSN TCH006-1451), only the ventral part of the jugal is preserved, but the bone is more complete on the right hand side (Fig. 5). The jugal forms the posteroventral corner of the orbit and contacts the maxilla ventrally and the quadratojugal posteriorly. The other contacts of the jugal with surrounding elements are unclear. As in Pl. etalloni, Pl. planiceps, and J. oleronensis, the jugal lacks a medial process extending to meet the pterygoid and/or palatine. Similarly, the maxilla lacks a corresponding posteromedial process and the foramen palatinum posterius remains open posterolaterally. The ventral margin of the jugal and the posterior border of the maxilla show that the lower temporal emargination was relatively well developed in Pl. bigleri, much like the condition in $\mathrm{Pl}$. etalloni, $\mathrm{Pl}$. planiceps and $J$. oleronensis (note that the condition in Portlandemys spp. is unknown). 
374 Quadratojugal. The morphology of the quadratojugal is poorly known in Pl. bigleri. Only a 375 small part of the right quadratojugal is preserved anterior to the cavum tympani in the holotype 376 (MJSN TCH007-252). A larger portion of the right quadratojugal is preserved in the paratype 377 (MJSN TCH006-1451), but the bone is fragmented in several pieces and misses its dorsal and

anterior margins. Anteriorly, the quadratojugal articulates with the jugal. Its ventral margin

forms the posterior half of the lower temporal emargination. Posteriorly, the quadratojugal braces the external margin of the cavum tympani along an extended, curved suture with the quadrate (Figs. 4 and 5). It seems that the posteroventral process of the quadratojugal along the processus articularis of the quadrate is proportionally shorter in Pl. bigleri than in Pl. etalloni and Po. gracilis (unknown in other plesiochelyids). Posterodorsally, the quadratojugal has a broad vertical contact with the squamosal just dorsal and slightly anterior to the level of the incisura columellae auris.

Squamosal. The squamosal is best preserved in the holotype (MJSN TCH007-252), but the paratype (MJSN TCH006-1451) provides additional information on the morphology of this element. As usual in turtles, the squamosal forms the posterolateral corner of the otic chamber, notably contributing to the formation of the antrum postoticum. The anterodorsal part of the bone is unfortunately not preserved in any specimen. The contacts of the squamosal in the temporal roof (notably with the postorbital and parietal) are therefore unknown in Pl. bigleri. The other contacts of the squamosal are as follows: quadrate anteromedially and ventrally; quadratojugal anterolaterally; and opisthotic posteromedially. Compared to other turtles, the antrum postoticum of plesiochelyids is usually described as moderately developed (Gaffney, 1976; Rieppel, 1980; Anquetin, Püntener \& Billon-Bruyat, 2015). In Pl. bigleri, the antrum postoticum is also 
moderately developed, but, compared to other plesiochelyids, the cavity is deeper both medially and posterodorsally. Remarkably, the anterior margin of the antrum postoticum is formed entirely by the quadrate (MJSN TCH007-252; Fig. 4). This differs from the condition observed in Pl. etalloni and Po. gracilis (as well as J. oleronensis and most basal pan-cryptodires) in which the squamosal contributes to the anterolateral margin of the antrum postoticum. The posterodorsal parasagittal crest of the squamosal is well developed in Pl. bigleri, notably the posterior part that forms an extended and somewhat pointed lamina (MJSN TCH007-252; Figs. 4I-4J). A wide concavity is present on the lateral surface of the squamosal just posterior to the opening of the antrum postoticum. Posteroventrally, the squamosal contributes only to a limited extent to the rugose area for the attachment of the M. depressor mandibulae (Werneburg, 2011).

Maxilla. The maxilla is not preserved in the holotype specimen. Only the posterior part of the bone is preserved in the paratype (MJSN TCH006-1451), but about half of the original bone is present on the right hand side in that specimen (Fig. 5). As preserved, the maxilla contacts the jugal posterodorsally and the palatine posteromedially. As for the jugal, the maxilla lacks a posteromedial process that would close the foramen palatinum posterius posterolaterally. The maxilla seems to participate to the anterolateral margin of the foramen palatinum posterius both in dorsal and ventral views. The labial ridge is slender and very high, notably posteriorly. Anteriorly, the labial ridge is somewhat blunted in MJSN TCH006-1451, but this is possibly a preservational artifact. The labial ridge is separated from the lingual ridge by a deep trough. As in Pl. etalloni, Pl. planiceps, and Po. mcdowelli (unknown in Po. gracilis), the lingual ridge is broad and high. In these species, the lingual ridge is rugose, which contrasts with the condition in J. oleronensis where the summit of the lingual ridge is acute and smooth. In Pl. bigleri, the 
420 lingual ridge is closer to the condition in other plesiochelyids, but the bone surface is slightly

421 eroded. In contrast to Po. mcdowelli, the lingual ridge is formed entirely by the maxilla. Due to

422 poor preservation and the presence of markings on the bone surface, we were unable to locate the

423 foramen supramaxillare in MJSN TCH006-1451.

Palatine. The palatine is only preserved in the paratype (MJSN TCH006-1451). The bone is not complete and only the posterior and lateral parts can be observed (Fig. 5). As preserved, the palatine contacts the pterygoid posteriorly, the vomer medially on the ventral surface of the palate, the other palatine medially on the dorsal surface of the palate, and the maxilla anterolaterally. Laterally, the palatine defines the anteromedial border of the foramen palatinum posterius. The outline of the foramen palatinum posterius is impossible to assess in Pl. bigleri since the lateral margin of the palatine and anterolateral part of the pterygoid are incomplete in all of the specimens. The palatine was initially described as forming a small portion of the lingual ridge in Plesiochelys and Portlandemys (Gaffney, 1976). In fact, the palatine really contributes to the lingual ridge only in Po. mcdowelli (condition unknown in Po. gracilis). In Pl. 
443

444

445

446

447

448

449

450

451

452

etalloni, Pl. bigleri, Pl. planiceps and J. oleronensis, the palatine-maxilla suture extends along the medial base of the lingual ridge, i.e. on its dorsomedial edge, and the palatine therefore does not take part into the formation of the ridge or triturating surface.

Quadrate. On the dorsal surface of the otic chamber, the quadrate contacts the prootic anteromedially, the opisthotic posteromedially, and the squamosal posterolaterally. As usual, quadrate and prootic contribute relatively equally to the formation of the foramen stapediotemporale, but variability exists (see right side of the holotype MJSN TCH007-252). Anterolaterally, the quadrate has a long curved suture with the quadratojugal. This suture is mostly parallel to the anterior margin of the cavum tympani, but lies anterior to it (the quadratojugal does not enter the margin of the cavum tympani). The cavum tympani of $P l$. bigleri is deeper than in other plesiochelyids. This is notably apparent anteroventral and posterodorsal to the incisura columellae auris. In contrast to other plesiochelyids, the lateral margin of the cavum tympani faces more posterolaterally than laterally in Pl. bigleri (Figs. 4 and 5). The quadrate forms the entire anterior margin of the antrum postoticum, which is remarkable (see Squamosal). The incisura columellae auris remains open posteroventrally. The processus articularis of the quadrate is damaged in the holotype (MJSN TCH007-252), which may give the misleading impression that this process is short. This structure is better preserved in the paratype (MJSN TCH006-1451). A prominent ventrally-infolding ridge occurs on the posterior surface of the processus articularis. Starting from the posterolateral corner of the condylus mandibularis, this ridge extends dorsomedially toward the incisura columellae auris increasing in height. Ventral to the incisura, the ridge thickens and bends sharply medially. Pursuing its medial course, the ridge thins progressively and finally merges with the posterolateral border of the 
pterygoid. This ventrally-infolding ridge is found in all plesiochelyids, but also in J. oleronensis, Solnhofia parsonsi Gaffney, 1975b and Parachelys eichstaettensis Meyer, 1864, and is a strong argument to support the monophyly of these Late Jurassic coastal marine turtles from Europe (Anquetin, Püntener \& Billon-Bruyat, 2015). The condylus mandibularis of Pl. bigleri is remarkably narrow anteroposteriorly compared to other plesiochelyids. The condyle consists of two slightly concave facets separated by a wide, but shallow parasagittal furrow.

The quadrate forms about half of the moderately developed processus trochlearis oticum, which is less prominent than in Plesiochelys etalloni. On the anterior surface of the otic chamber, the quadrate contacts the prootic dorsomedially, the parietal medially, and the pterygoid ventromedially. This region is best preserved on the left hand side of the holotype MJSN TCH007-252. Inside the cavum acustico-jugulare, the quadrate forms the lateral part of the aditus canalis stapedio-temporalis and canalis stapedio-temporalis, as well as the lateral half of the posterior opening of the canalis cavernosus. Below the antrum postoticum, a rugose area occurs on the ventral surface of the skull and probably served for muscular attachment. In $P l$. bigleri, this area is mostly formed by the quadrate, with minor contributions from the opisthotic and squamosal.

Epipterygoid. The epipterygoid is best preserved in the holotype (MJSN TCH007-252), whereas only the ventral part of the bone is preserved in the paratype (MJSN TCH006-1451). In lateral view, the epipterygoid is a trapezoidal element located between the crista pterygoidea of the pterygoid and the processus inferior parietalis of the parietal. The epipterygoid is exposed on the medial surface of the anterior braincase wall, albeit to a more moderate extent. Posteriorly, a broad contact between the parietal and pterygoid excludes the epipterygoid from the anterior 
margin of the foramen nervi trigemini (Figs. 4I-4L). The same configuration seemingly occurs on the medial surface of the anterior braincase wall. Posteroventrally, a fossa cartilaginis epipterygoidei is present and prevents a contact between the epipterygoid and the quadrate. The anterolateral process of the epipterygoid that extends onto the dorsal surface of the pterygoid is well developed. A shallow furrow prolongs this process on the dorsal surface of the pterygoid in Pl. bigleri (MJSN TCH006-1451). A similar process occurs in Pl. etalloni and Po. medowelli. This process is more reduced in Pl. planiceps and J. oleronensis.

Pterygoid. Except for each processus pterygoideus externus, the pterygoids are complete in the paratype (MJSN TCH006-1451), but their ventral surface is somewhat abraded. Longitudinal striae extend from the pterygoid fossae posteriorly to the palatines and vomer anteriorly (Fig. 5C). In the holotype (MJSN TCH007-252), the anterior part of the pterygoids is more poorly preserved, although the left processus pterygoideus externus is complete. In contrast, the posterior part of the pterygoids (pterygoid fossa and quadrate process) is better preserved. The pterygoids are disarticulated from the basicranium in the holotype.

In ventral view, the pterygoid contacts the vomer anteromedially, the palatine anteriorly, the quadrate posterolaterally, and the basisphenoid posteromedially. Posteriorly, the pterygoid probably also contacted the basioccipital, but the sutures in this region are poorly preserved in both specimens. As preserved, the pterygoid does not seem to contact the exoccipital posteriorly, but this region is rarely well preserved in plesiochelyids and the presence/absence of this contact is probably of poor systematic value (Anquetin, Püntener \& Billon-Bruyat, 2015). In ventral view, the processus pterygoideus externus is similar in development and shape to that of $P l$. etalloni and Pl. planiceps. However, the parasagittal plate on the lateral margin of the processus 
512 pterygoideus externus is more developed in Pl. etalloni than in the two other species. A distinct 513 ridge extends posteromedially from the posterior edge of the processus pterygoideus externus to 514 the posterolateral part of the ventrally open canalis caroticus internus. This ridge forms the medial margin of the pterygoid fossa. Compared to other plesiochelyids, J. oleronensis and eurysternids (Anquetin, Püntener \& Billon-Bruyat, 2015), the pterygoid fossa of Pl. bigleri stands out as being remarkably shallow. The configuration of the canalis caroticus internus is similar to the condition in Pl. etalloni and J. oleronensis (see Anquetin, Püntener \& BillonBruyat, 2015 for a review). The canalis caroticus internus is superficial and open ventrally at least along its anterior half (Figs. 4 and 5). The posterior half of the canalis caroticus internus may have been floored by a thin ventromedial flap of the pterygoid, but the preservation of the paratype (MJSN TCH006-1451) prevents a definitive conclusion. Since no flooring is preserved in any specimen, the position of the foramen posterius canalis carotici interni cannot be determined with precision. The anterior part of the canalis caroticus internus follows the basisphenoid-pterygoid suture. By comparison with Pl. etalloni, the split between the palatine and cerebral branches of the internal carotid artery was probably not floored by bone, but the preservation of the specimens prevents a clear observation of the foramen posterius canalis carotici palatinum (possibly visible on the left hand side of MJSN TCH006-1451) and foramen posterius canalis carotici cerebralis. The flooring of the cavum acustico-jugulare by the posterolateral part of the pterygoid is not very extensive. The processus interfenestralis of the opisthotic therefore remains largely visible in ventral view. For that matter, Pl. bigleri is closer to the condition observed in $\mathrm{Pl}$. planiceps. Although this contact is now disarticulated in the holotype, there was a contact between the processus interfenestralis of the opisthotic and the pterygoid. Based on the disarticulated surface, this contact was probably not sutural. Lateral to 
535 this contact, the pterygoid forms the medial part of the floor of the posterior opening of the 536 canalis cavernosus.

In the ethmoid region, the pterygoid forms the ventral margin of the foramen nervi trigemini, the rest of the foramen margin being formed by the parietal (Figs. 4I-4L). The pterygoid-parietal contact anterior to the foramen nervi trigemini excludes the epipterygoid from the margin of this foramen. Medial to the crista pterygoidea, the pterygoid forms the floor of the sulcus cavernosus. This region is best preserved in the paratype specimen (MJSN TCH0061451). The foramen anterius canalis carotici palatinum opens in the anterior part of the sulcus cavernosus about halfway between the level of the foramen anterius canalis carotici interni and the tip of the trabecula. After exiting the foramen anterius canalis carotici palatinum, the palatine branch of the internal carotid artery continues forward in a groove within the floor of the sulcus cavernosus and is not obstructed anteriorly by a crest extending from the crista pterygoidea to the midline shelf of the pterygoid, as seen in some plesiochelyids (Anquetin, Püntener \& BillonBruyat, 2015). Anterolaterally, a small foramen occurs on the dorsal surface of the pterygoid medial to the anterolateral process of the epipterygoid. This foramen may correspond to the foramen nervi vidiani, but this should be further investigated (see also Anquetin, Püntener \& Billon-Bruyat, 2015). Anterior to this small foramen, the dorsal surface of the pterygoid forms a shallow, rounded depression, which likely served for the attachment of one of the eye muscles (Gaffney, 1976). Finally, as noted above (see Epipterygoid), a shallow furrow prolongs the anterolateral process of the epipterygoid on the dorsal surface of the pterygoid.

\section{Supraoccipital. The supraoccipital contacts the parietal anteriorly, the prootic anterolaterally,} the opisthotic posterolaterally, and the exoccipital posteriorly. A broad contact between the 
558 prootic and opisthotic separates the supraoccipital from the quadrate on the floor of the fossa

559

560

561

562

563

564

565

566

567

568

569

570

571

572

573 temporalis superior (Figs. 4 and 5). This contrasts with the condition observed in Po. mcdowelli and most specimens referred to Pl. etalloni. Most of the crista supraoccipitalis is preserved in the holotype MJSN TCH007-252. This structure is relatively low, especially compared to $\mathrm{Pl}$. planiceps and Po. mcdowelli. The condition in Pl. etalloni is more difficult to appreciate based on the available material, but it seems to be intermediate in development between Pl. bigleri and the two aforementioned species. The posterior part of the crista supraoccipitalis is broken in MJSN TCH007-252, but it is unlikely that this structure projected far behind the level of the condylus occipitalis. As usual, the supraoccipital forms the dorsal part of the foramen magnum.

Exoccipital. The exoccipital contacts the supraoccipital dorsomedially, the opisthotic laterodorsally, the basioccipital ventrally, and the processus interfenestralis of the opisthotic anterolaterally. As preserved, there is no contact between the exoccipital and pterygoid, which may be a difference with Pl. etalloni, but this contact is often difficult to observe in this taxon (Anquetin, Püntener \& Billon-Bruyat, 2015). An exoccipital-pterygoid contact is otherwise present in Portlandemys ssp. and J. oleronensis. In contrast to Pl. etalloni, Pl. planiceps, Po. mcdowelli (condition unknown in Po. gracilis), and J. oleronensis, the exoccipitals apparently do not meet in the floor of the foramen magnum, but this feature can present some intraspecific variability (Anquetin \& Chapman, 2016). The contribution of the exoccipital to the condylus occipitalis is uncertain, but probably reduced. There are two foramina nervi hypoglossi on each side and they are formed exclusively by the exoccipital. 
580 Basioccipital. The ventral aspect of the basioccipital is poorly preserved in all specimens.

581 However, it is apparent that the basioccipital contacts the basisphenoid anteriorly and the

582

583

584

585

586

587

pterygoid anterolaterally in this area. The tubercula basioccipitale are only moderately developed and correspond to what is known in similarly-sized individuals of Pl. etalloni, but not in larger specimens (Anquetin \& Chapman, 2016). Posterodorsally, there is an extensive contact with the exoccipital, but the basioccipital nevertheless enters the ventral margin of the foramen magnum. It appears that the basioccipital forms most of the condylus occipitalis, which is only preserved (poorly) in MJSN TCH006-1451. In dorsal aspect, the basioccipital offers little remarkable features. The basis tuberculi basalis is relatively low, and an oval depressed area occurs in front of it. Finally, there is also a contact with the ventromedial margin of the processus interfenestralis of the opisthotic in the floor of the recessus scalae tympani.

Prootic. On the dorsal surface of the otic chamber, the prootic contacts the parietal anteromedially, the quadrate laterally and anteroventrally, the opisthotic posteriorly, and the supraoccipital posteromedially. The prootic forms the medial half of the processus trochlearis oticum, which is reduced compared to that of $P l$. etalloni. Anteromedially, the prootic is excluded from entering the posterior margin of the foramen nervi trigemini by an elongate descending process of the parietal (Figs. 4I-4L). A broad contact between this descending process of the parietal and the quadrate prevents a prootic-pterygoid contact in this area. This configuration is found in all plesiochelyids but $P l$. planiceps, as well as in J. oleronensis and possibly also in eurysternids (Anquetin, Püntener \& Billon-Bruyat, 2015).

Inside the cavum acustico-jugulare, the prootic forms the anterior half of the fenestra ovalis, the medial part of the aditus canalis stapedio-temporalis, and most of the roof of the 
603 posterior opening of the canalis cavernosus. As in other plesiochelyids, the aditus canalis 604 stapedio-temporalis is located more posteriorly than the posterior opening of the canalis cavernosus rather than in the roof of the latter as in many turtles. In this area, the prootic contacts the opisthotic posterodorsally, the pterygoid ventrally, and the quadrate laterally. A C-shaped furrow occurs on the surface of the prootic dorsolateral to the fenestra ovalis. Inside the cavum cranii, the prootic contacts the supraoccipital posterodorsally, the parietal anterodorsally, the basisphenoid ventromedially, and the pterygoid anteroventrally. In contrast to Pl. etalloni, the pila prootica is not ossified. Medial to the foramen nervi trigemini, the prootic forms a welldefined recess that accommodated the ganglion of the trigeminal (V) nerve.

Opisthotic. On the dorsal surface of the otic chamber, the opisthotic contacts the prootic anteriorly, the quadrate anterolaterally, the squamosal posterolaterally, the supraoccipital medially, and the exoccipital posteromedially. The anterior contact with the prootic is relatively wide and clearly separates the supraoccipital and quadrate (Figs. 4 and 5). This condition is found also in Pl. planiceps, Po. gracilis, and J. oleronensis. In contrast, the prootic-opisthotic contact is reduced or absent in Po. mcdowelli and most specimens of Pl. etalloni. The posterior aspect of the opisthotic is complete only on the right hand side of the paratype (MJSN TCH0061451). The extremity of the processus paroccipitalis forms a distinct crest for muscular attachment. In Pl. bigleri, as well as in Po. mcdowelli and J. oleronensis, the processus paroccipitalis extends posterolaterally. This contrasts with Pl. etalloni, Pl. planiceps, and Po. gracilis in which the processus paroccipitalis extends more posteriorly. This difference changes the occipital outline as seen in dorsal view from a broad arch in Pl. bigleri to a more narrow arch in Pl. etalloni. 
this area, the opisthotic contacts the prootic anteriorly, the quadrate anterolaterally, the

squamosal posterolaterally, and the exoccipital posteromedially. The extremity of processus

interfenestralis is triangular in shape and contacts the exoccipital, basioccipital, and pterygoid.

The medial margin of the processus interfenestralis is pierced by a large fenestra perilymphatica, which is apparently entirely contained in bone thanks to a ventromedial contribution from the basioccipital (MJSN TCH007-252). A well-defined foramen externum nervi glossopharyngei opens at the base of the processus interfenestralis. It is noteworthy that this foramen opens more laterally than in other plesiochelyids and J. oleronensis. Lateral to the base of the processus interfenestralis and foramen externum nervi glossopharyngei, the opisthotic forms a strong curving ridge oriented anteroposteriorly. As far as we know, this ridge is not present in other plesiochelyids.

Basisphenoid. In ventral aspect, the basisphenoid contacts the pterygoid anteriorly and laterally, and the basioccipital posteriorly (Figs. 4 and 5). As noted above, the basisphenoid-pterygoid suture is disarticulated in the holotype, but this contact is better preserved in the paratype (MJSN TCH006-1451). The posterior contact with the basioccipital is poorly preserved in both specimens. The general outline of the basisphenoid in ventral view is triangular, as in most plesiochelyids (Anquetin, Püntener \& Billon-Bruyat, 2015). The ventral surface of the basisphenoid is apparently slightly concave. The morphology of the canalis caroticus internus is similar to the condition observed in Pl. etalloni and J. oleronensis (Anquetin, Püntener \& BillonBruyat, 2015). The canalis caroticus internus is superficial and runs along the basisphenoidpterygoid suture as a ventrally open canal. The posterior part of the canalis caroticus internus 
may have been partly floored by a ventromedial flap formed by the pterygoid, but this region is not well preserved in any specimen. Based on the available material, the position of the foramen posterius canalis carotici interni cannot be determined. As in Pl. etalloni, the split between the cerebral and palatine branches of the internal carotid artery was probably not floored by bone. However, the preservation prevents a clear observation of the foramen posterius canalis carotici palatinum. In the holotype, a portion of each canalis caroticus cerebralis is preserved on the anterior part of the basisphenoid. Anteriorly, these two canals penetrate deeply in the basisphenoid and exit in the sella turcica dorsally. A small unnamed foramen opens dorsomedially along the canalis caroticus cerebralis (only visible in MJSN TCH007-252; Fig. 4). The dorsal aspect of the basisphenoid is better preserved in the paratype (MJSN TCH0061451) and can be readily observed in that specimen thanks to the loss of the anterior part of the roof of the cavum cranii (Fig. 6). The basioccipital contacts the basioccipital posteriorly, the prootic posterolaterally, and the pterygoid anterolaterally and anteriorly. The part of the basisphenoid that floors the cavum cranii is slightly concave. A moderately raised area located sagittally on the posterior margin of the basisphenoid corresponds to the anterior part of the basis tuberculi basalis. The posterior foramen nervi abducentis opens about midway along the part of the basisphenoid that floors the cavum cranii. The anterior foramen nervi abducentis opens ventral and slightly anteromedial to the base of the processus clinoideus, relatively close to the basisphenoid-pterygoid suture. This is the condition usually found in plesiochelyids, with the exception of Pl. etalloni (Anquetin, Püntener \& Billon-Bruyat, 2015). The processus clinoideus is formed just medial to the basisphenoid-prootic suture. In contrast to Pl. etalloni, the pila prootica is not ossified. The dorsum sellae is high and does not overhang the sella turcica, as usual in plesiochelyids. The surface below the dorsum sellae is devoid of ridge and slopes 
672 relatively gently anteriorly. In that matter, $P l$. bigleri is intermediate between $P l$. etalloni, in

673 which the surface below the dorsum sellae is near vertical, and Portlandemys spp., in which that

674 surface slopes very gently anteriorly resulting in a relatively long distance between the dorsum

675 sellae and the foramina anterius canalis carotici cerebralis (Anquetin, Püntener \& Billon-Bruyat,

676 2015). The foramina anterius canalis carotici cerebralis are separated by a broad bar of bone,

677 which is unusual in plesiocheyids, and open slightly posterior to the level of the foramina

678 anterius canalis carotici palatinum. The trabeculae are relatively short and straight, and frame a

679 small, well-defined sella turcica. The rostrum basisphenoidale is short, and the anterior tip of the 680 trabeculae actually represents the anteriormost extension of the basisphenoid in dorsal view.

681

682

683

684

685

686

687

688

689

690

691

692

693

694

Carapace

General description. Elements of the carapace are preserved in 39 out of the 41 shells herein referred to Plesiochelys bigleri (Figs. 7 and 8). The largest specimens reach a carapace length of about 550 mm (MJSN BSY006-307, MJSN SCR011-30, MJSN TCH005-21), whereas the smallest have a carapace length of about 220-250 mm (MJSN BSY008-848, MJSN SCR010327, MJSN TCH007-516). Measuring carapace length with precision in disarticulated and incomplete specimens is not possible, but we estimate that most specimens are about $450 \mathrm{~mm}$ in carapace length, which corresponds approximately to what is known for Pl. etalloni in Solothurn. Most shells of $\mathrm{Pl}$. bigleri are disarticulated, but two shells (MJSN BSY006-307 and MJSN TCH007-519) were found articulated. Bones were prepared out of the marly matrix individually and we were able to reassemble them on a moldable sand bed and reconstruct the 3D shape of the shell. Post-mortem deformation occurred in most specimens and to variable extents. Our 
695 reconstructions are therefore tentative. The resulting carapace outlines are either evenly oval 696 (e.g., MJSN TCH006-767), or roundish (e.g., MJSN TCH007-252; Figs. 7A-7B). In some 697 specimens the posterior carapace part is pointed (e.g., MJSN BSY009-815, MJSN SCR011-30).

The shells of $P l$. bigleri and $P l$. etalloni are very similar. The following description therefore primarily focuses on the few differences between the two species and the intraspecific variations observed in $\mathrm{Pl}$. bigleri. A general description of the shell morphology of $\mathrm{Pl}$. etalloni and a discussion of its intraspecific variability can be found elsewhere (Anquetin, Deschamps \& Claude, 2014; Anquetin, Püntener \& Billon-Bruyat, 2014).

\section{Nuchal. The shape of the nuchal in Pl. bigleri varies from almost rectangular (e.g., MJSN} SCR011-140; Figs. 8I-8J) to trapezoidal (e.g., MJSN BSY007-257). This element can be about as wide as long (e.g., MJSN BSY009-815) or clearly wider than long (e.g., MJSN SCR011-160). The nuchal notch is usually shallow, but can also be much reduced (e.g., MJSN SCR011-160) or strongly pronounced (e.g., MJSN BSY007-257). In some specimens (e.g., MJSN TCH006-1420; Figs. 8A-8B), the posteromedial part of the nuchal that articulates with the first neural projects posteriorly.

Neurals, suprapygals and pygal. Like Pl. etalloni, Pl. bigleri usually has eight neurals, one intermediate element, two suprapygals, and one pygal. However, this condition may vary. Neural bones can be split in two (e.g., neural 2 in MJSN SCR010-342), fused together (e.g., neural 8 with the intermediate element in MJSN TCH005-21), or be reduced (e.g., neural 7 in MJSN SCR011-140) or completely obliterated (e.g., neural 7 in MJSN SCR011-413 and MJSN TCH006-1420; Figs. 8A-8B) by costals with midline contact. The first neural is rectangular to 
718 oval in shape. It usually tapers posteriorly (not in MJSN BSY007-257 and MJSN TCH005-42;

719 Figs. 8M-8N). Neurals 2 to 6 are elongated hexagons with shorter sides facing anteriorly.

720 However, these hexagons are often deformed (e.g., MJSN BSY007-257, MJSN SCR010-342,

721

722

723

724

725

726

727

MJSN SCR011-30, MJSN SCR011-276, MJSN SCR011-413, MJSN TCH005-42, MJSN

TCH006-767). Neurals 7 and 8 are shorter and more irregular in shape than the preceding neurals. Their growth is often constrained by a midline contact of the costals. Neural 8 is usually the smallest bone in the series. In some specimens, it is pentagonal with shorter sides facing posteriorly (e.g., MJSN BSY009-815, MJSN TCH007-252; Figs. 7A-7B). The thickness of the neural bones in $\mathrm{Pl}$. bigleri is significantly reduced compared to Pl. etalloni (Fig. 9). This is especially obvious for neurals 2 to 5 . We statistically demonstrate this difference herein (see below).

As relatively common in turtles (Zangerl, 1969), the posteromedial region of the carapace is characterized by a great deal of intraspecific variation in $P l$. bigleri. The element that follows neural 8 corresponds to the intermediate element of Anquetin, Püntener \& Billon-Bruyat (2014). This intermediate element varies much in shape, but usually tapers anteriorly (e.g., MJSN SCR011-140, MJSN SCR011-160, MJSN SCR011-276). In one specimen (MJSN TCH0061420; Figs. 8A-8B) the intermediate element is fused to the first suprapygal.

Plesiochelys bigleri usually has two suprapygals that are clearly wider than long. Although irregular in shape (usually from trapezoidal to sub-triangular), the first suprapygal usually tapers anteriorly and the second posteriorly (e.g., MJSN BSY009-815, MJSN SCR011-160, MJSN TCH006-1420; Figs. 8A-8B). The two suprapygals can fuse into a single element (e.g., MJSN TCH007-519, MJSN SCR011-148). In some specimens, the first suprapygal is divided in two 
740 (e.g., MJSN SCR011-30, MJSN TCH007-252; Figs. 7A-7B). The pygal is a trapezoidal element

741 that is wider than long. Its relative size varies substantially from one individual to another.

742

743

744

745

746

747

748

749

750

751

752

753

754

755

756

757

758

759

760

761

762

Costals and peripherals. Plesiochelys bigleri has eight pairs of costals and eleven pairs of peripherals. Their shape and arrangement are relatively stable within the species. The lengthwidth ratio of costal 4 corresponds to that of $\mathrm{Pl}$. etalloni and differs notably from that of Craspedochelys jaccardi (Anquetin, Püntener \& Billon-Bruyat, 2014). The costals in Pl. bigleri are not as thick as the same elements in Pl. etalloni. In the latter the proximal part of the costals is very thick, matching the thick neural bones, and the costals usually remain relatively thick on their distal margin. In Pl. bigleri, both the proximal and distal parts of the costals are thinner. A midline contact occurs frequently between costals 7 (e.g., MJSN SCR011-140; Figs. 8I-8J), sometimes also between costals 6 (e.g., MJSN SCR011-30, MJSN TCH006-1420; Figs. 8A-8B), and rarely between costals 8 (e.g., MJSN TCH005-42; Figs. 8M-8N). Such a reduction of posterior neurals and midline contacts of costals can also occur in Pl. etalloni (e.g., MAJ 200511-1, MJSN TCH006-574), but more rarely than in Pl. bigleri. This condition appears to occur more commonly in Craspedochelys jaccardi (Anquetin, Püntener \& Billon-Bruyat, 2014).

Scutes of the carapace. There are three cervical scutes of about equal size in Pl. bigleri (best preserved in MJSN CRT007-2 and MJSN TCH007-519). However, as common in plesiochelyids (see Anquetin, Püntener \& Billon-Bruyat, 2014), cervical scutes are difficult to discern in many specimens.

There are usually five vertebrals, four pairs of pleurals, and twelve pairs of marginals. Vertebrals 1 and 5 are always the shortest in the series. The second and third vertebrals are 
763 rectangular (e.g., MJSN BSY009-815) to hexagonal (e.g., MJSN SCR011-30) in shape and cover 764 one third (e.g., MJSN TCH007-519) to about half (e.g., MJSN TCH006-767) of the costal length 765 laterally. Vertebral 4 is usually hexagonal in shape. In some specimens it almost extends as far as 766 the peripherals laterally, significantly reducing the size of pleural 4 (e.g., MJSN BSY006-326

767 768 769 770 and MJSN SCR011-160). The intervertebral scute sulci usually run on neurals 1, 3, and 5. The scute sulcus between vertebrals 4 and 5 most often runs on the intermediate element (e.g., MJSN BSY009-815), but can also cross neural 8 (e.g., MJSN SCR011-148) or the first suprapygal (e.g., MJSN TCH007-252; Fig. 7B). The twelfth pair of marginals is either restricted to the pygal and peripheral 11 (e.g., MJSN BSY006-326, MJSN TCH006-767), or extends on the suprapygal 2 (e.g., MJSN TCH006-1420, MJSN SCR011-140; Figs. 8B and 8J).

One specimen (MJSN TCH005-42; Figs. 8M-8N) shows an anomalous scute pattern. It has eight partially wedged vertebrals and five irregularly sized pleurals (maybe even six on the right side). This scute pattern shows no symmetry and we consider it as an abnormal condition in Pl. bigleri.

\section{Plastron}

General description. Elements of the plastron are preserved in 40 out of the 41 shells herein referred to Pl. bigleri. With $481 \mathrm{~mm}$, MJSN SCR10-1279 has the longest preserved plastron. In contrast, the well preserved juvenile specimen MJSN SCR010-327 has a plastron length of only $194 \mathrm{~mm}$. The anterior plastral lobe of Pl. bigleri is most often quadrangular in outline (e.g., MJSN SCR010-1196, MJSN SCR011-140; Figs. 8K-8L), but can exceptionally also be rounded (e.g., MJSN CRT007-2), or even pointed (e.g., MJSN TCH006-1420; Figs. 8C-8D). In Pl. 
786 787

etalloni, the anterior plastral lobe usually has a rather rounded, sometimes pointed, anterior outline (Anquetin, Püntener \& Billon-Bruyat, 2014). Like in Pl. etalloni, a central plastral fontanelle (always longer than wide) is occasionally present (e.g., MJSN TCH006-1420; MJSN BSY006-307; Figs. 8C-8D and 8G-8H).

Epiplastra and entoplastron. The shape of the epiplastra varies from rather rectangular (MJSN SCR010-1196) to triangular (e.g., MJSN TCH006-1420; Figs. 8C-8D). The anterolateral border of the epiplastra is often somewhat angular, mirroring the anterior outline of the anterior plastral lobe. Epiplastral bulbs, as described in Pl. etalloni (Bräm, 1965; Anquetin, Püntener \& BillonBruyat, 2014), are absent or only weakly expressed (e.g., MJSN TCH007-252; Fig. 7C). The entoplastron is usually roundish (e.g., MJSN SCR011-140; Figs. 8K-8L) to roughly kite-shaped (e.g., MJSN TCH007-252; Figs. 7C-7D), but its relative size and length-width proportion varies greatly from one individual to another. The entoplastron of the juvenile specimen MJSN SCR010-327 is elongated and kite-shaped.

Hyo-, hypo-, and xiphiplastra. The hyoplastra are always longer than wide, although only by a small amount in a few individuals (e.g., MJSN BSY009-815). This corresponds to what is known in Pl. etalloni and many other turtles, and contrasts with the condition in C. jaccardi, where the hyoplastra are clearly wider than long (Anquetin, Püntener \& Billon-Bruyat, 2014). The suture between the hyo- and hypoplastra is generally straight, but sometimes shows individual symmetric anteroposterior projections (e.g., MJSN CRT007-2, MJSN BSY006-307; Figs. 8G$8 \mathrm{H})$. There is a small supernumerary bone between the hyoplastra of the juvenile specimen MJSN SCR010-327, but the sutures of this roundish bone are absent on the visceral side of the 
809

810

811

812

813

814

815

816

817

818

819

820

821

822

823

824

825

826

827

828

829

830

831

plastron. The posterolateral borders of the hypoplastra often project so as to articulate with the corresponding notches of the xiphiplastra (e.g., MJSN SCR011-413). The xiphiplastra are always

longer than wide and often asymmetric. In most specimens, the xiphiplastra are relatively long elements, possibly more elongated in proportion than in $P l$. etalloni. However, in some individuals the xiphiplastra appear to be significantly reduced in length, but still longer than wide (e.g., MJSN BSY009-815).

Scutes of the plastron. The gular and extragular scute sulci are relatively shallow. In $P l$. etalloni, the gular and extragular sulci are usually deeper, notably anteriorly, as a result of the presence of the epiplastral bulbs. As in Pl. etalloni, the gular scute is either restricted to the epiplastra (e.g., MJSN CRT007-2), or extends to the entoplastron (e.g., MJSN TCH007-252; Fig. 7D). In those specimens where the plastral midline sulcus is discernable, it is irregularly sinuous, sometimes creating small supernumerary scutes (e.g., MJSN SCR011-30). A similar condition is also known in Pl. etalloni.

Generally, the sulcus between the humeral and pectoral scutes is straight, while the sulcus between the pectoral and abdominal scutes is curving anteriorly. The sulcus between the femoral and anal scutes is usually restricted to the xiphiplastron, but extends to the hypoplastron in some specimens. In the latter case, the anal scutes may form a rectangular anterior projection on the hypoplastra (e.g., MJSN SCR011-30). A similar variability is present in Pl. etalloni (Anquetin, Püntener \& Billon-Bruyat, 2014).

There are usually four pairs of inframarginal scutes. As in Pl. etalloni, the third one is generally the longest in the series. It covers the suture between hyo- and hypoplastron. The juvenile specimen MJSN SCR010-327 shows a variation of this pattern by having three 
832 inframarginal scutes on the left hypoplastron. It is however unclear whether this resulted in a

833 total of five inframarginal scutes on the left side and whether this was also the case on the right

834 side. The inframarginal scutes usually extend laterally on the peripherals. Occasionally some of

835 them are restricted to plastral elements (e.g., MJSN CRT007-2, MJSN TCH006-767). This is

836 also a condition known in Pl. etalloni (Anquetin, Püntener \& Billon-Bruyat, 2014).

837

838

839

840

841

842

843

844

845

846

847

848

849

850

851

852

853

854

\section{Pectoral girdle}

Eight partially preserved scapulae are associated with shells of Pl. bigleri (MJSN BSY008-567, MJSN BSY009-815, MJSN SCR011-30, MJSN SCR011-148, MJSN TCH007-252, MJSN

TCH007-519, MJSN TCH005-42; Fig. 10). The two scapulae of MJSN BSY008-567 are attached to the visceral side of the plastron by sediment, approximately in situ and in contact with the humeri. The other six scapulae are disarticulated.

The dorsally projecting scapular process and anteromedially projecting acromion process are elliptic cylinders. The distal parts of these processes are missing in most specimens. Only the acromion process in the right scapula of MJSN BSY008-567 is probably complete. It measures $59 \mathrm{~mm}$ from its distal end to the notch between the scapular process and the coracoid. The two processes form a scapular angle of $102^{\circ}$ in MJSN TCH005-42 (Fig. 10), the only scapula of $P l$. bigleri where this angle can be measured with confidence. None of the scapulae associated with Pl. bigleri provides clear information about the nature of the glenoid fossa or about the articular surface for the coracoid. As in other plesiochelyids, as well as thalassemydids and eurysternids, the glenoid neck is well developed.

The posteromedially projecting coracoid itself is only partially preserved in MJSN TCH005-42 (proximal part) and MJSN TCH007-519 (distal part, partially covered by bones and 
855 sediment). It is unclear whether the disarticulated coracoid of MJSN TCH005-42 belongs to the

856 left (preserved) or right (unpreserved) scapula. The short diaphysis is irregularly cylindric in

857 858

859

860

861

862

863

864 865 866

867

868

869

870

871

872

873

874

875

876

877

cross section. It broadens proximally where it articulates with the scapular neck. The distal end

of the bone is missing, but the broadening diaphysis indicates yet the beginning of the coracoid blade. The latter is partially observable in MJSN TCH007-519, where it forms a broad blade.

The scapula is also known in Pl. etalloni (NMS 8584, NMS 8731, NMS 9153 and NMB

435), as well as in Thalassemys bruntrutana and Thalassemys hugii (Püntener, Anquetin \&

Billon-Bruyat, 2015). The scapular angle of Pl. bigleri (see above) corresponds to the angle

previously measured for $\mathrm{Pl}$. etalloni in specimens from Solothurn and contrasts with the wider angles in Th. bruntrutana and Th. hugii (Püntener, Anquetin \& Billon-Bruyat, 2015: table 1).

The scapula of $\mathrm{Pl}$. etalloni does not show any significant anatomical differences to the scapula of Pl. bigleri.

\section{Humerus}

Four humeri are associated with shells of $\mathrm{Pl}$. bigleri (the proximal parts of both humeri of MJSN BSY008-567 and MJSN TCH007-252 respectively). While both humeri of MJSN TCH007-252

(Fig. 11) are disarticulated, the humeri of MJSN BSY008-567 are attached to the visceral side of the plastron by sediment, approximately in situ and in contact with the scapulae.

The proximal articulation is a hemispherical head that projects dorsally with approximately $135^{\circ}$ from the horizontal plane of the humerus (only measurable in the humeri of MJSN TCH007-252). The anteriorly expanding lateral process is the smaller one, as in most cryptodires (Gaffney, 1990). A strong deltopectoral crest projects ventrally from its lateral border (best visible in the left humerus of MJSN TCH007-252; Figs. 11F-11G). The larger, posteriorly 
878 expanding medial process is only slightly bulged ventrally, so that the intertubercular fossa is

879 mainly defined by the deltopectoral crest. More distally, the narrowing diaphysis forms a waist 880 almost circular in section.

881 The humerus is also partly known in Pl. etalloni (NMS 8584 and NMB 435) and

882

883

884

885

886

887

Tropidemys langii (MJSN VTT006-253 and MJSN VTT010-17). The observed features of the humerus of $\mathrm{Pl}$. bigleri correspond in all aspects to the humerus of $\mathrm{Pl}$. etalloni. According to Püntener et al. (2014), the humerus of Tr. langii (MJSN VTT006-253) has a more expanded medial process and a broader and flatter diaphysis. However, a more recent discovery of a humerus of Tr. langii (MJSN VTT010-17) contradicts this statement and suggests that the observed features of MJSN VTT006-253 are probably due to postmortem flattening. On the base of the new material, the humerus of Tr. langii does not show significant anatomical differences to the humerus of Pl. bigleri and Pl. etalloni.

\section{Radius and Ulna}

The radius and ulna are only known in the holotype specimen (MJSN TCH007-252; Figs. 12A12H). The ulna can be confidently identified as a right ulna, but the radius is more poorly preserved and is only tentatively identified as a right one. The radius is a slim bone with a cylindric diaphysis of only $5 \mathrm{~mm}$ diameter at its narrowest point (Figs. 12A-12D). The bone is twisted, so that the proximal and distal heads stand perpendicular to each other. Although not completely preserved, it is clear that the distal expansion was broader and flatter than the proximal one, which is a common condition in turtles.

The ulna is strongly bent along the long axis due to postmortem deformation (Figs. 12F and $12 \mathrm{H})$. It is clearly broader than the radius. The proximal head forms a moderately concave 
901 sigmoid notch, and the olecranon is poorly developed. Below the proximal head, the medial 902 surface of the bone bears a well developed bicipital tubercle (Figs. 12E-12G). The diaphysis is 903 flat and $7 \mathrm{~mm}$ broad at its narrowest point. Towards the distal end, the bone remains flat and 904 broadens up to $16 \mathrm{~mm}$. The articulation for the carpals is not preserved.

Bräm (1965) briefly described one radius of Pl. etalloni (NMS 8731). Unfortunately, only 906 907 908 909 910

a fragment of this radius has been preserved into the present day, leaving only Bräm's

description as a reference. According to Bräm (1965), the distal expansion of the radius of $P l$. etalloni is larger and more stoutly built than the proximal expansion.

Both ulnae of the same specimen (NMS 8731) are preserved. The distal expansion of these bones is quadrangular in shape. In contrast, this part is triangular shaped in Pl. bigleri. However, it is not clear whether this is a real anatomical difference or whether it is due to an insufficient preservation of MJSN TCH007-252.

\section{Pelvic girdle}

Ten partially preserved pelves are associated with shells of Pl. bigleri (MJSN BSY006-307, MJSN BSY-147, MJSN BSY009-815, MJSN SCR010-30, MJSN SCR011-148, MJSN SCR011413, MJSN TCH006-767, MJSN TCH006-1420, MJSN TCH007-252, MJSN TCH007-519). The following description is mainly based on the sub-complete pelvis of MJSN BSY006-307 that is still articulated in its original three dimensional shape, though it suffered minor postmortem deformation (Figs. 13). Right and left halves of the pelvis are still interconnected posteriorly by the ischium plate. The anterior midline connection of the pubes is not preserved. Although both acetabula are completely preserved on both sides of the pelvis, the ilium and pubis are much better preserved on the right side. 

longer axis (about $35 \mathrm{~mm}$ long in MJSN BSY006-307) lies in the horizontal plane, its shorter

926 axis (about $20 \mathrm{~mm}$ ) in the vertical plane. The three bones of the pelvis (ilium, pubis, ischium) form the acetabulum with their proximal parts. The sutures between these bones are best visible on the medial surface of the right acetabular region in MJSN BSY006-307.

The ilium extends posterodorsally (Fig. 13). Proximally, where it contributes to the acetabulum, its maximal width reaches $29 \mathrm{~mm}$. More distally it narrows to form an irregularly oval, slightly twisted shaft (about $15 \mathrm{~mm}$ wide in MJSN BSY006-307). At the distal end, the ilium is flatter and expands in the anteroposterior direction. However, the posterodorsal iliac process and the anterodorsal articulation surface with the sacral rib are only very partially preserved in Pl. bigleri (MJSN TCH007-519 and MJSN SCR011-30 respectively).

The proximal part of the pubis extends anteroventrally approximately in the same axis as the ilium (Fig. 13). It narrows below the acetabulum, but the shaft remains much broader and flatter than the ilium shaft. Distally, the pubis divides into two parts: a ventrally orientated lateral pubic process and an anteriorly orientated part that normally forms the thyroid fenestra together with the ischium. The lateral pubic process is about $24 \mathrm{~mm}$ long in MJSN BSY006-307. At the distal end it has an oval articulation surface (only partially preserved in MJSN BSY006-307) that rested on the dorsal surface of the xiphiplastra. The anteromedial part of the pubis is broken in MJSN BSY006-307, and the shape of the thyroid fenestra remains unclear in Pl. bigleri.

The ischium extends posteroventrally, first narrowing into a short, circular shaft, then broadening again medially in order to form a broad plate that meets the other ischium medially. This ischial plate is concave dorsally. The contact between ischium and pubis at the anterior margin of this plate is not preserved in any specimen. The lateral ischial process is strong and 
947 extends posteriorly from the ischium. Due to postmortem deformation, the right process is 948 strongly bent dorsally in MJSN BSY006-307. The posterior margin of the ischium, between the 949 lateral ischial process and the midline contact with the other ischium, forms a shallow 950 depression. The ventral surface of the ischial plate is generally convex. It bears a shallow V951 shaped rugose area that points anteriorly.

952 The exceptional preservation of the pelvis of MJSN BSY006-307 is unique among 953 plesiochelyids. Bräm (1965) described the pelvis of Pl. etalloni (mainly based on NMS 8731) and C. jaccardi (based on NMS 8713-8718), but this material is strongly fragmented and no significant differences between the pelvis of Pl. etalloni and C. jaccardi.

\section{Femur}

Three femora are associated with shells of Pl. bigleri (both of MJSN SCR010-1279 and one of MJSN TCH005-21). The femur of MJSN TCH005-21 is strongly deformed and its proximal part is badly damaged. Only the proximal head of the left femur of MJSN SCR010-1279 is preserved. The right femur of MJSN SCR010-1279 is almost completely preserved, but most of the bone surface is covered by encrustation. The following description is therefore mainly based on the right femur of MJSN SCR010-1279 (Figs. 14A-14D).

The femur of $P l$. bigleri is essentially a straight bone that is only slightly arched dorsally. The dorsally projecting proximal head and the ventrally projecting distal articulations give the left femur an elongated S-shape in posterior view (Fig. 14D). The right femur of MJSN SCR0101279 is $134 \mathrm{~mm}$ long. The proximal head projects from the long axis of the femur at an angle of 
970 about $50^{\circ}$ (Figs. 14B and 14D). It is hemispherical, but elongated along the long axis of the

971 femur (about twice as long as wide), which is apparently more consistent with swimming than

972 walking (Zug, 1971). This contrasts with the more roundish femoral head of Tr. langii (Püntener

973 et al., 2014). In ventral view, the two trochanters form a deep, narrow, and V-shaped

974 intertrochanteric fossa (Fig. 14C). The posteriorly situated trochanter major is slightly shorter

975 than the trochanter minor (anteriorly), but expands more prominently on the horizontal plane.

976 Lateral ridges on both trochanters form a shallow V-shaped depression just distal to the

977 intertrochanteric fossa, giving the latter a terraced appearance.

978 The diaphysis is oval to circular in cross section. The bone is gradually broadening towards

979 the distal end. The condyles are only slightly less expanded than the trochanters. The medial

980 condyle is strongly arched and tappers proximally. The lateral condyle is not completely

981 preserved, but it seems smaller and more roundish than the medial condyle. A deep fossa (about

$9826 \mathrm{~mm}$ deep) separates the two articulation surfaces from each other (Fig. 14C).

983 Within plesiochelyids, the femur is partly known in Pl. etalloni (NMS 8584 and MNS

984 8731), C. jaccardi (NMS 8713-8718), and Tr. langii (MJSN VTT010-13). Based on this

985 incomplete material, the femur of Pl. bigleri, Pl. etalloni and C. jaccardi cannot be

986 differentiated. On the other hand, these species differ from Tr. langii, in which the trochanters

987 expand more prominently along the horizontal plane and the intertrochanteric fossa is shallower, 988 wider, and more rounded at its base (Püntener et al., 2014).

$990 \quad$ Fibula

991 Two left fibulae are associated with shells of Pl. bigleri (MJSN TCH005-21 and MJSN SCR010992 1279). The proximal third of the fibula of MJSN TCH005-21 is missing. The fibula of MJSN 
993

994

995

996

997

998

999

1000

1001

1002

1003

1004

1005

1006

1007

1008

1009

1010

1011

1012

1013

1014

1015

SCR010-1279 is complete (Figs. 14E-14H). It is $84 \mathrm{~mm}$ long, which corresponds to $63 \%$ of the femur length. Proximally, the fibula is only slightly expanded and has a small, hemispherical articulation surface facing moderately ventrally. A swelling on the medial edge probably marks the attachement site of the proximal tibiofibular ligament (Figs. 14E-14G). The shaft is a rather flat, elliptic cylinder. At its narrowest point it has only one third of the width of the proximal expansion. Distally, the fibula is almost twice as expanded as proximally. Here the bone is slightly concave dorsally and has a somewhat triangular articulation surface facing moderately ventrally (Figs. 14E and 14G). The attachement site for the distal tibiofibular ligament is again marked by a swelling on the medial edge of the bone (Figs. 14E-14G).

The fibula is also partly known in Pl. etalloni (NMS 8584 and MNS 8731) and C. jaccardi (NMS 8713-8718). Based on this incomplete and deformed material, the fibula of $P l$. bigleri, $P l$. etalloni and C. jaccardi cannot be differentiated.

\section{Vertebral column}

Two disarticulated cervical vertebrae are associated with shells of $P l$. bigleri. The cervical vertebra of MJSN TCH005-21 is almost complete, but somewhat deformed (Fig. 15). The cervical vertebrae associated with MJSN SCR011-30 is more damaged and lacks three zygapophyses. The precise position of these two vertebrae in the cervical series is unclear. The centrum is moderately elongated and oval in cross section (slightly flattened dorsoventrally). There is a robust, but low ventral keel running all of the length of the centrum in MJSN TCH005-21 (Fig. 15D; not preserved in MJSN SCR011-30). The two known cervical vertebra are amphicoelous, with oval and slightly concave central articulations (Figs. 15B and 15E). The neural arch is moderately high (especially posteriorly) and the neural spine is reduced to a low 
1016 longitudinal ridge (MJSN SCR011-30). The prezygapophyses and postzygapophyses are widely

1017 separated (Figs. 15A and 15D). The articular surface of the prezygapophyses is oriented dorsally

1018 and slightly medially. The anterior margin of the neural arch forms a deep embayment between

1019 the prezygapophyses (Fig. 15A). The articular surface of the postzygapophyses faces ventrally

1020 and slightly laterally. A strong V-shaped ridge occurs on the dorsal surface of the

1021 postzygapophyses and defines a deep triangular fossa between the postzygapophyses (Figs. 15A

1022 and 15E). The transverse processes is poorly developed and is situated anteriorly along the 1023 centrum (MJSN SCR011-30).

1024 Cervical vertebrae are known in Pl. etalloni (NMS 8584), C. jaccardi (NMS 8713-8718), 1025 and Th. hugii (NMS 8595-8609). The cervical vertebrae of Pl. etalloni and C. jaccardi are 1026 strongly deformed and broken. The few discernable features are consistent with what is known in 1027 Pl. bigleri. The cervical vertebrae of Th. hugii are much better preserved, even though they 1028 suffered strong lateral pressure. Taking postmortem deformation into account, these cervical 1029 vertebrae are also consistent with what is known in Pl. bigleri: moderately long amphicoelous 1030 centrum, robust but low ventral keel, moderately high neural arch (notably posteriorly), and 1031 widely separated zygapophyses. and MJSN TCH007-519, as well as in the disarticulated specimen MJSN SCR011-30. In these specimens, all sufficiently preserved thoracic vertebrae belong to the posterior part of the 1035 thoracic series (6th thoracic vertebra and behind), and are biconcave, smoothly rounded ventrally 1036 and without keel: e.g., 6th thoracic vertebra in MJSN BSY007-147, 7th thoracic vertebra in MJSN TCH007-519, and the disarticulated thoracic vertebrae (probably 9th and 10th) of MJSN 1038 SCR011-30. 
According to Bräm (1965), the thoracic vertebrae of Pl. etalloni and C. jaccardi are keeled

1040

1041

1042

1043

1044

1045

1046

1047

1048

1049

1050

1051

1052

1053

1054

1055

1056

1057

1058

1059

1060

ventrally, but the best preserved available vertebrae all belong to the anterior part of the thoracic series (from 1 st to 5 th thoracic vertebrae): e.g., 1st thoracic vertebra of NMS 8723, 4th thoracic vertebra of NMS 8731, and 5th thoracic vertebra of MJSN TCH006-574. In the absence of complete thoracic series in either $\mathrm{Pl}$. etalloni or $\mathrm{Pl}$. bigleri, it is uncertain whether the condition in these two species differs or not.

One sacral and two caudal vertebrae of MJSN SCR011-30 are preserved. The sacral vertebra is short, and has two narrow prezygapophyses and a small keel on the centrum. The centrum of one caudal vertebra bears a robust ventral keel, similar to the cervical vertebrae. Poor preservation prevents any conclusion on the type of central articulation in the caudal vertebrae.

A still articulated series of caudal vertebrae is preserved in specimen NMS 8584 referred to Pl. etalloni. As far as observable, their shape is consistent with what is known in Pl. bigleri. Bräm (1965) described their centra as procoelous. However, the state of preservation of these centra does not allow to confirm Bräm's observation.

\section{PLESIOCHELYS ETALLONI}

Fifteen specimens from Porrentruy are referred to Plesiochelys etalloni (Table 1). They are all represented by elements of the carapace and most of them also by the plastron. The shells MJSN BSY007-205, MJSN TCH005-332, and MJSN TCH006-574 are still articulated, the latter being by far the best preserved specimen (Fig. 16). Non-shell post-cranial material is only poorly preserved. For example, small remains of the scapula and pelvis are associated with MJSN BSY003-347, but the poor preservation impedes any anatomical comparisons. 
As mentioned above, $P l$. bigleri and Pl. etalloni mostly differ in their cranial anatomy.

1062

1063

1064

1065

1066

1067

1068

1069

1070

1071

1072

1073

1074

1075

1076

1077

1078

1079

1080

1081

1082

1083

However, some characteristics of the shell allow to tell the two species apart. The main

characters we used for this study are the thickness of neural and costal bones, and the presence and development of the epiplastral bulbs. In Pl. bigleri, the epiplastral bulbs are reduced or absent (Fig. 7C), whereas they are usually well developed in Pl. etalloni (Figs. 16D-16E). The neural and costal bones of $\mathrm{Pl}$. etalloni are usually remarkable for their great relative thickness (Fig. 9D). Specimens of adult size regularly have neurals reaching 15 to $20 \mathrm{~mm}$ in thickness. Similarly sized specimens of $P l$. bigleri usually have a neural thickness ranging between 11 and $14 \mathrm{~mm}$. However, there is a great deal of variation in both species, and the difference between the two is less obvious in juvenile specimens. Neural (and costal) thickness alone is therefore not always sufficient to discriminante between the two species. In order to test whether differences in neural thickness are significant in the two species, we measured 43 specimens from Porrentruy referred to Pl. bigleri, Pl. etalloni, or Plesiochelys sp. (see below).

The newly discovered shells of $P l$. etalloni show about the same range of variation as previously described for this species (Anquetin, Püntener \& Billon-Bruyat, 2014). MJSN TCH006-574 is however remarkable in its extremely reduced fourth pleurals, which are restricted to the peripheral bones due to the great posterolateral development of the fourth vertebral scute (Fig. 16B). The fourth pleurals are similarly reduced in some specimens from Solothurn, but they always occupy at least a small part of the costals (e.g., NMS 8514 and NMS 8517; Anquetin, Püntener \& Billon-Bruyat, 2014: figs. 2, 8). In MJSN TCH006-574, the twelfth pair of marginal scutes is restricted to the pygal, which is a common variation in Pl. bigleri (see above), but is unknown in other specimens referred to Pl. etalloni (Anquetin, Püntener \& BillonBruyat, 2014). 


\section{NEURAL THICKNESS IN PLESIOCHELYS}

1086 The neural length and thickness was measured on selected specimens (see Material and Methods; 1087 Fig. 17B; Table 3). The scatter plot of mean length and thickness measurements reveals a relatively clear separation between Plesiochelys bigleri and Plesiochelys etalloni (Fig. 17A). This separation is mostly due to the proportionally increased neural thickness observed in $P l$. etalloni, as confirmed by the Mann-Whitney tests for mean thickness and length/thickness ratio $(\mathrm{p}<0.0001$, respectively). Mean neural length however is not significantly different in the two species $(\mathrm{p}=0.1156$; Fig. 17D).

The discriminant analysis resulted in a relatively good classification of specimens $(93.94 \%$ of individuals correctly identified; Fig. 17C). Only two specimens (MJSN BSY009-815 and MJSN TCH006-767) are incorrectly classified as Pl. etalloni. These two specimens happen to be the ones that lie the closest to the Pl. etalloni morphospace (Fig. 17A). The discriminant analysis also provided tentative classifications for the 10 indeterminate specimens (Plesiochelys sp.), which correspond fairly well with the conclusions we can draw based on the length/thickness scatter plot (Fig. 17A; Table 4). We consider the classification of only two of these indeterminate specimens to be dubious. MJSN BSY 009-310 is classified by the discriminant analysis as $P l$. etalloni, but this specimen actually lies on the margin of the Pl. bigleri morphospace (Fig. 17A). SCR010-479 is classified by the discriminant analysis as Pl. bigleri, but lies so far from the known morphospaces of $\mathrm{Pl}$. bigleri and $\mathrm{Pl}$. etalloni that this classification must be regarded with caution for the moment. and $P$ l. etalloni. In the analyzed sample, mean neural thickness ranges from 9.61 to $13.77 \mathrm{~mm}$ 
1107 (mean $=11.95 \mathrm{~mm})$ in $\mathrm{Pl}$. bigleri, and from 12.82 to $17.76 \mathrm{~mm}($ mean $=14.83 \mathrm{~mm})$ in $P l$.

1108 etalloni (Fig. 17E). This difference between the two species is even more clearly expressed in the

1109 length/thickness ratio, which ranges from 4 to $5.65($ mean $=4.79)$ in Pl. bigleri, and from 3.1 to

$11103.91($ mean $=3.67)$ in $P l$. etalloni $($ Fig. 17F $)$.

1111

1112 DISCUSSION

1113

1114 Alpha taxonomy

1115 There is a dual issue with the identification and distinction of Plesiochelys bigleri and

1116 Plesiochelys etalloni. First, the two species are so closely related that differences in their shell

1117 and appendicular anatomy are minimal (see above). Second, each of the two species is known by

1118 tenths of shells from a single locality and horizon. These extensive collections reveal a great

1119 intraspecific variability in the two species (Anquetin, Püntener \& Billon-Bruyat, 2014; this

1120 study). Therefore, differentiating the two species can be challenging.

1121 The holotype (MJSN TCH007-252) and paratype (MJSN TCH006-1451) specimens of $P l$.

1122 bigleri are of paramount importance to establish the distinction between the two species. The

1123 isolated cranium MJSN TCH006-1451 (Figs. 5 and 6) exhibits a number of characteristics that

1124 clearly set it apart from Pl. etalloni: reduced processus trochlearis oticum, reduced posterior

1125 flooring of the cavum acustico-jugulare by the pterygoid, clear prootic-opisthotic contact on the

1126 floor of the fossa temporalis superior, pila prootica not ossified, processus paroccipitalis

1127 extending posterolaterally, anterior foramen nervi abducentis opening ventral and slightly

1128 anteromedial to the base of the processus clinoideus, surface below the dorsum sellae sloping

1129 more gently anteriorly, and foramina anterius canalis carotici cerebralis widely separated. The 
1130 preservation of the cranium associated with the holotype specimen (Fig. 4) is not as good as that

1131 of the paratype, but it also exhibits most of the above differences with Pl. etalloni, in addition to

1132 the following: more rounded foramen nervi trigemini, and absence of midline contact of the

1133 exoccipital in the floor of the foramen magnum. Based on our experience of Late Jurassic coastal

1134 marine turtles, these differences cannot be attributed to intraspecific variations, sexual

1135 dimorphism, or ontogeny. Most importantly, the cranium of the holotype is associated with a

1136 near-complete carapace and partial plastron (Fig. 7). The cranium was found literally within the

1137 associated shell during preparation alongside elements of the appendicular skeleton. There is

1138 therefore no doubt regarding the natural state of this association. Interestingly, the holotype shell

1139 is remarkably similar to that of $\mathrm{Pl}$. etalloni, except for the much thinner neural and costal bones

1140 and for the absence of epiplastral bulbs.

1141 Among the 80 relatively complete shells studied herein, 41 can be confidently referred to

1142 the new species $P l$. bigleri based on the reduced neural and costal thickness, the absence or great

1143 reduction of epiplastral bulbs, and a generally more quadrangular anterior plastral lobe. Among

1144 the remaining 39 shells, 15 exhibit features that are consistent with an identification as $P l$.

1145 etalloni, notably the great thickness of neural and costal bones and/or the presence of well-

1146 developed epiplastral bulbs. The remaining 24 shells are provisionally identified as Plesiochelys

1147 sp. because they lack sufficient diagnostic features. Among the 56 specimens referred either to

$1148 P$ Pl. bigleri or to $P l$. etalloni, 33 with well-preserved neural bones were selected for a statistical

1149 analysis of neural thickness. This analysis confirmed that the mean thickness and

1150 length/thickness ratio were statistically different in the two species, with a mean length/thickness

1151 ratio of 4.79 for $P l$. bigleri and 3.67 for $P$ l. etalloni (see above). The length/thickness ratio of 
1152 neural bones (notably from neurals 2 to 5) is therefore an important additional feature to consider

1153 in order to differentiate these two species.

1154

1155 Is Plesiochelys bigleri also present in Solothurn?

1156 The Solothurn turtle assemblage is diversified and slightly younger than the one from Porrentruy.

1157 However, the two localities share a number of species in common: Plesiochelys etalloni,

1158 Tropidemys langii, Thalassemys hugii, and Thalassemys bruntrutana (Rütimeyer, 1873; Bräm,

1159 1965; Püntener et al., 2014; Püntener, Anquetin \& Billon Bruyat, 2015). Given the similarity

1160 observed between $P$ l. bigleri and Pl. etalloni in Porrentruy, the presence of Pl. bigleri among

1161 Solothurn specimens referred to Pl. etalloni would certainly not come as a surprise.

1162 Six skulls from Solothurn are referred to Pl. etalloni (NMS 8738, NMS 8739, NMS 8740,

1163 NMS 9145, NMS 40870, and NMS 40871; Gaffney, 1975a; Gaffney, 1976; Anquetin, Püntener

$1164 \&$ Billon-Bruyat, 2015). They all appear to belong to that species, although there may be some

1165 doubts regarding NMS 9145 which is associated with unprepared postcranial material including

1166 relatively thin costal bones. The latter specimen should be re-evaluated. Remaining specimens

1167 referred to $\mathrm{Pl}$. etalloni are otherwise often preserved as articulated shells, which complicates

1168 observation of neural and costal bones thickness in some cases and prevents a statistical analysis

1169 of neural bone thickness. Most of these specimens exhibit traits that are compatible with $P l$.

1170 etalloni, notably: relatively thick neurals or costal bones (e.g., NMS 8461, NMS 8515, NMS

1171 8517, NMS 8732), well-developed epiplastral bulbs (e.g., NMS 8533, NMS 8693, NMS 9150,

1172 NMS 9153, NMS 9173), or both features at the same time (e.g., NMS 8582). In some specimens,

1173 neither of the two main distinguishing features can be observed due to preservation (e.g., NMS

1174 8727). The attribution of other specimens might be questioned because one of the distinguishing 
1175 feature is poorly expressed, whereas the other is impossible to check. For example, NMS 8731

1176 has only moderately expressed epiplastral bulbs, and the thickness of the neurals and costals is

1177 difficult to evaluate (the costals seem to be relatively thin).

1178 For the moment, none of the Plesiochelys specimens from Solothurn can be confidently

1179 referred to $\mathrm{Pl}$. bigleri. However, this material should definitely be re-evaluated in the future in 1180 light of the new material from Porrentruy.

\section{CONCLUSIONS}

1183 Plesiochelys bigleri is a new plesiochelyid turtle known based on 41 relatively complete, but

1184 mostly disarticulated shells and two crania (one associated with a shell, and another one

1185 isolated). All of this material originates from a series of close by localities west of the small town

1186 of Courtedoux, near Porrentruy, Canton of Jura, Switzerland. Most of the specimens were

1187 collected from a single stratigraphically limited horizon, the Lower Virgula Marls, dated from

1188 the early late Kimmeridgian. A few additional specimens were found in two underlying horizons,

1189 the Corbis Limestones and Banné Marls, dated from the late early Kimmeridgian.

1190 The shell morphology of $\mathrm{Pl}$. bigleri is remarkably similar to that of $P l$. etalloni, a species

1191 known based on tenths of shells and several crania from the Kimmeridgian of Switzerland,

1192 France, Germany, and England. These two closely related species however differ in the thickness

1193 of the neural and costal bones of the carapace (a difference that is statistically tested herein), and

1194 the presence and development of the epiplastral bulbs in the plastron. Differentiating the two

1195 species based only on shell morphology can be challenging in some incomplete or juvenile

1196 individuals. The two species co-occur in Porrentruy and 24 shells $(30 \%$ of the shells referable to

1197 Plesiochelys) cannot be identified at the species level as a result of this great similarity. 
1198 However, the two species are more easily separated based on cranial morphology. Actually, $P l$.

1199 bigleri exhibits cranial features that clearly set it apart from Pl. etalloni and other plesiochelyids,

1200 such as: a rounded foramen nervi trigemini, a shallow pterygoid fossa, a reduced processus

1201 trochlearis oticum, the absence of ossification of the pila prootica, the surface below the dorsum

1202 sellae sloping rather gently anteroventrally, and the widely separated foramina anterius canalis

1203 carotici cerebralis.

1204 For the moment, Pl. bigleri is known only in Porrentruy. However, Solothurn and

1205 Porrentruy share several species of turtles in common (Pl. etalloni, Tropidemys langii,

1206 Thalassemys hugii, and Thalassemys bruntrutana), and these species are also known in the

1207 Kimmeridgian of southern England (Püntener et al., 2014; Püntener, Anquetin \& Billon-Bruyat, 1208 2015; Anquetin \& Chapman, 2016). Finding Pl. bigleri in other localities would therefore not 1209 come as a surprise.

1210 The abundant material from Solothurn and Porrentruy referred to Pl. etalloni and Pl.

1211 bigleri illustrates the extent of intraspecific variability in these two species. Although these

1212 results may not be blindly transposable to other groups of turtles, they represent an important

1213 point of comparison for other studies on Mesozoic turtle diversity.

1215 Institutional Abbreviations

1216 MAJ Musée d'archéologie du Jura, Lons-le-Saunier, France

1217 MJSN JURASSICA Museum, Porrentruy, Switzerland

1218 NHMUK Natural History Museum, London, UK

1219 NMB Naturhistorisches Museum Basel, Switzerland

1220 NMS Naturmuseum Solothurn, Switzerland 
1221 OUMNH Oxford University Museum of Natural History, Oxford, UK

1222 PIMUZ Paläontologisches Institut und Museum, Universität Zürich, Switzerland

1223

1224 Locality Abbreviations

1225 BSY Bois de Sylleux, Courtedoux, near Porrentruy, Switzerland

1226 CRT Crat, Chevenez, near Porrentruy, Switzerland

1227 SCR Sur Combe Ronde, Courtedoux, near Porrentruy, Switzerland

1228 TCH Tchâfoué, Courtedoux, near Porrentruy, Switzerland

1229 VTT Vâ Tche Tchâ, Courtedoux, near Porrentruy, Switzerland

1231

\section{ACKNOWLEDGEMENTS}

1232 We thank Loïc Bocat (excavation), Pierre Bigler, Renaud Roch and Sébastien Bergot 1233 (preparation team), Bernard Migy and Olivier Noaillon (photographs), Pierre Widder (scientific 1234 drawings), Apolline Lefort (discussion on stratigraphy) and the whole Paleontology A16 team.

1235 We furthermore thank Silvan Thüring (NMS) and Loïc Costeur (NMB) for access to collections 1236 in their care. Editor Mark Young and the reviewers Adán Pérez-García and Márton Rabi 1237 provided very helpful comments to improve the manuscript.

1238

\section{REFERENCES}

Anquetin J, Chapman SD. 2016. First report of Plesiochelys etalloni and Tropidemys langii from the Late Jurassic of the UK and the palaeobiogeography of plesiochelyid turtles. Royal Society Open Science 3:150470. DOI: 10.1098/rsos.150470. 
1243 Anquetin J, Deschamps S, Claude J. 2014. The rediscovery and redescription of the holotype of 1244 the Late Jurassic turtle Plesiochelys etalloni. PeerJ 2:e258 DOI 10.7717/peerj.258.

1245 Anquetin J, Püntener C, Billon-Bruyat J-P. 2014. A taxonomic review of the Late Jurassic 1246 eucryptodiran turtles from the Jura Mountains (Switzerland and France). PeerJ 2:e369. 1247 DOI: $10.7717 /$ peerj.369.

1248 Anquetin J, Püntener C, Billon-Bruyat J-P. 2015. Portlandemys gracilis n. sp., a new coastal 1249 marine turtle from the Late Jurassic of Porrentruy (Switzerland) and a reconsideration of plesiochelyid cranial anatomy. PLOS ONE 10:e0129193. DOI:

10.1371/journal.pone.0129193.

Bardet N. 1994. Extinction events among Mesozoic marine reptiles. Historical Biology 7:313324.

Bardet N. 1995. Evolution et extinction des reptiles marins au cours du Mésozoïque. Palaeovertebrata 24:177-283.

Bardet N, Falconnet J, Fischer V, Houssaye A, Jouve S, Pereda Suberbiola X, Pérez-García A, Rage J-C, Vincent P. 2014. Mesozoic marine reptile palaeobiogeography in response to drifting plates. Gondwana Research 26:869-887. DOI: 10.1016/j.gr.2014.05.005.

Batsch AJGC. 1788. Versuch einer Anleitung, zur Kenntniß und Geschichte der Thiere und Mineralien. Jena: Akademische Buchhandlung.

Baur G. 1888. Osteologische Notizen über Reptilien (Fortsetzung II). Zoologischer Anzeiger $11: 417-424$.

Billon-Bruyat J-P. 2005a. A "turtle cemetery" from the Late Jurassic of Switzerland. Abstracts, 3rd Swiss Geoscience Meeting, Zürich: 238. 
1265 Billon-Bruyat J-P. 2005b. First record of a non-pterodactyloid pterosaur (Reptilia: Archosauria)

1266

1267

1268

1269

1270

1271

1272

1273

1274

1275

1276

1277

1278

1279

1280

1281

1282

1283

1284

1285

1286

1287 from Switzerland. Eclogae Geologicae Helvetiae 98:313-317.

Billon-Bruyat J-P, Marty D, Bocat L, Paratte G. 2012. Under the feet of sauropods: a trampled coastal marine turtle. Abstracts, Symposium on turtle evolution, Tübingen: 10.

Bräm H. 1965. Die Schildkröten aus dem oberen Jura (Malm) der Gegend von Solothurn. Schweizerische Paläontologische Abhandlungen 83:1-190.

Comment G, Ayer J, Becker D. 2011. Deux nouveaux membres lithostratigraphiques de la Formation de Reuchenette (Kimméridgien, Ajoie, Jura suisse) - Nouvelles données géologiques et paléontologiques acquises dans le cadres de la construction de l'autoroute A16 (Transjurane). Swiss Bulletin für angewandte Geologie 16:3-24.

Comment G, Lefort A, Koppka J, Hantzpergue P. 2015. Le Kimméridgien d'Ajoie (Jura, Suisse): lithostratigraphie et biostratigraphie de la Formation de Reuchenette. Revue de Paléobiologie 34:161-194. DOI: 10.5281/zenodo.34341.

Dollo L. 1886. Première note sur les Chéloniens du Bruxellien (Eocène moyen) de la Belgique. Bulletin du Musée Royal d'Histoire Naturelle de Belgique 4:75-100.

Gaffney ES. 1972. An illustrated glossary of turtle skull nomenclature. American Museum Novitates 2486:1-33.

Gaffney ES. 1975a. A taxonomic revision of the Jurassic turtles Portlandemys and Plesiochelys. American Museum Novitates 2574:1-19.

Gaffney ES. 1975b. Solnhofia parsonsi, a new cryptodiran turtle from the Late Jurassic of Europe. American Museum Novitates 2576:1-22.

Gaffney ES. 1975c. A phylogeny and classification of the higher categories of turtles. Bulletin of the American Museum of Natural History 155:387-436. 
1288 Gaffney ES. 1976. Cranial morphology of the European Jurassic turtles Portlandemys and 1289 Plesiochelys. Bulletin of the American Museum of Natural History 157:487-544.

1290 Gaffney ES. 1979. Comparative cranial morphology of Recent and fossil turtles. Bulletin of the

1291

1292 American Museum of Natural History 164:65-376.

Gaffney ES. 1990. The comparative osteology of the Triassic turtle Proganochelys. Bulletin of the American Museum of Natural History 194:1-263.

Hammer Ø, Harper DAT, Ryan PD. 2001. PAST: Paleontological statistics software package for education and data analysis. Palaeontologia Electronica 4(9).

Joyce WG. 2007. Phylogenetic relationships of Mesozoic turtles. Bulletin of the Peabody Museum of Natural History 48:3-102. DOI 10.3374/0079032X(2007)48[3:PROMT]2.0.CO;2.

Joyce WG, Parham JF, Gauthier JA. 2004. Developing a protocol for the conversion of rankbased taxon names to phylogenetically defined clade names, as exemplified by turtles. Journal of Paleontology 78:989-1013.

Karl H-V, Staesche U, Tichy G, Lehmann J, Peitz S. 2007. Systematik der Schildkröten (Anapsida: Chelonii) aus Oberjura und Unterkreide von Nordwestdeutschland. Geologisches Jahrbuch B 98:5-89.

Koppka J. 2015. Revision of the Bivalvia from the Upper Jurassic Reuchenette Formation, Northwest Switzerland-Ostreoidea. Zootaxa 3927(1):1-117.

Leuzinger L, Kocsis L, Billon-Bruyat J-P, Spezzaferri S, Vennemann T. 2015. Stable isotope study of a new chondrichthyan fauna (Kimmeridgian, Porrentruy, Swiss Jura): an unusual freshwater-influenced isotopic composition for the hybodont shark Asteracanthus. Biogeosciences 12:6945-6954. 
1311 Maack GA. 1869. Die bis jetzt bekannten fossilen Schildkröten und die im oberen Jura bei

1312 Kelheim (Bayern) und Hannover neu aufgefundenen ältesten Arten derselben.

1313 Palaeontographica 18:193-338.

1314 Mallison H, Wings O. 2014. Photogrammetry in paleontology - A practical guide. Journal of

1315

1316

1317

1318

1319

1320

1321

1322

1323

1324

1325

1326 Paleontological Techniques 12:1-30.

Marty D. 2008. Sedimentology, taphonomy, and ichnology of Late Jurassic dinosaur tracks from the Jura carbonate platform (Chevenez-CombeRonde tracksite, NW Switzerland): insights into the tidalflat palaeoenvironment and dinosaur diversity, locomotion, and palaeoecology. GeoFocus 21:1-278.

Marty D, Hug WA. 2003. Le Kimméridgien en Ajoie (Mésozoïque): premiers résultats de fouilles et de recherches paléontologique sur le tracé de la Transjurane (A16). Actes de la Société jurassienne d'émulation 2003:27-44.

Marty D, Billon-Bruyat J-P. 2009. Field-trip to the excavations in the Late Jurassic along the future Transjurane highway near Porrentruy (Canton Jura, NW Switzerland): dinosaur tracks, marine vertebrates and invertebrates [Abstract]. In: Billon-Bruyat J-P, Marty D, Costeur L, Meyer CA, Thüring B, eds. Abstracts and Field Guides, 5th International Symposium on Lithographic Limestone and Plattenkalk, Actes 2009 bis de la Société jurassienne d'émulation. Porrentruy, Switzerland, 94-129.

Marty D, Ayer J, Becker D, Berger J-P, Billon-Bruyat J-P, Braillard L, Hug WA, Meyer CA. 2007. Late Jurassic dinosaur tracksites of the Transjurane highway (Canton Jura, NW Switzerland): overview and measures for their protection and valorization. Bulletin for Applied Geology 12:75-89. 
1333 Meyer CA. 1994. Depositional environment and paleoecology of the Solothurn turtle limestone (Kimmeridgian, Northern Switzerland). Geobios 27 (Supplement 1):227-236.

1335

1336

1337

1338

1339

1340

1341

1342

1343

1344

1345

1346

1347

1348

1349

1350

1351

1352

1354 1355 Palaeontographica 11:289-295.

Oertel W. 1924. Die Schildkrötenfauna des nordwestdeutschen oberen Jura. Paläontologische Zeitschrift 6:43-79.

Owen R. 1842. Report on British fossil reptiles, part II. Report for the British Association for the Advancement of Science, Plymouth 1841 11:60-204.

Parsons TS, Williams EE. 1961. Two Jurassic turtle skulls: A morphological study. Bulletin of the Museum of Comparative Zoology 125:43-107.

Pérez-García A. 2015. New data on the poorly-known Late Jurassic turtles Thalassemys and Enaliochelys and description of a new basal eucryptodiran taxon. Journal of Iberian Geology 41:21-30. DOI: 10.5209/rev_JIGE.2015.v41.n1.48652.

Pérez-García A, Scheyer TM, Murelaga X. 2013. The turtles from the Uppermost Jurassic and Early Cretaceous of Galve (Iberian Range, Spain): anatomical, systematic, biostratigraphic and palaeobiogeographical implications. Cretaceous Research 44:64-82.

Pérez-García A, Ortega F, Murelaga X, Dantas P. 2008. Plesiochelys sp. (Testudines; Eucryptodira) de la Fm. Freixial (Jurásico Superior) en Ulsa (Torres Vedras, Portugal). Publicaciones del Seminario de Paleontología de Zaragoza 8:331-344.

Philippe M, Billon-Bruyat J-P, Garcia-Ramos JC, Bocat L, Gomez B, Piñuela L. 2010. New occurrences of the wood Protocupressinoxylon purbeckensis Francis: implications for terrestrial biomes in southwestern Europe at the Jurassic/Cretaceous boundary. Palaeontology 53:201-214. 
1356 Pictet F-J, Humbert A. 1857. Description d'une émyde nouvelle (Emys Etalloni) du terrain

1357

1358

1359

1360

1361

1362

1363

1364

1365

1366

1367

1368

1369

1370

1371

1372

1373

1374

1375

1376

1377 jurassique supérieur des environs de St-Claude. In: Pictet F-J, ed. Matériaux pour la paléontologie suisse, Première série. Genève: J. Kessmann, 1-10.

Püntener C, Billon-Bruyat J-P, Bocat L, Berger J-P, Joyce WG. 2014. Taxonomy and phylogeny of the turtle Tropidemys langii Rütimeyer, 1873 based on new specimens from the Kimmeridgian of the Swiss Jura Mountains. Journal of Vertebrate Paleontology 34:353374. DOI: $10.1080 / 02724634.2013 .804412$.

Püntener C, Anquetin J, Billon-Bruyat J-P. 2015. Thalassemys bruntrutana n. sp., a new coastal marine turtle from the Late Jurassic of Porrentruy (Switzerland), and the paleobiogeography of the Thalassemydidae. PeerJ 3:e1282. DOI: 10.7717/peerj.1282.

Rabi M, Zhou C-F, Wings O, Ge S, Joyce WG. 2013. A new xinjiangchelyid turtle from the Middle Jurassic of Xinjiang, China and the evolution of the basipterygoid process in Mesozoic turtles. BMC Evolutionary Biology 13:203.

Rieppel O. 1980. The skull of the Upper Jurassic cryptodire turtle Thalassemys, with a reconsideration of the chelonian braincase. Palaeontographica, Abt. A 171:105-140.

Rütimeyer L. 1873. Die fossilen Schildkröten von Solothurn und der übrigen Juraformation. Neue Denkschrift der allgemeinen schweizerischen naturforschenden Gesellschaft 25:1185.

Schaefer K. 2012. Variabilité de la morphologie dentaire des crocodiliens marins (Thalattosuchia) du Kimméridgien d'Ajoie (Jura, Suisse). Unpublished Master Thesis, University of Fribourg.

Werneburg I. 2011. The cranial musculature of turtles. Palaeontologia Electronica 14:15A. 
1378 Zangerl R. 1969. The turtle shell. In: Gans C, Bellairs AA, Parsons TS, eds. Biology of the Reptilia. Volume 1, Morphology A. London: Academic Press, 311-339.

1380 Zittel KA. 1889. Handbuch der Palaeontologie. Section 1: Palaeozoologie, Volume 3, 1381 Vertebrata, Shipment 3: Reptilia. München: R. Oldenbourg.

1382 Zug GR. 1971. Buoyancy, locomotion, morphology of the pelvic girdle and hindlimb, and systematics of cryptodiran turtles. Miscellaneous Publications Museum of Zoology, University of Michigan 142:1-98. 
Figure 1

Geographical map of the Ajoie Region, Canton Jura, Switzerland.

The five excavation sites Bois de Sylleux (BSY), Crat (CRT), Sur Combe Ronde (SCR), Tchâfouè (TCH), and Vâ Tche Tchâ (VTT) are situated along the Transjurane Al6 highway (gray).

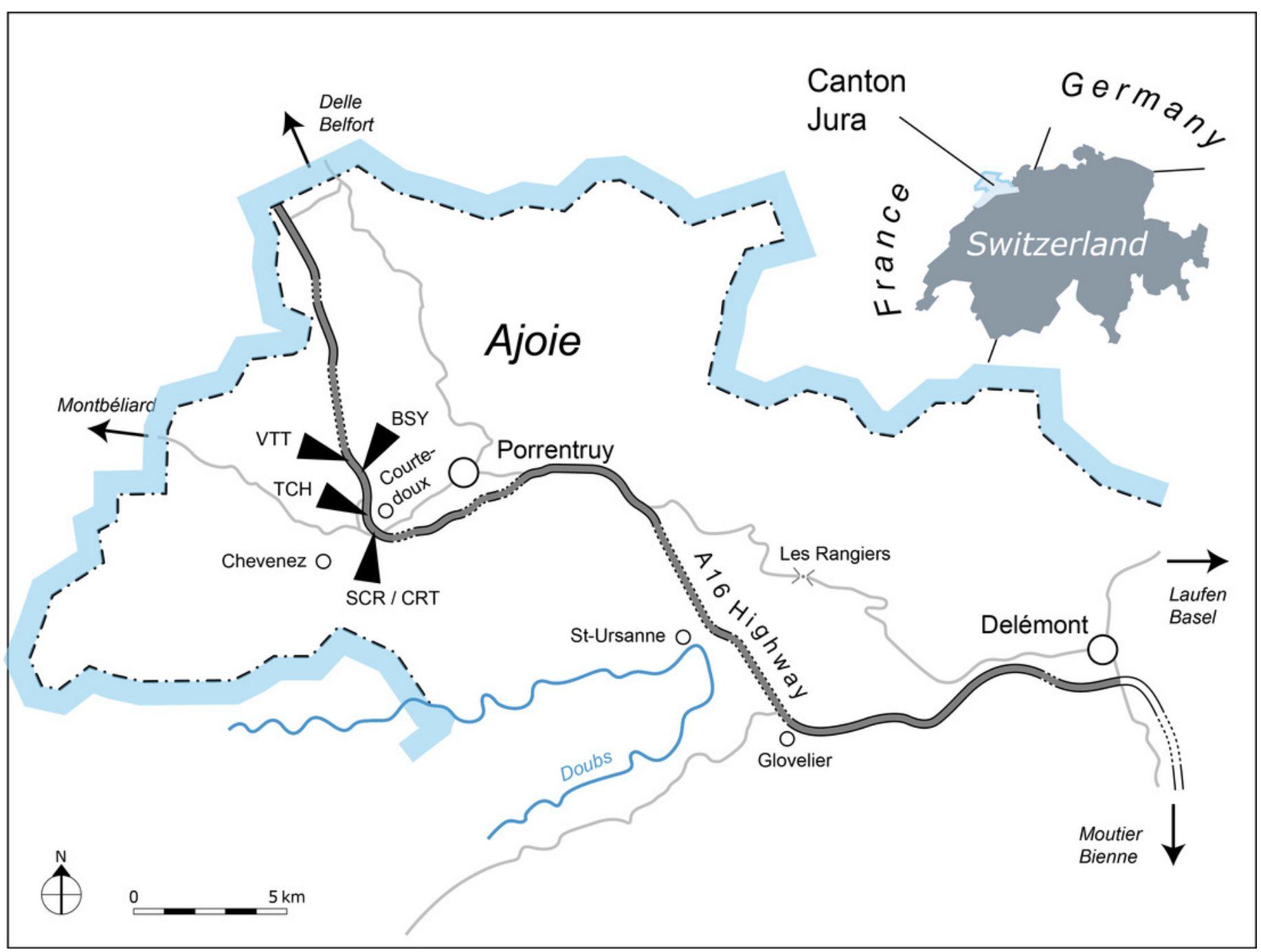


Figure 2

Stratigraphic section of the Reuchenette Formation.

Most specimens were discovered within the Lower Virgula Marls (sites of BSY, SCR, and TCH).

One specimen comes from dinosaur track-bearing tidal laminites (CRT), and two from the Banné Marls (VTT). Scheme modified after Comment et al. (2015). 


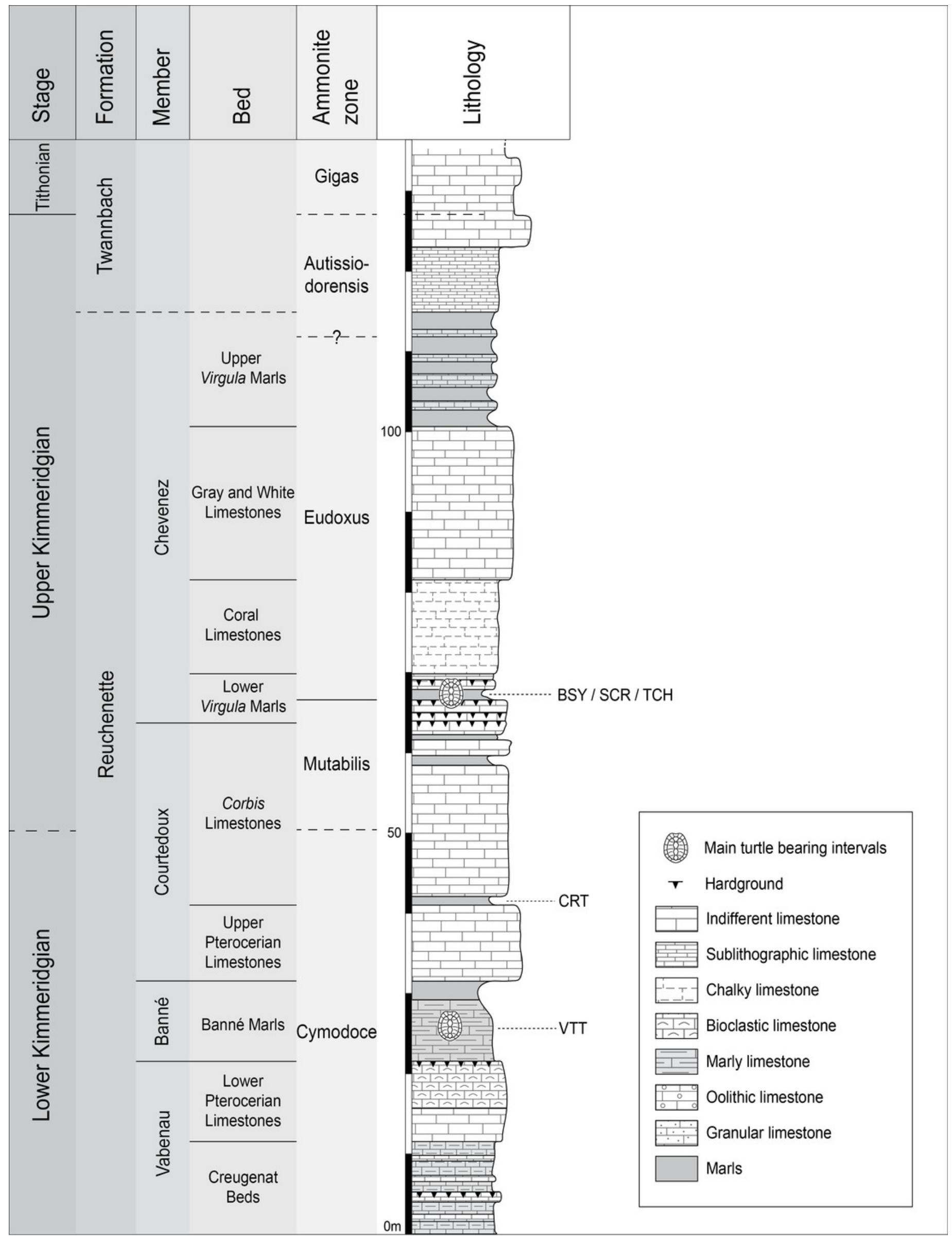


Figure 3

MJSN TCH006-1420, Plesiochelys bigleri (Kimmeridgian, Porrentruy, Switzerland).

Field photograph of the specimen embedded in the Lower Virgula Marls.

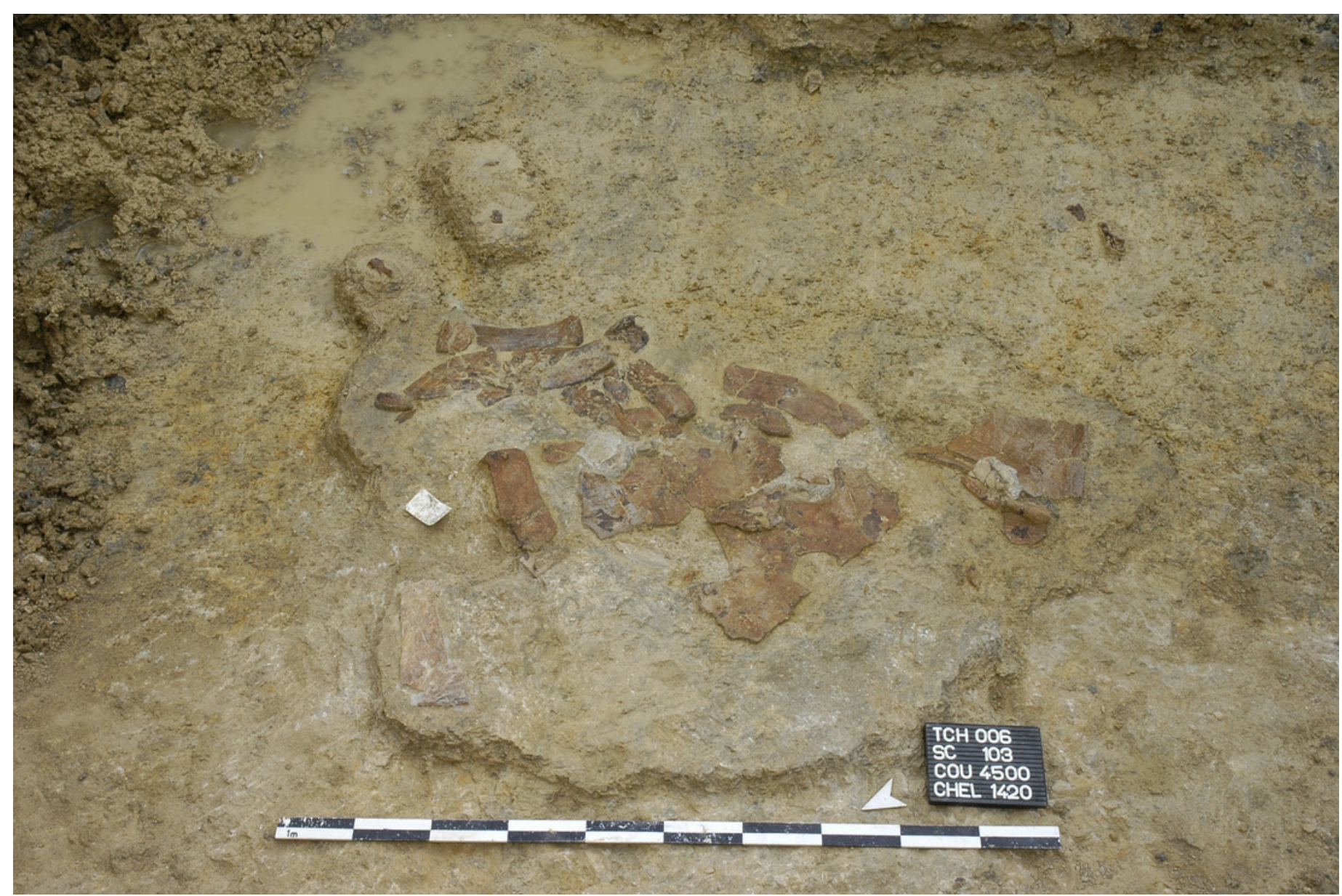




\section{Figure 4}

MJSN TCH007-252, holotype of Plesiochelys bigleri (Kimmeridgian, Porrentruy, Switzerland).

Cranium in dorsal $(A, B)$, ventral $(C, D)$, anterior $(E, F)$, posterior $(G, H)$, right lateral $(I, J)$, and left lateral $(K, L)$ views. Gray areas indicate disarticulated sutural surfaces. Hatchings represent damaged areas. Abbreviations: ap, antrum postoticum; bo, basioccipital; bs, basisphenoid; ccc, canalis caroticus cerebralis; cci, canalis caroticus internus; cs, crista supraoccipitalis; ct, cavum tympani; ds, dorsum sellae; epi, epipterygoid; ex, exoccipital; fce, fossa cartilaginis epipterygoidei; feng, foramen externum nervi glossopharyngei; fna, foramen nervi abducentis; fnh, foramen nervi hypoglossi; fnt, foramen nervi trigemini; fo, fenestra ovalis; fp, fenestra perilymphatica; fst, foramen stapedio-temporale; ica, incisura columellae auris; op, opisthotic; pa, parietal; pi, processus interfenestralis; pcl, processus clinoideus; ppe, processus pterygoideus externus; pr, prootic; pt, pterygoid; ptf, pterygoid fossa; pto, processus trochlearis oticum; qj, quadratojugal; qr, quadrate ridge; qu, quadrate; so, supraoccipital; sq, squamosal; tra, trabecula; un. f., unnamed foramen. 

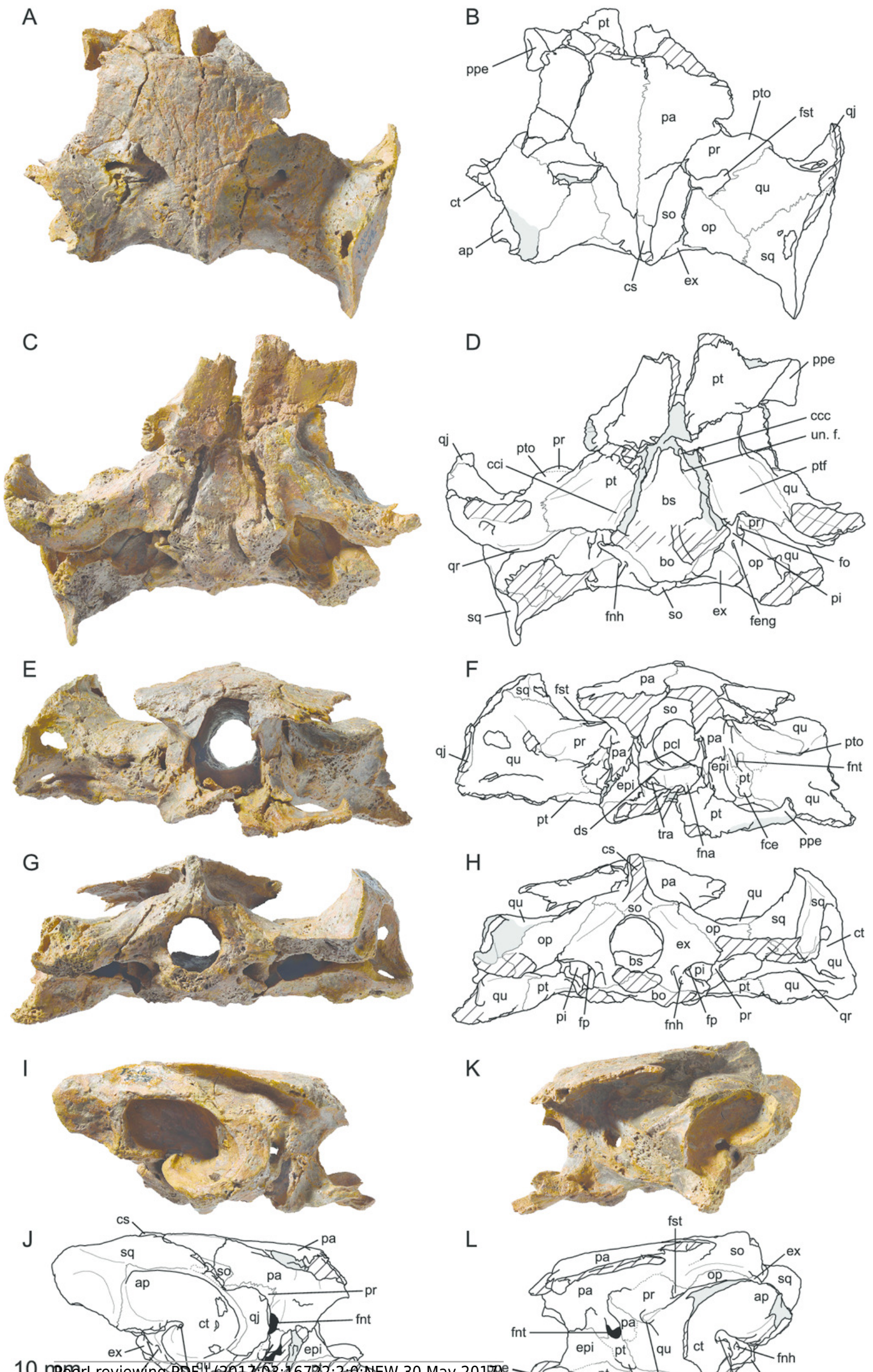

L

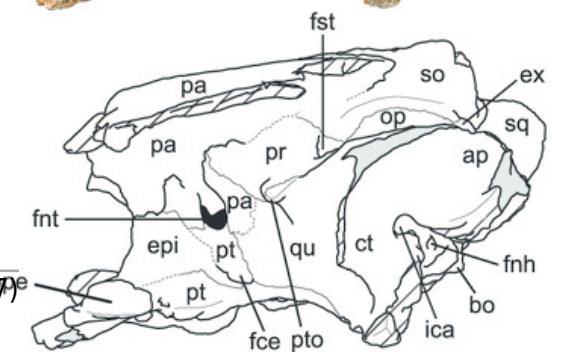




\section{Figure 5}

MJSN TCH006-1451, paratype of Plesiochelys bigleri (Kimmeridgian, Porrentruy, Switzerland).

Cranium in dorsal $(A, B)$, ventral $(C, D)$, posterior $(E, F)$, and right lateral $(G, H)$ views. Hatchings represent damaged areas. Abbreviations: ap, antrum postoticum; bo, basioccipital; bs, basisphenoid; cci, canalis caroticus internus; $\mathrm{cm}$, condylus mandibularis; cs, crista supraoccipitalis; ct, cavum tympani; ds, dorsum sellae; epi, epipterygoid; ex, exoccipital; faccc, foramen anterius canalis carotici cerebralis; faccp, foramen anterius canalis carotici palatinum; feng, foramen externum nervi glossopharyngei; fm, foramen magnum; fna, foramen nervi abducentis; fnh, foramen nervi hypoglossi; fnv, foramen nervi vidiani; fo, fenestra ovalis; fpp, foramen palatinum posterius; fst, foramen stapedio-temporale; ica, incisura columellae auris; ju, jugal; lar, labial ridge; lir, lingual ridge; mx, maxilla; op, opisthotic; pal, palatine; pi, processus interfenestralis; pcl, processus clinoideus; pr, prootic; pt, pterygoid; pto, processus trochlearis oticum; qj, quadratojugal; qr, quadrate ridge; qu, quadrate; so, supraoccipital; sq, squamosal; vo, vomer. 

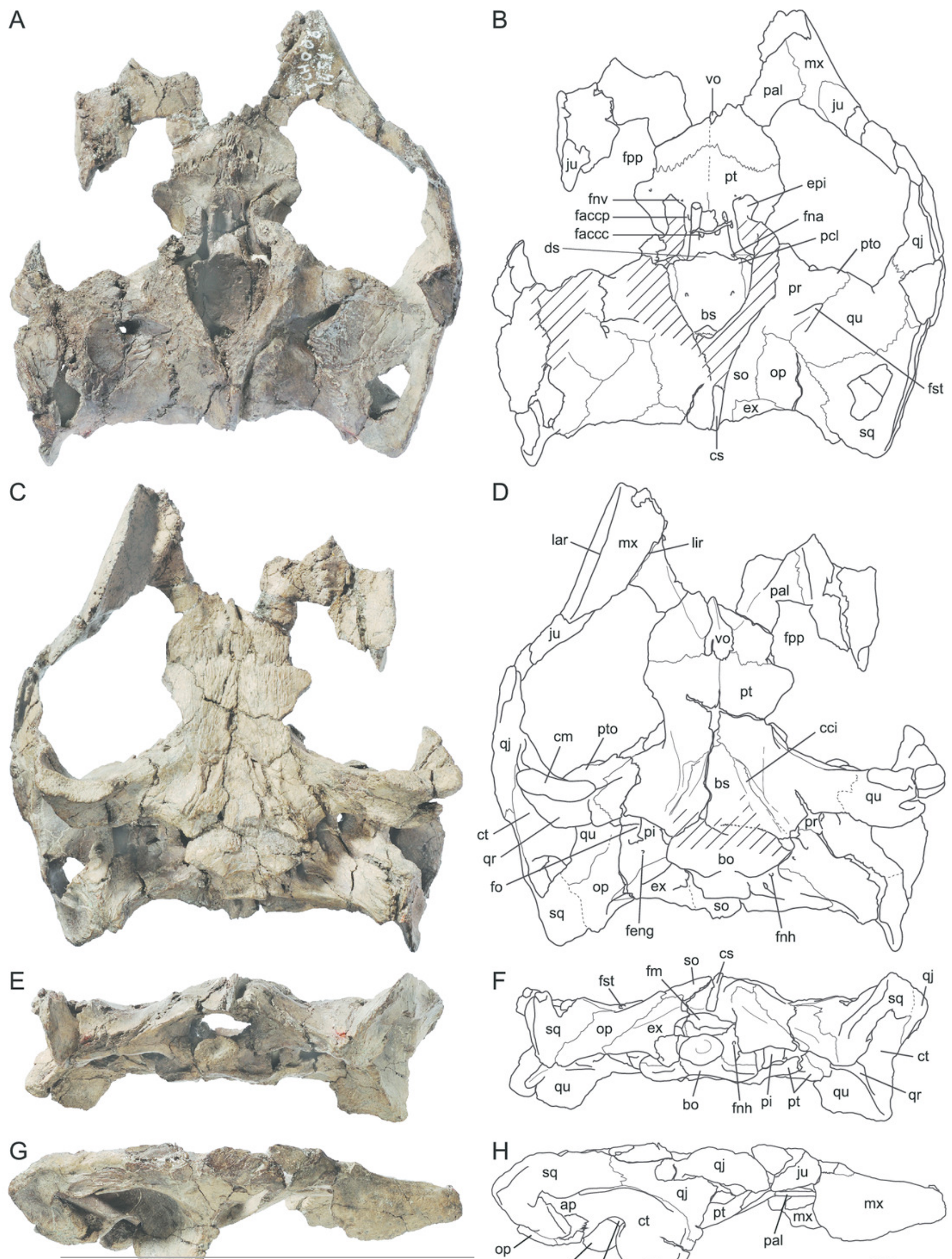

Peer] reviewing PDF / (2017:03:16722:2:0:NEW 30 May 2017)

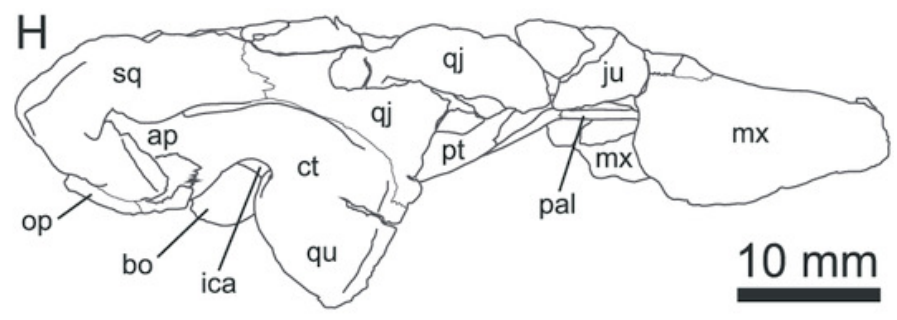




\section{Figure 6}

MJSN TCH006-1451, paratype of Plesiochelys bigleri (Kimmeridgian, Porrentruy, Switzerland).

Dorsal view of the dorsum sellae and sella turcica region. Hatchings represent damaged areas. The lattice pattern represents matrix infilling. Abbreviations: bs, basisphenoid; ds, dorsum sellae; epi, epipterygoid; faccc, foramen anterius canalis carotici cerebralis; faccp, foramen anterius canalis carotici palatinum; fna, foramen nervi abducentis; fnv, foramen nervi vidiani; pcl, processus clinoideus; pr, prootic; pt, pterygoid; sc, sulcus cavernosus; st, sella turcica; tra, trabecula.

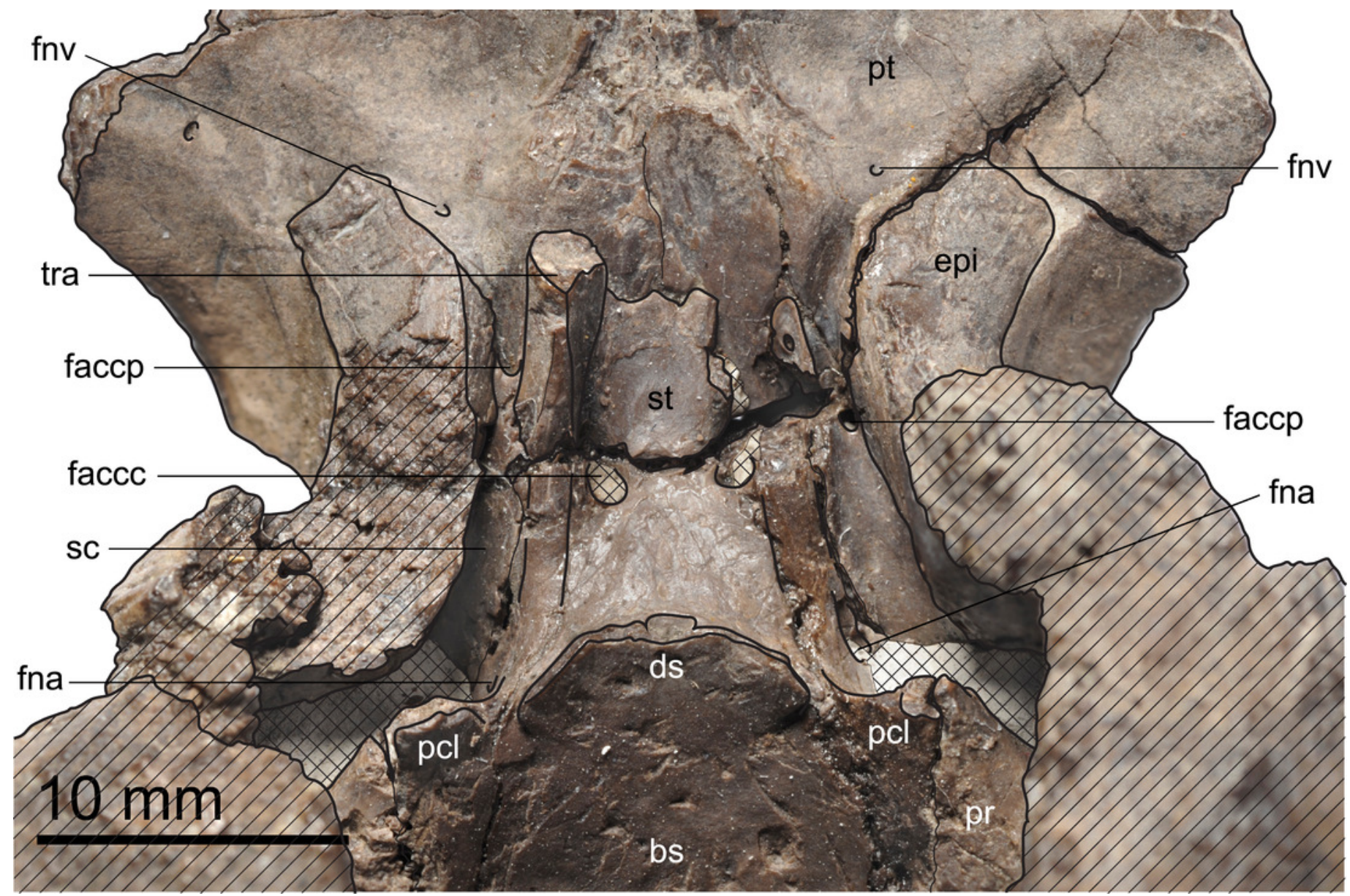




\section{Figure 7}

MJSN TCH007-252, holotype of Plesiochelys bigleri (Kimmeridgian, Porrentruy, Switzerland).

(A, B) carapace; (C, D) plastron. Line width indicates natural borders (thick lines), bone sutures (medium lines), and fractures (thin lines); double lines indicate scale sulci. Abbreviations: co, costal; ent, entoplastron; epi, epiplastron; hypo, hypoplastron; n, neural; sp, supragygal; $v$, vertebral scale; $x i$, xiphiplastron; ${ }^{*}$, intermediate element (see text). 
A

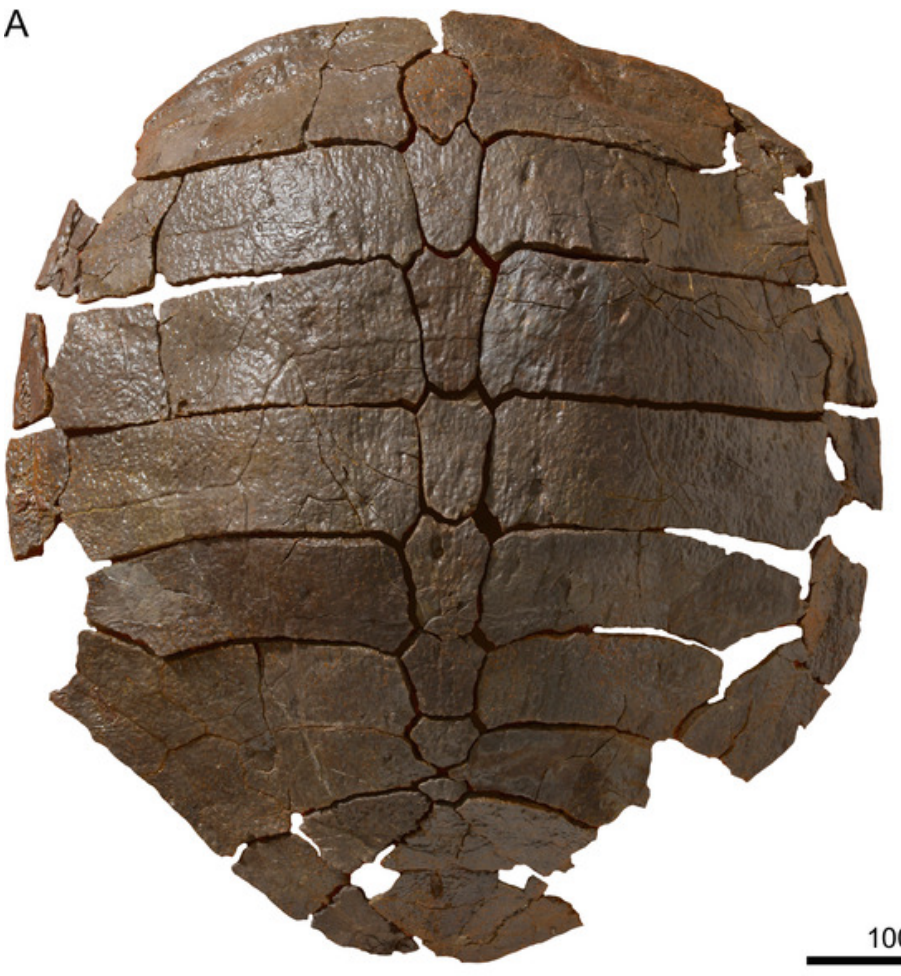

C
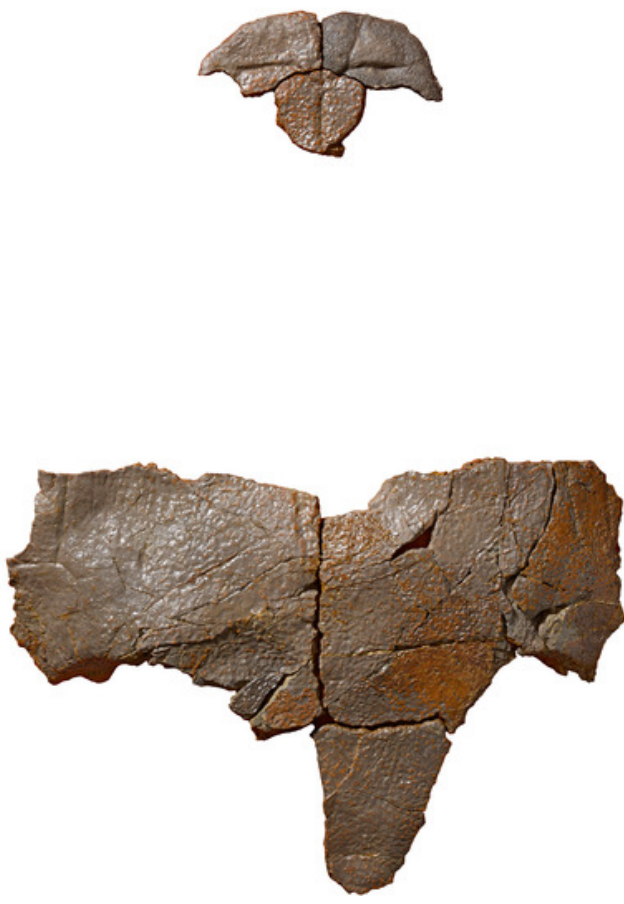

B

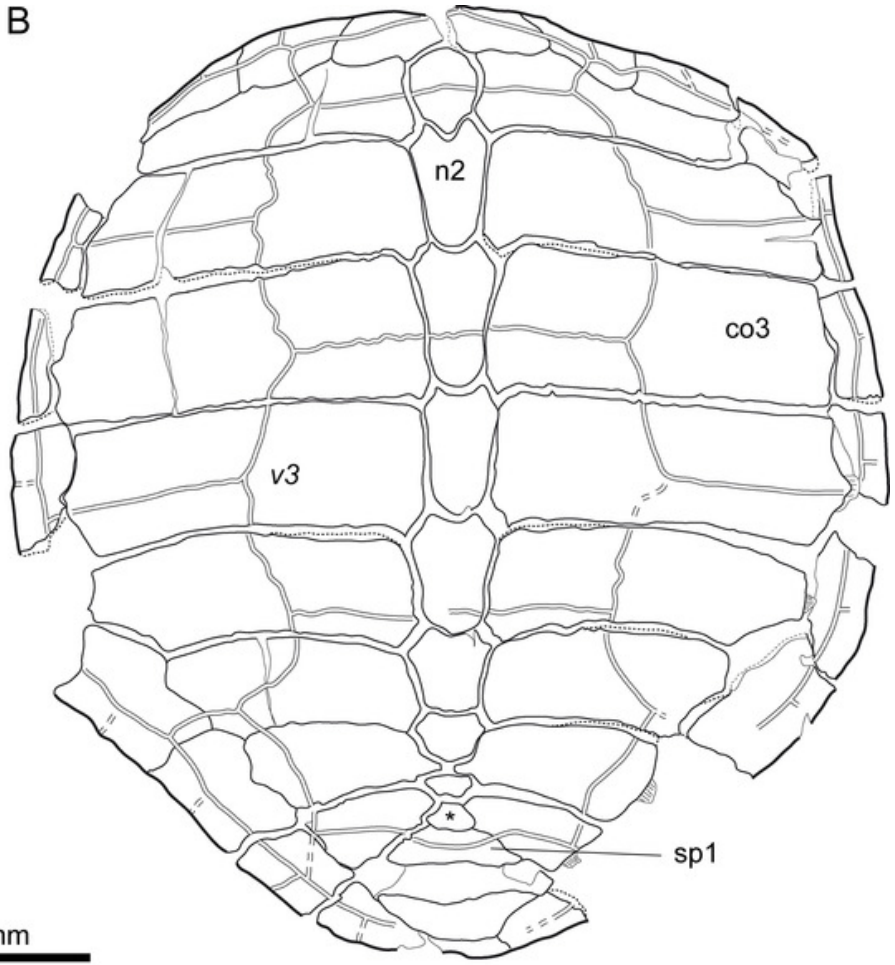

D

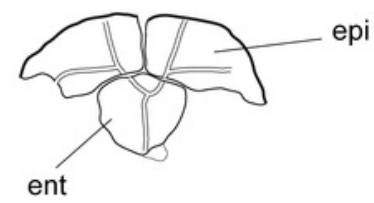

$100 \mathrm{~mm}$

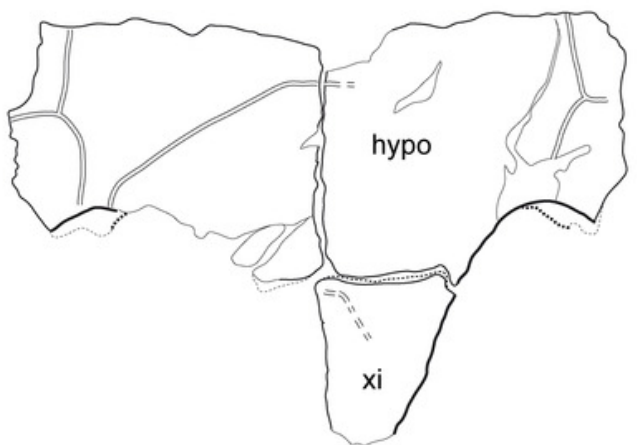




\section{Figure 8}

Shells of Plesiochelys bigleri.

Carapace (A, B) and plastron (C, D) of specimen MJSN TCH006-1420 (Kimmeridgian, Porrentruy, Switzerland); carapace (E, F) and plastron (G, H) of specimen MJSN BSY006-307 (Kimmeridgian, Porrentruy, Switzerland); carapace $(\mathrm{I}, \mathrm{J})$ and plastron $(\mathrm{K}, \mathrm{L})$ of specimen MJSN SCR011-140 (Kimmeridgian, Porrentruy, Switzerland); carapace (M, N) of specimen MJSN TCH005-42 (Kimmeridgian, Porrentruy, Switzerland). Line width indicates natural borders (thick lines), bone sutures (medium lines), and fractures (thin lines); double lines indicate scale sulci. Abbreviations: co, costal; ent, entoplastron; epi, epiplastron; hyo, hyoplastron; hypo, hypoplastron; nu, nuchal; pl, pleural scale; sp, supragygal; v, vertebral scale; xi, xiphiplastron; *, intermediate element (see text). 


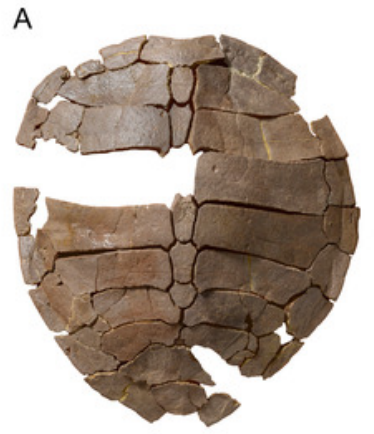

C
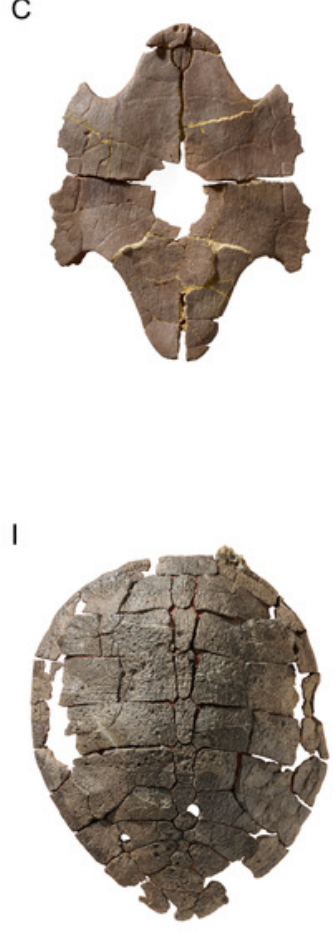

$\mathrm{K}$

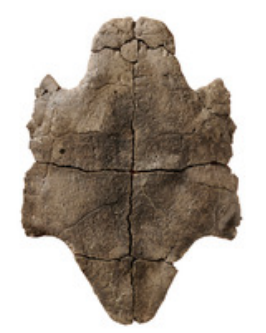

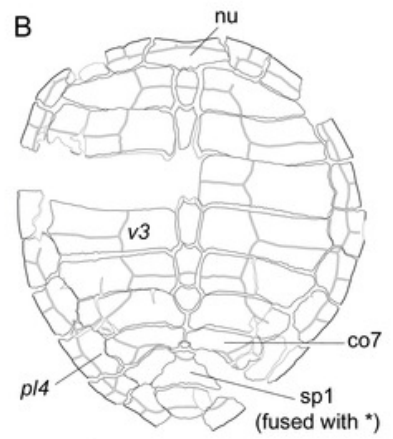

D

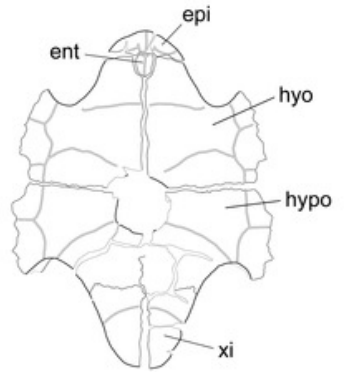

$\underline{100 \mathrm{~mm}}$

J

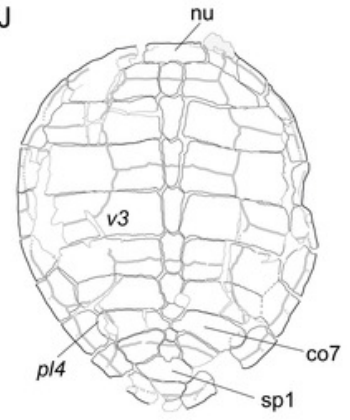

L

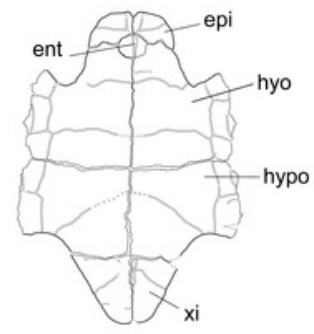

E
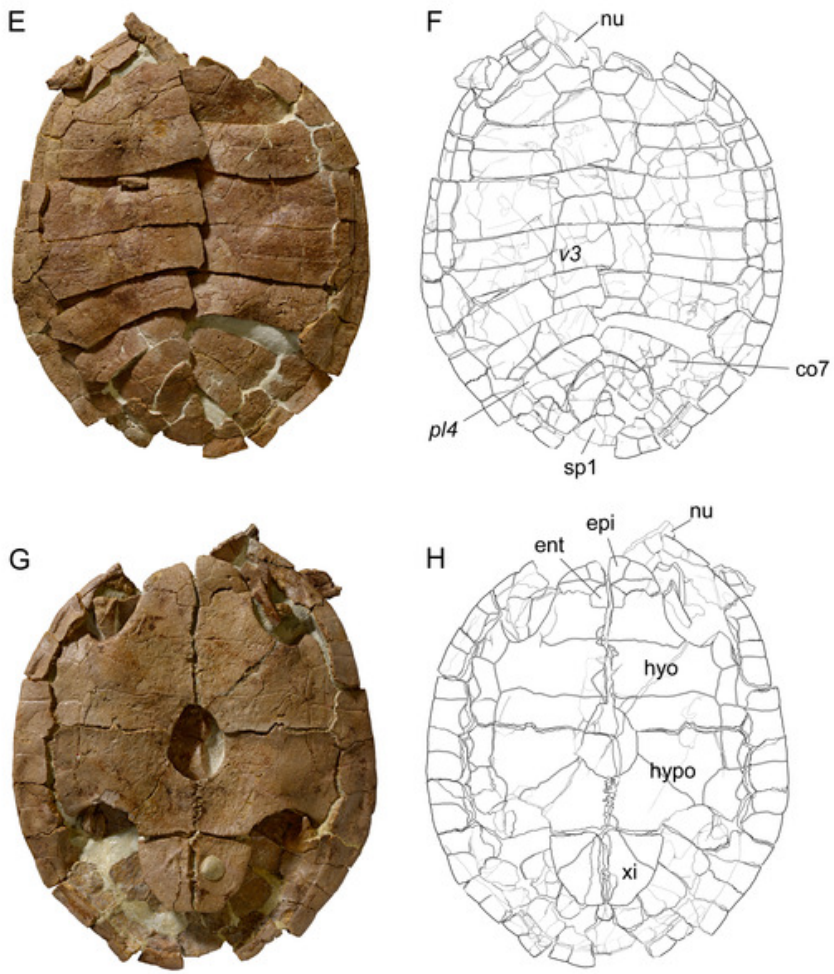

N

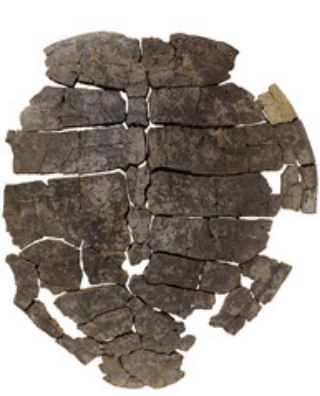

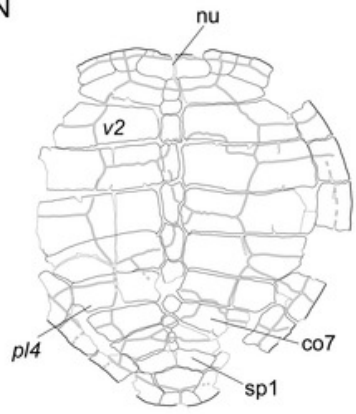




\section{Figure 9}

Neural bones of Plesiochelys bigleri and Plesiochelys etalloni (Kimmeridgian, Porrentruy, Switzerland).

Neural 4 of specimen MJSN TCH006-1420 (Plesiochelys bigleri) in dorsal (A) and lateral left view (B); neural 4 of specimen MJSN BSY006-347 (Plesiochelys etalloni) in dorsal (C) and lateral left view (D).

A

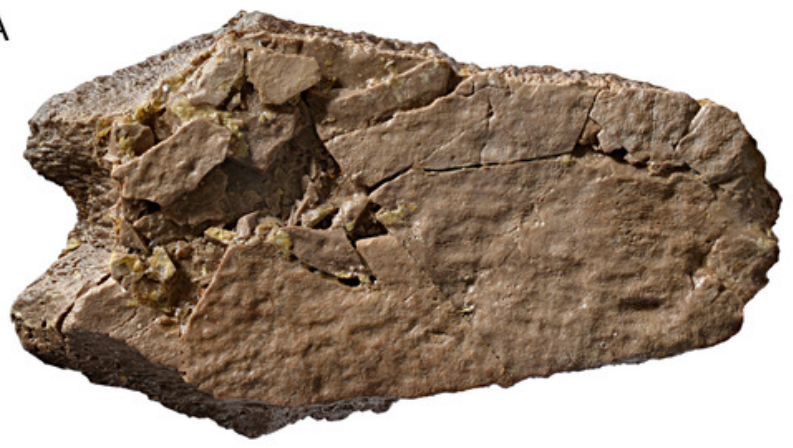

B

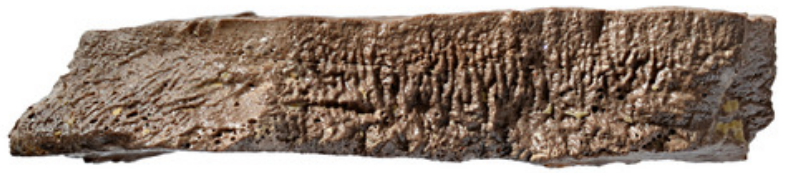

C
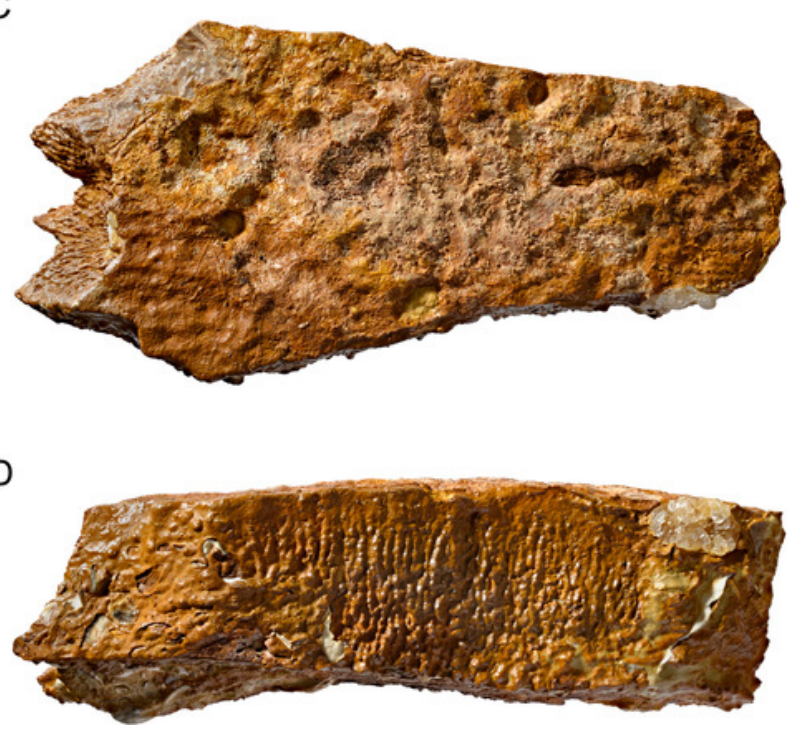


\section{Figure 10}

MJSN TCH005-42, Plesiochelys bigleri (Kimmeridgian, Porrentruy, Switzerland).

Left scapula in lateral (A) and medial view (B).

A

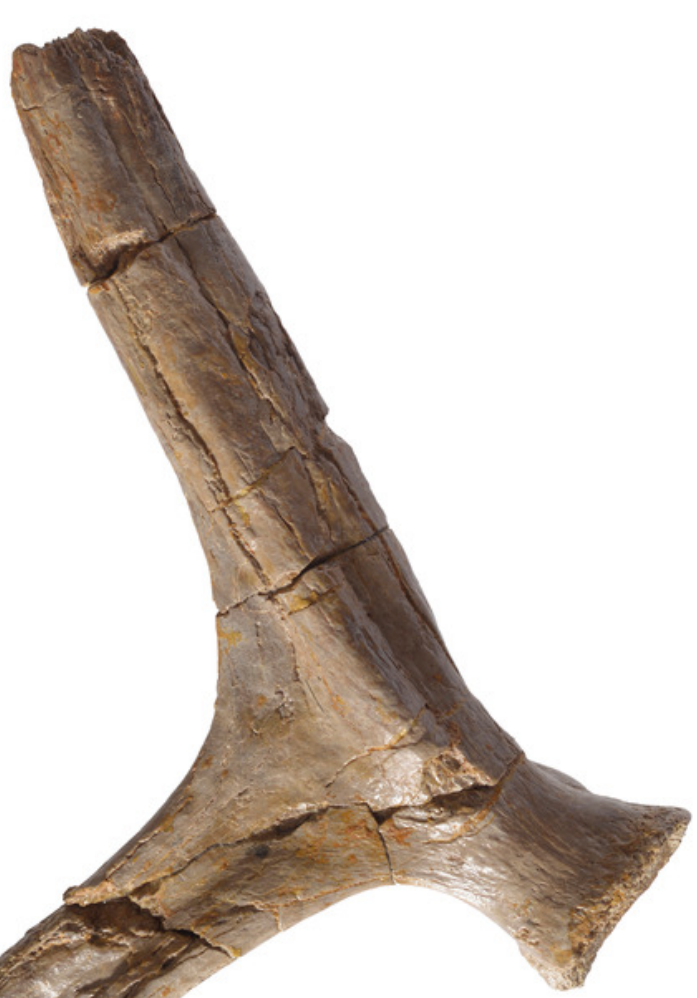

B

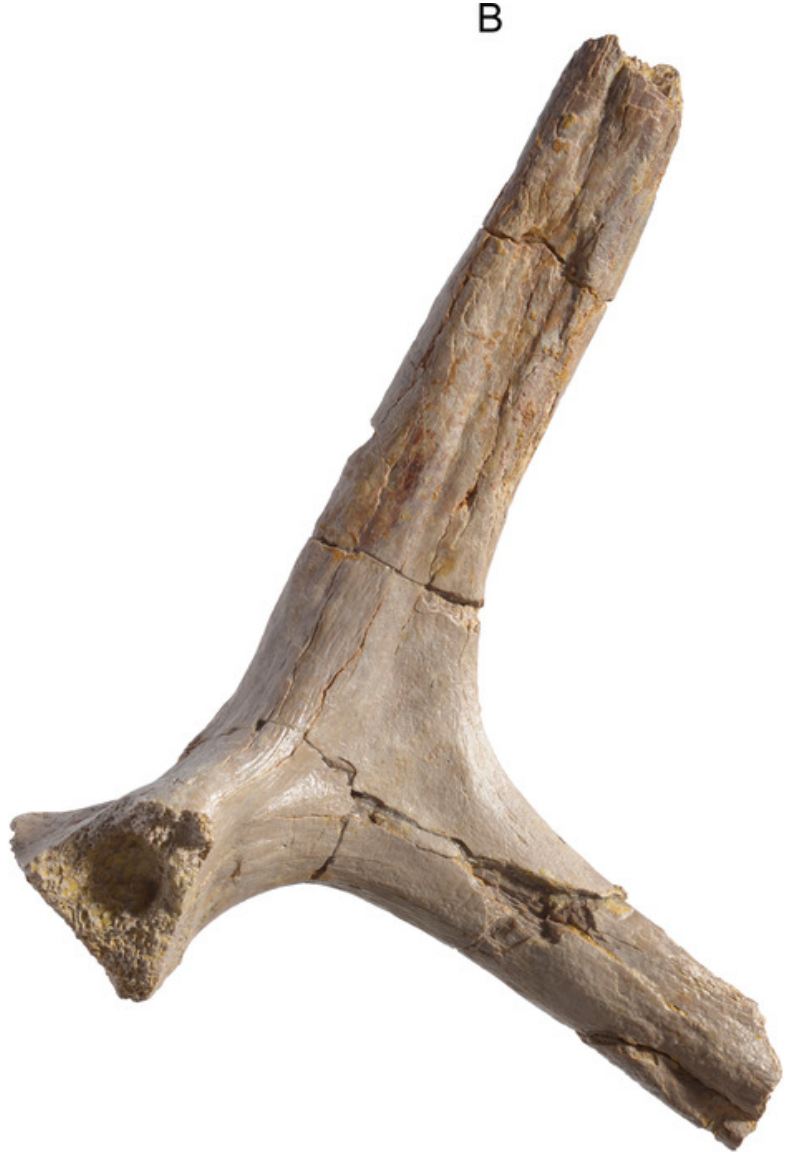




\section{Figure 11}

MJSN TCH007-252, holotype of Plesiochelys bigleri (Kimmeridgian, Porrentruy, Switzerland).

Right humerus in dorsal (A), anterior (B), ventral (C), and posterior view (D); left humerus in dorsal $(E)$, anterior $(F)$, ventral $(G)$, and posterior view $(H)$.

A

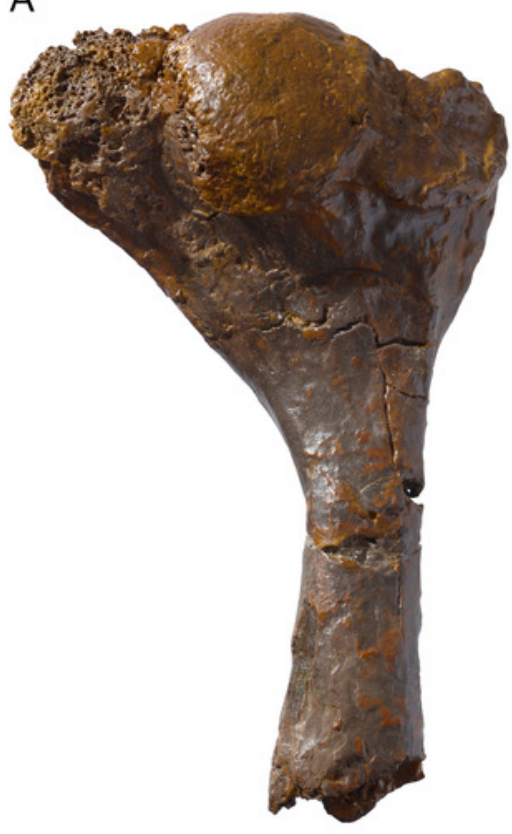

$E$

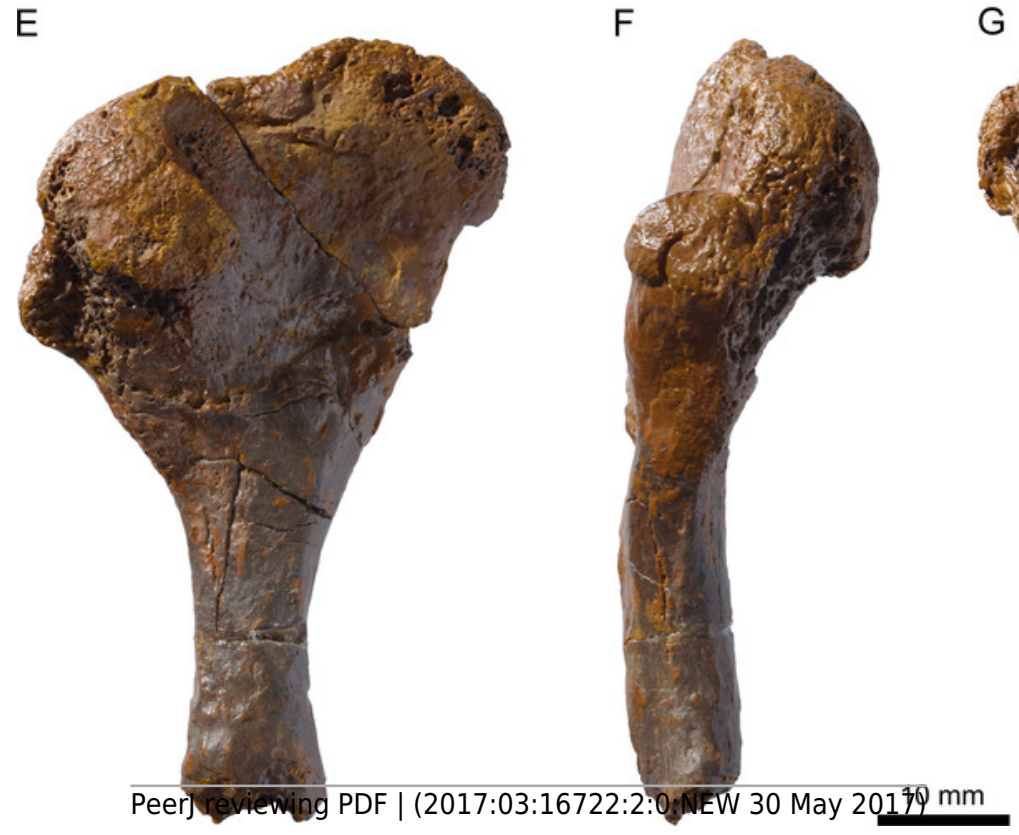

B

C

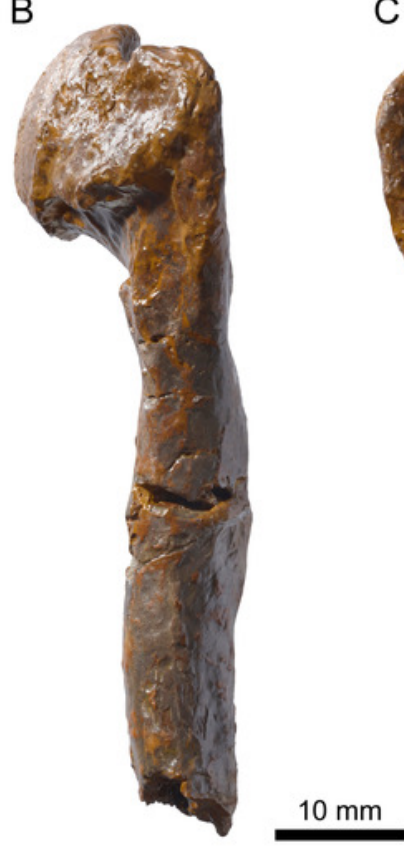

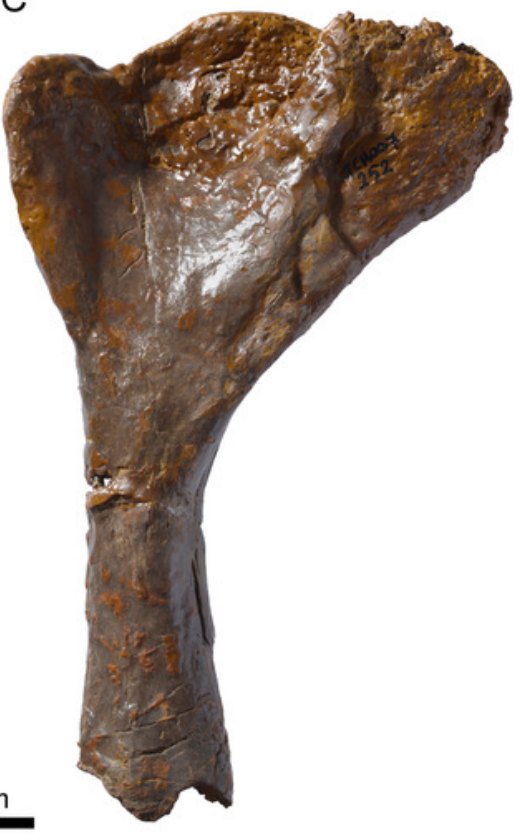

G

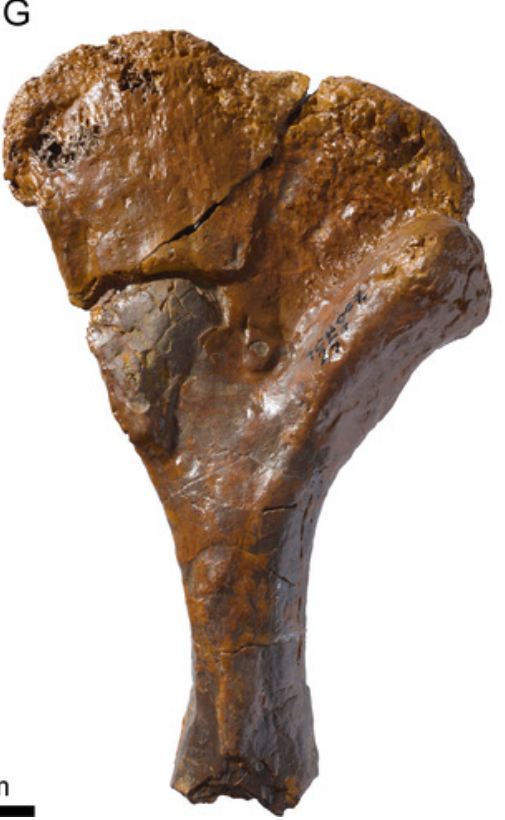

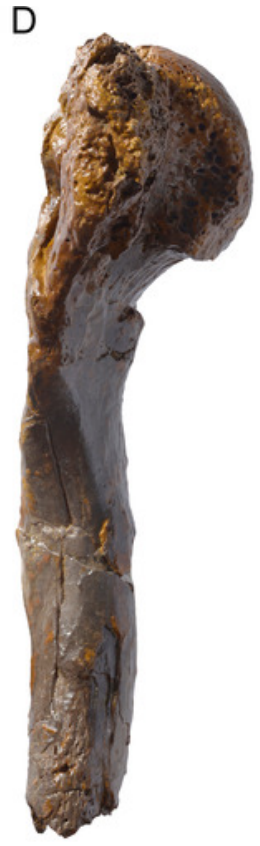

$\mathrm{H}$

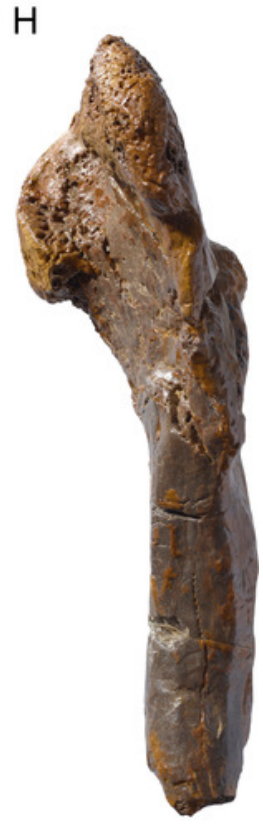




\section{Figure 12}

MJSN TCH007-252, holotype of Plesiochelys bigleri (Kimmeridgian, Porrentruy, Switzerland).

Right radius in dorsal (A), medial (B), ventral (C), and lateral view (D); right ulna in dorsal $(E)$, medial $(F)$, ventral $(G)$, and lateral view $(H)$. 


$$
\begin{aligned}
& 1111 \\
& 1<1\}
\end{aligned}
$$


Figure 13

MJSN BSY006-307, Plesiochelys bigleri (Kimmeridgian, Porrentruy, Switzerland).

Pelvis in right lateral view. 


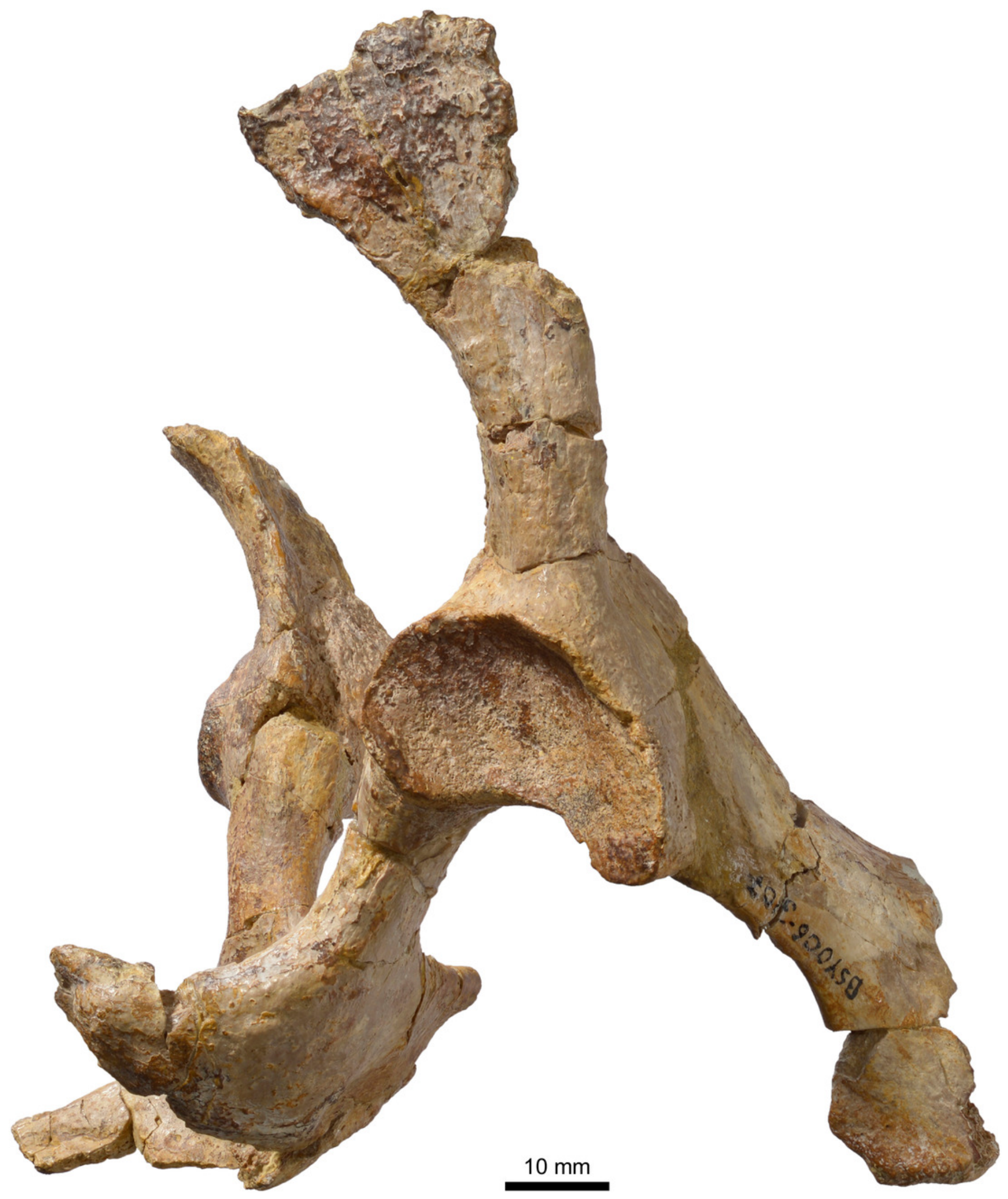




\section{Figure 14}

MJSN SCR010-1279, Plesiochelys bigleri (Kimmeridgian, Porrentruy, Switzerland).

Right femur in dorsal (A), anterior (B), ventral (C), and posterior view (D); left fibula in dorsal $(E)$, medial $(F)$, ventral $(G)$, and lateral view $(H)$. 
A

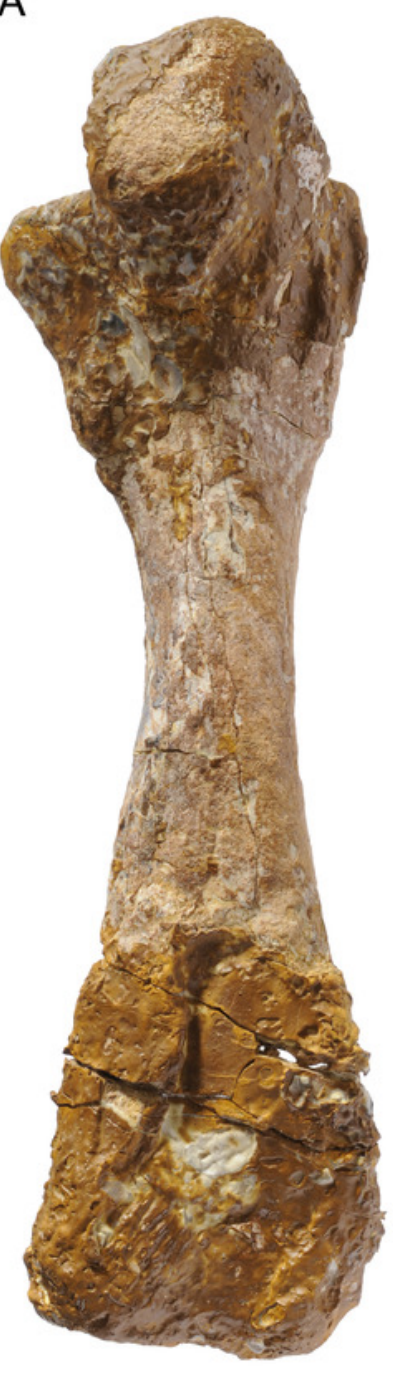

B

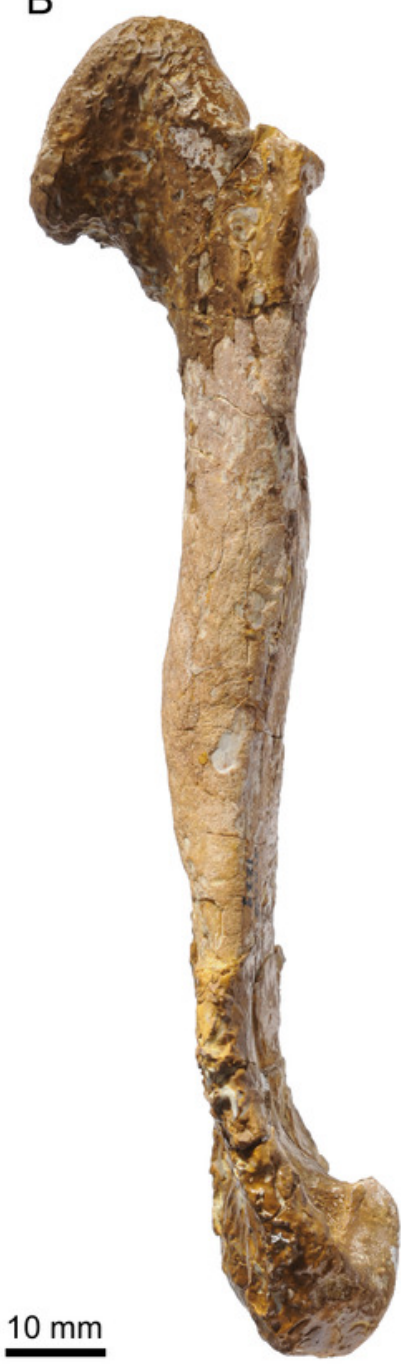

C

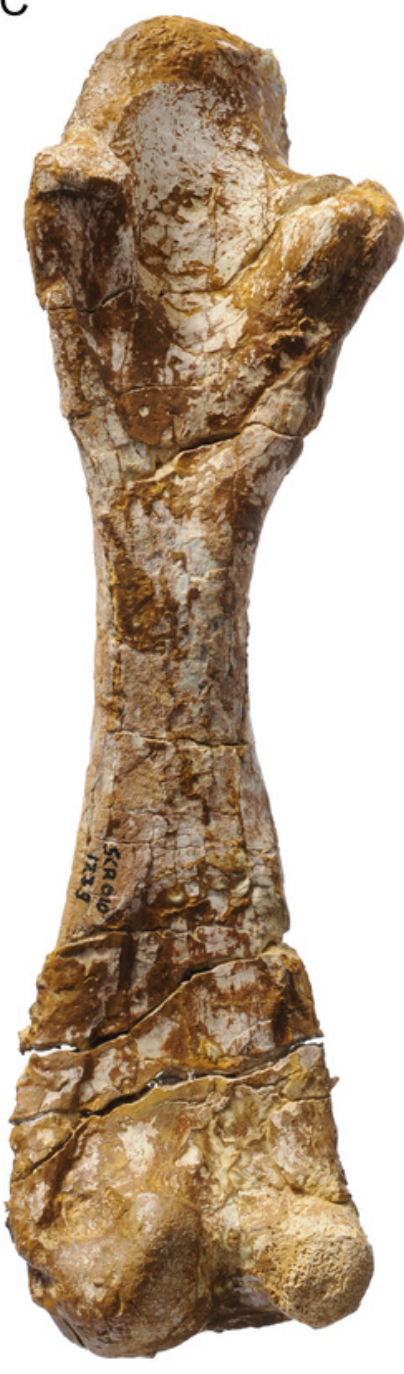

D

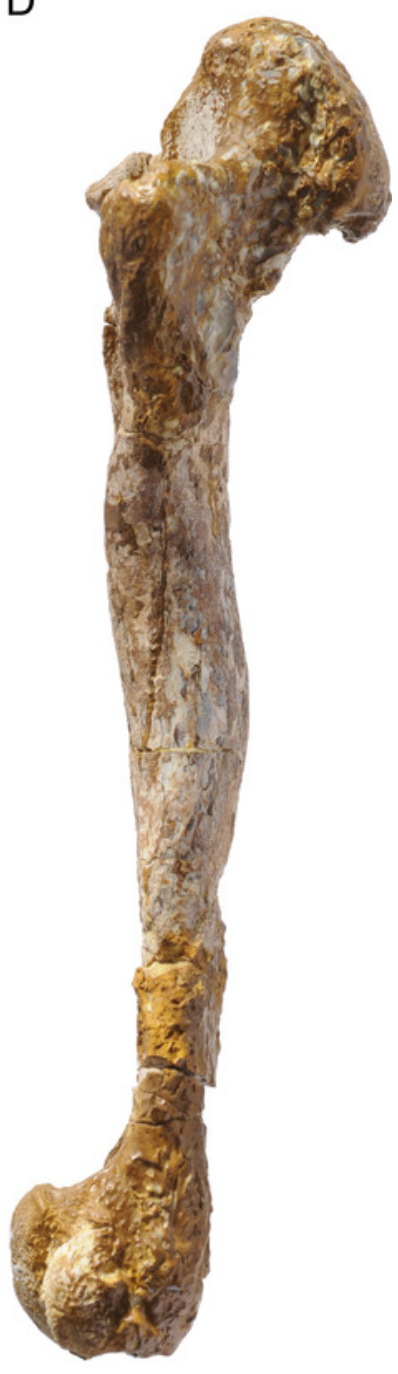

E

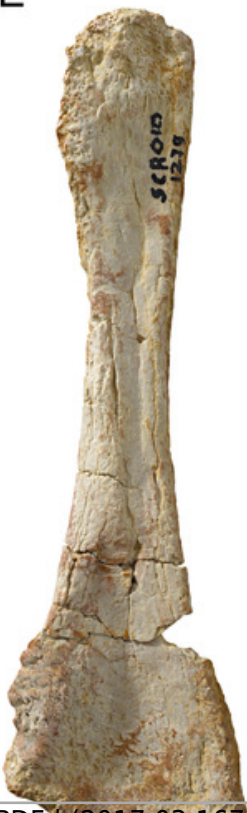

F

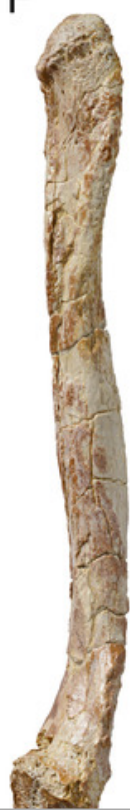

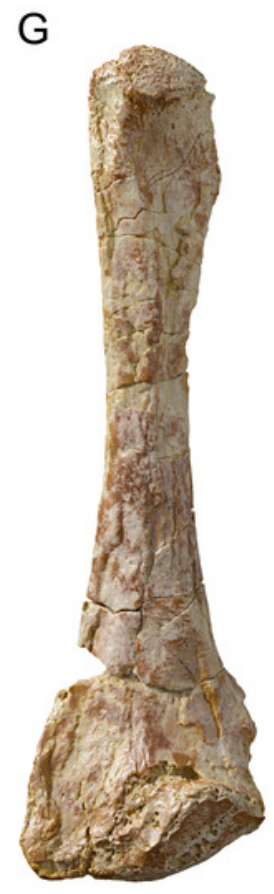

$\mathrm{H}$

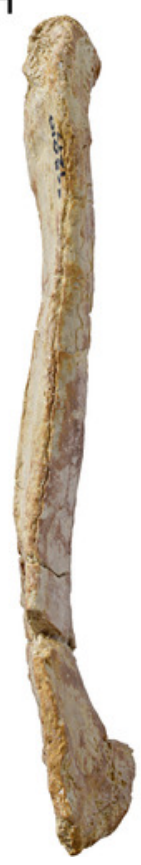




\section{Figure 15}

MJSN TCH005-21, Plesiochelys bigleri (Kimmeridgian, Porrentruy, Switzerland).

Cervical vertebra in dorsal (A), anterior (B), left lateral (C), ventral (D), posterior (E), and right lateral view (F).

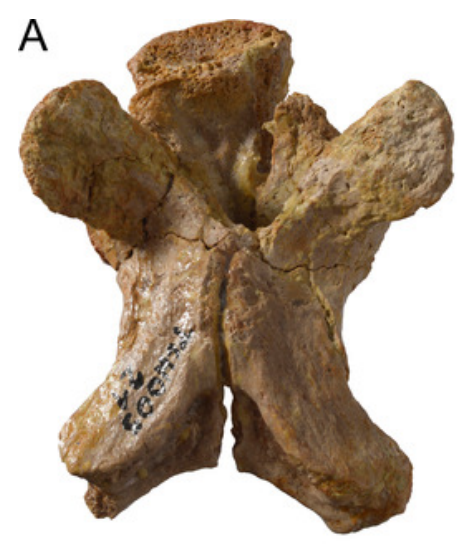

D

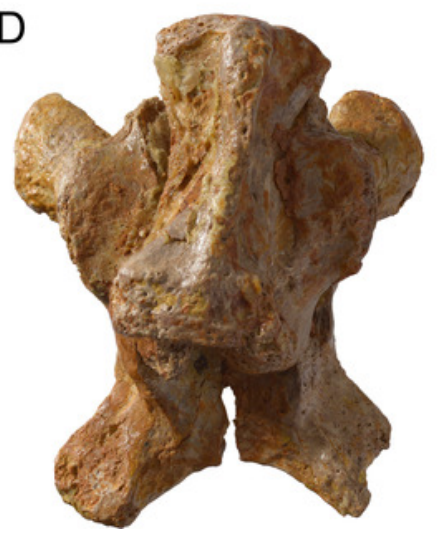

B

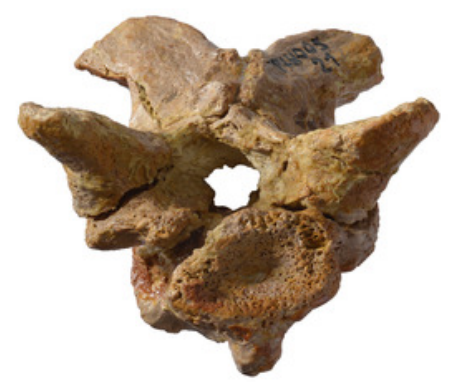

$10 \mathrm{~mm}$

C

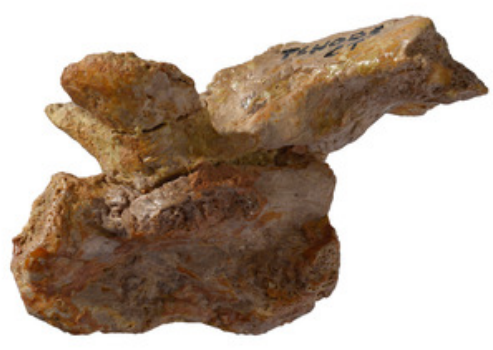

E

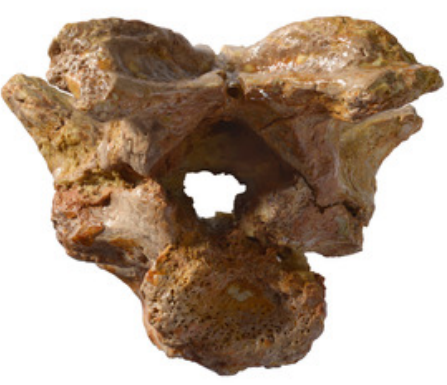

$\mathrm{F}$

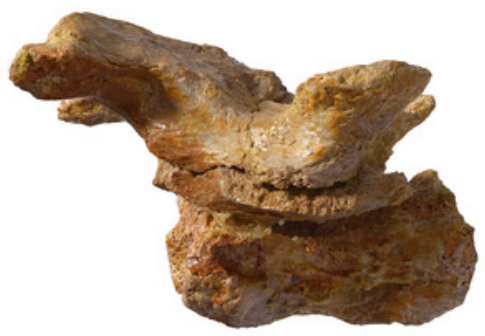




\section{Figure 16}

MJSN TCH006-574, Plesiochelys etalloni (Kimmeridgian, Porrentruy, Switzerland).

Carapace in dorsal $(A, B)$ and right lateral view $(C)$; plastron in ventral view $(D, E)$. Line width indicates natural borders (thick lines), bone sutures (medium lines), and fractures (thin lines); double lines indicate scale sulci. Abbreviations: epi, epiplastron; pl, pleural scale; py, pygal. 
A

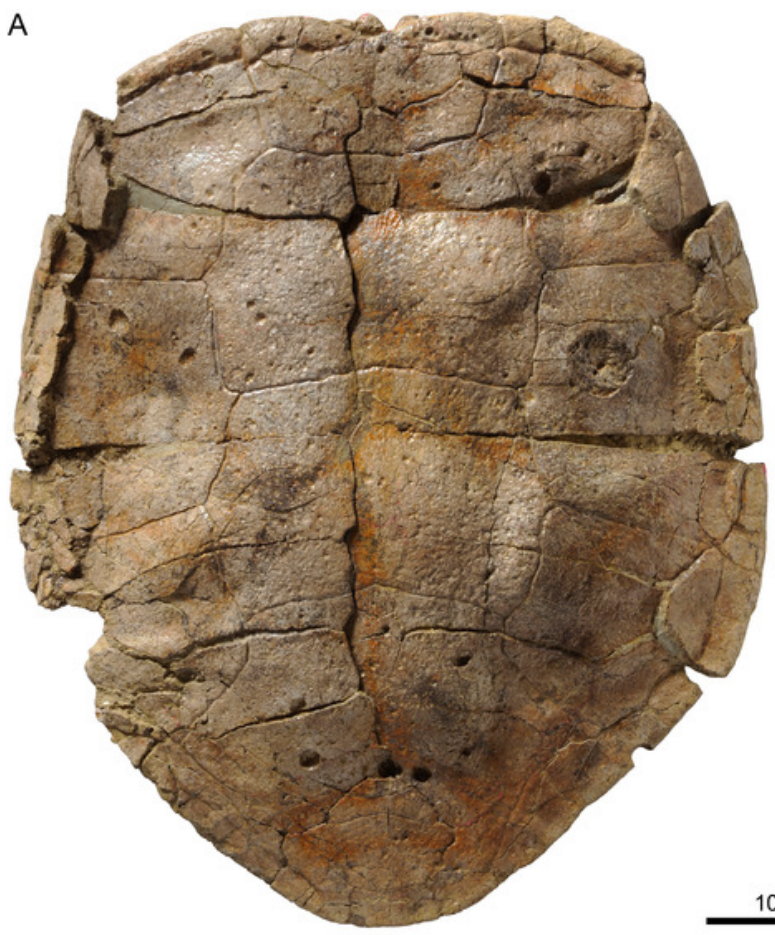

D

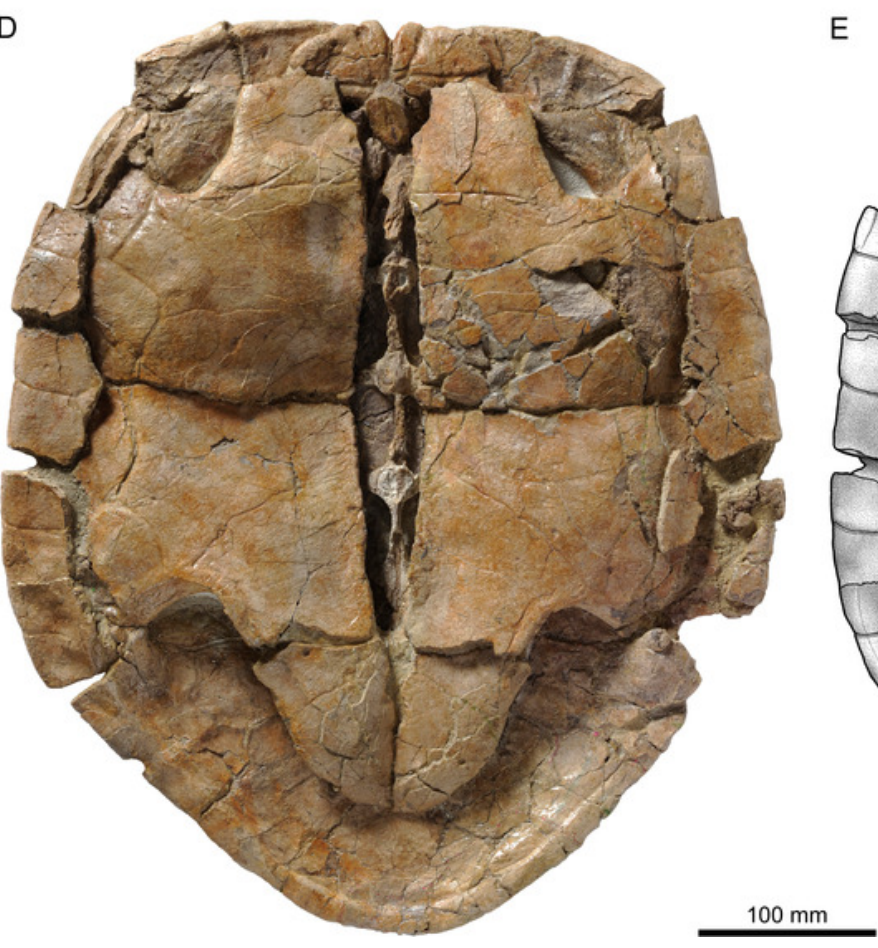

B

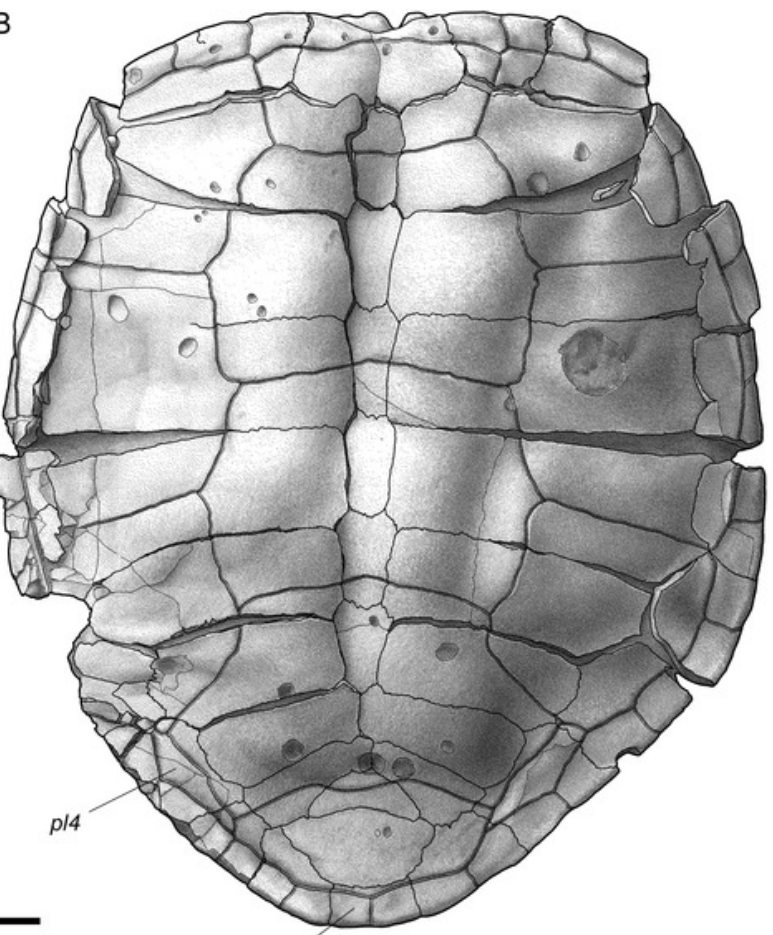

py
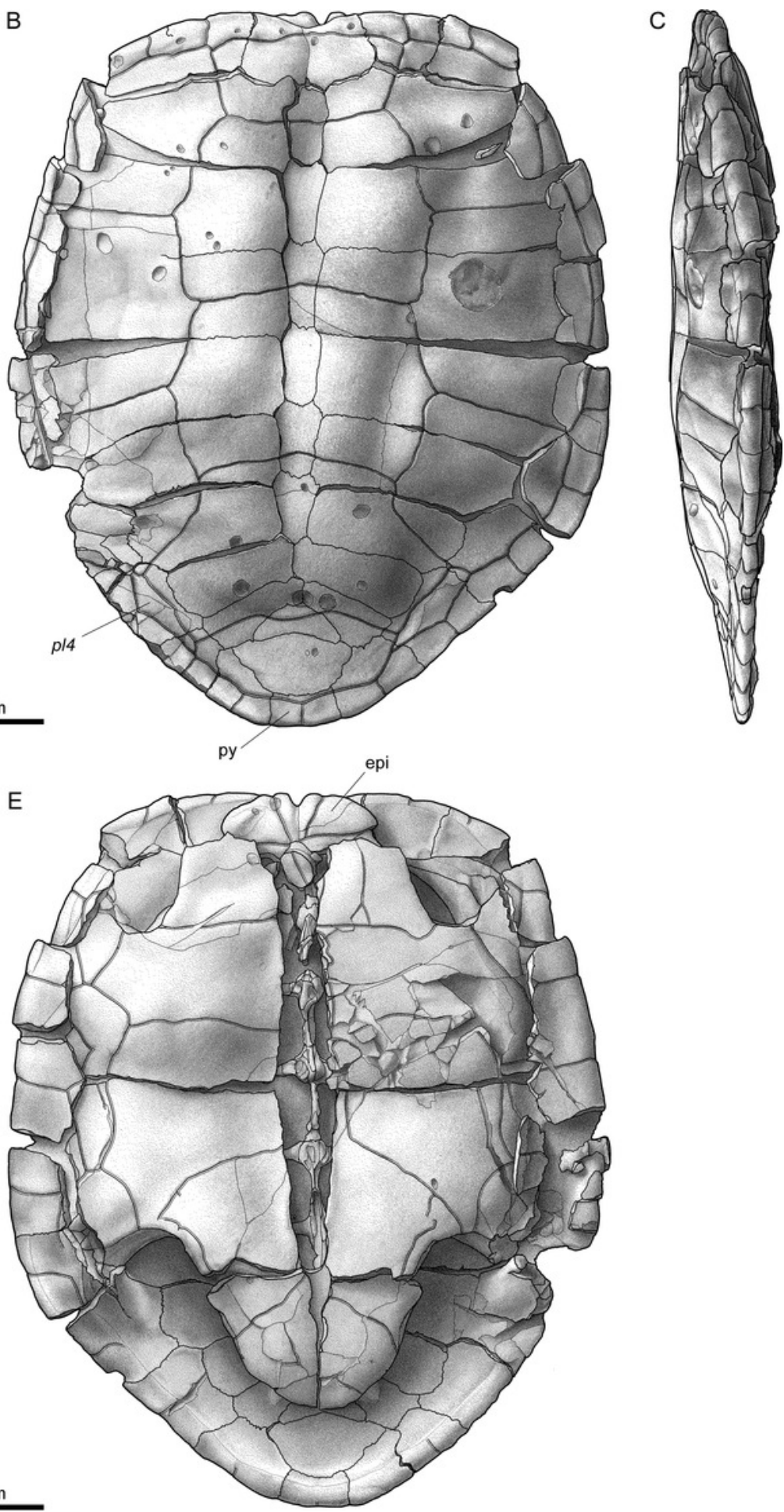


\section{Figure 17}

Neural bone thickness in Plesiochelys etalloni and Plesiochelys bigleri.

Statistical analysis of mean neural length, mean neural thickness, and corresponding length/thickness ratio (see text) for 25 specimens of Plesiochelys bigleri (green), 8 specimens of Plesiochelys etalloni (blue), and 10 indeterminate specimens (Plesiochelys sp.; gray) (all specimens from the Kimmeridgian of Porrentruy, Switzerland). (A) Mean length/thickness scatter-plot (specimen numbers are indicated for indeterminate specimens). (B) Length and thickness measurements on the fifth neural bone of specimen BSY006-307 (scale bar = $20 \mathrm{~mm}$ ). (C) Discriminant histogram. (D-F) Box-and-whisker plots for mean length, mean thickness, and length/thickness ratio, respectively. 

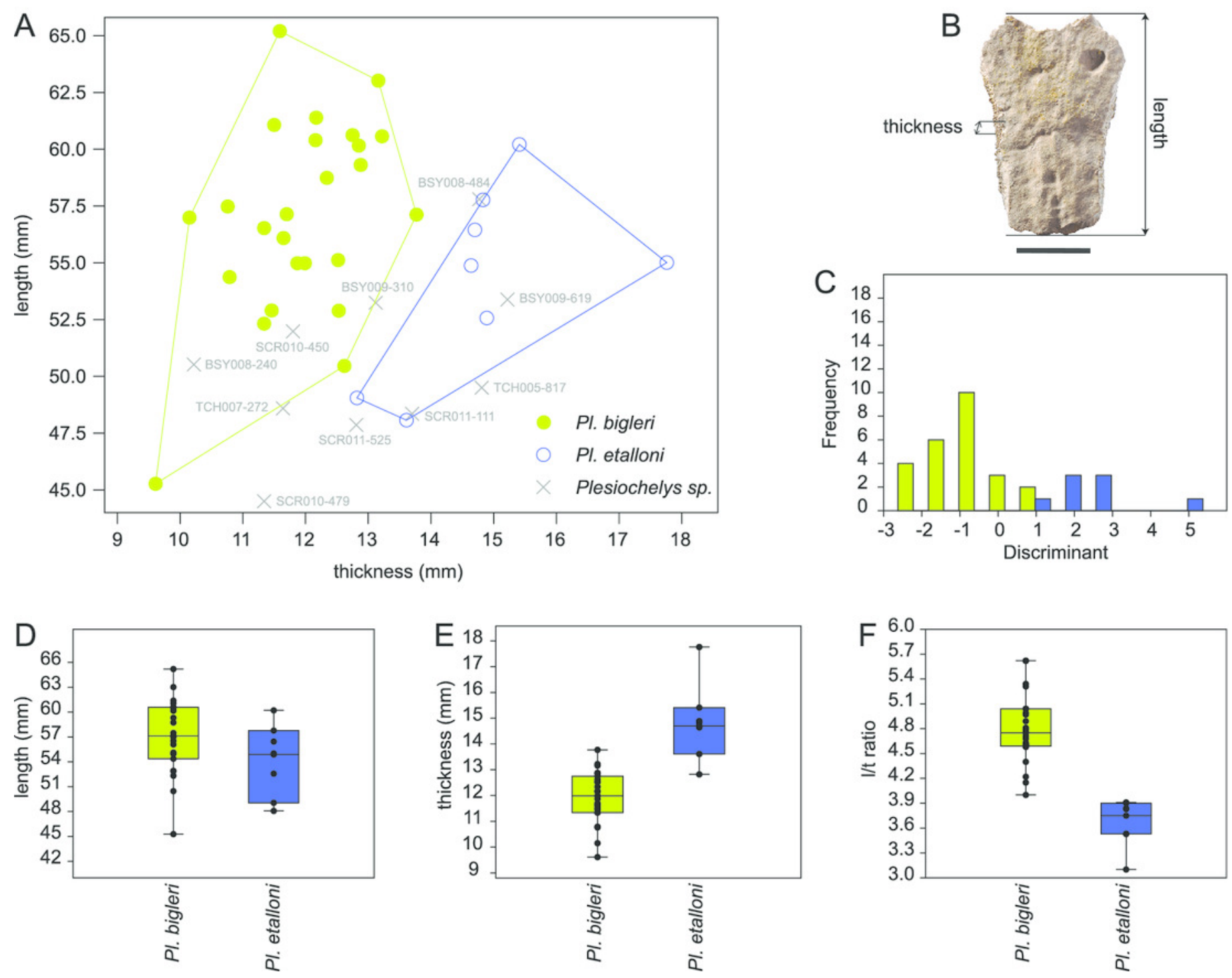


\section{Table $\mathbf{1}$ (on next page)}

The new Plesiochelys material from Porrentruy.

42 specimens are attributed to the new species Plesiochelys bigleri, 15 specimens to Plesiochelys etalloni, and 24 specimens to Plesiochelys sp. Abbreviations: c, carapace; cv, cervical vertebra; fl, forelimb; hl, hindlimb; $p$, pelvis; pl, plastron; s, scapula; sk, skull. All specimens are housed at the MJSN. 
1

\section{Plesiochelys bigleri}

MJSN BSY006-307 (c, pl, p)

MJSN BSY006-326 (c, pl)

MJSN BSY007-147 (c, pl, p)

MJSN BSY007-257 (c, pl)

MJSN BSY008-206 (c, pl)

MJSN BSY008-242 (c, pl)

MJSN BSY008-512 (c, pl)

MJSN BSY008-567 (c, pl, s, fl)

MJSN BSY008-848 (c, pl)

MJSN BSY009-639 (c, pl)

MJSN BSY009-743 (pl)

MJSN BSY009-815 (c, pl, s, p)

MJSN BSY009-892 (c, pl)

MJSN CRT007-2 (c, pl)

MJSN SCR010-327 (c, pl)

MJSN SCR010-342 (c, pl)

MJSN SCR010-1009 (c, pl)

MJSN SCR010-1047 (c, pl)

MJSN SCR010-1196 (c, pl)

MJSN SCR010-1279 (c, pl, hl)

MJSN SCR011-30 (c, pl, s, p, cv)

MJSN SCR011-37 (c, pl)

MJSN SCR011-140 (c, pl)

MJSN SCR011-148 (c, pl, s, p)

MJSN SCR011-160 (c, pl)

MJSN SCR011-276 (c, pl)

MJSN SCR011-413 (c, pl, p)

MJSN TCH005-16 (c, pl)

MJSN TCH005-21 (c, pl, hl, cv)

MJSN TCH005-42 (c, pl, s)

MJSN TCH005-464 (c, pl)

MJSN TCH005-819 (c, pl)

MJSN TCH006-145 (c, pl)

MJSN TCH006-767 (c, pl, p)

MJSN TCH006-1420 (c, pl, p)

\section{Plesiochelys etalloni}

MJSN BSY006-347 (c, pl, s, p)

MJSN BSY006-376 (c, pl)

MJSN BSY007-205 (c, pl)

MJSN BSY009-694 (c, pl)

MJSN SCR003-1011 (c)

MJSN SCR008-33 (c)

MJSN SCR010-382 (c, pl)

MJSN SCR011-415 (c, pl)

MJSN TCH005-216 (c, pl)

MJSN TCH005-332 (c)

MJSN TCH005-457 (c, pl)

MJSN TCH006-574 (c, pl)

MJSN TCH007-265 (c, pl)

MJSN TCH007-505 (c, pl)

MJSN TCH007-771 (c, pl)

\section{Plesiochelys sp.}

MJSN BSY003-1 (c, pl, s) MJSN BSY008-240 (c, pl) MJSN BSY008-484 (c, pl, s, fl, p) MJSN BSY008-674 (c, pl) MJSN BSY009-171 (c, pl) MJSN BSY009-310 (c, pl, s, p) MJSN BSY009-619 (c, pl) MJSN SCR010-413 (pl) MJSN SCR010-450 (c, pl) MJSN SCR010-479 (c, pl, p) MJSN SCR010-559 (c) MJSN SCR010-560 (c, pl) MJSN SCR010-561 (pl) MJSN SCR010-562 (c, pl) MJSN SCR011-111 (c, pl) MJSN SCR011-525 (c, pl, p, hl) MJSN TCH005-286 (c, pl) MJSN TCH005-817 (c) MJSN TCH006-776 (c, pl, fl) MJSN TCH006-787 (c) MJSN TCH007-62 (c, pl) MJSN TCH007-272 (c, pl) MJSN TCH007-541 (c, pl) MJSN TCH007-580 (pl, fl, p) 
MJSN TCH006-1451 (sk)

MJSN TCH007-252 (sk, c, pl, s, fl, p)

MJSN TCH007-371 (pl)

MJSN TCH007-516 (c)

MJSN TCH007-519 (c, pl, s, p)

MJSN VTT006-299 (c, pl)

MJSN VTT006-579 (c, pl)

2 


\section{Table 2 (on next page)}

Length and width measurements of the skull in Plesiochelys bigleri.

These measurements should be compared with those of other plesiochelyid skulls (Anquetin, Püntener \& Billon-Bruyat, 2015: table 1). 


\begin{tabular}{|c|c|c|}
\hline $\begin{array}{l}\text { Total length from } \\
\text { condylus occipitalis to } \\
\text { tip of the snout (mm) }\end{array}$ & $\begin{array}{l}\text { Length from pt-vo/pal } \\
\text { suture to condylus } \\
\text { occipitalis }(\mathrm{mm})\end{array}$ & $\begin{array}{l}\text { Width at the level of } \\
\text { the condyli } \\
\text { mandibularis (mm) }\end{array}$ \\
\hline- & $38.5^{\mathrm{a}}$ & 60.6 \\
\hline $59.8^{\mathrm{a}}$ & 34.4 & 60.0 \\
\hline
\end{tabular}

2 a Specimen incomplete 


\section{Table 3(on next page)}

Measurements used for the analysis of neural thickness in Plesiochelys spp.

Mean neural length, mean neural thickness, and mean length/mean thickness ratio measured for selected specimens referred to Plesiochelys bigleri, Plesiochelys etalloni, and Plesiochelys sp. Measurements are expressed in millimeters. See Table S1 for original measurements. All specimens are housed at the MJSN. 


\begin{tabular}{|c|c|c|c|c|}
\hline Specimen & Identification & Mean length & Mean thickness & Ratio \\
\hline BSY006-307 & Pl. bigleri & 60.62 & 12.75 & 4.75 \\
\hline ТCH007-252 & Pl. bigleri & 56.99 & 10.15 & 5.62 \\
\hline SCR011-140 & Pl. bigleri & 57.48 & 10.76 & 5.34 \\
\hline BSY009-815 & Pl. bigleri & 57.12 & 13.77 & 4.15 \\
\hline BSY007-257 & Pl. bigleri & 45.27 & 9.61 & 4.71 \\
\hline SCR011-148 & Pl. bigleri & 52.89 & 12.53 & 4.22 \\
\hline SCR011-413 & Pl. bigleri & 54.98 & 11.99 & 4.59 \\
\hline ТCH006-1420 & Pl. bigleri & 56.09 & 11.65 & 4.81 \\
\hline SCR011-276 & Pl. bigleri & 60.57 & 13.22 & 4.58 \\
\hline VTT006-299 & Pl. bigleri & 61.39 & 12.17 & 5.04 \\
\hline TCH005-16 & Pl. bigleri & 61.07 & 11.50 & 5.31 \\
\hline ТCH005-464 & Pl. bigleri & 57.14 & 11.70 & 4.89 \\
\hline ТCH005-21 & Pl. bigleri & 63.02 & 13.16 & 4.79 \\
\hline SCR011-37 & Pl. bigleri & 52.90 & 11.46 & 4.61 \\
\hline BSY008-206 & Pl. bigleri & 59.31 & 12.88 & 4.60 \\
\hline SCR010-1279 & Pl. bigleri & 65.20 & 11.59 & 5.62 \\
\hline VTT006-579 & Pl. bigleri & 54.98 & 11.87 & 4.63 \\
\hline TCH006-145 & Pl. bigleri & 52.32 & 11.34 & 4.61 \\
\hline BSY009-892 & Pl. bigleri & 60.16 & 12.85 & 4.68 \\
\hline ТCH005-819 & Pl. bigleri & 60.40 & 12.16 & 4.97 \\
\hline BSY006-326 & Pl. bigleri & 54.37 & 10.79 & 5.04 \\
\hline SCR010-1009 & Pl. bigleri & 56.53 & 11.34 & 4.99 \\
\hline SCR011-160 & Pl. bigleri & 58.74 & 12.34 & 4.76 \\
\hline SCR010-1196 & Pl. bigleri & 55.12 & 12.52 & 4.40 \\
\hline TCH006-767 & Pl. bigleri & 50.46 & 12.62 & 4.00 \\
\hline BSY009-694 & Pl. etalloni & 57.77 & 14.83 & 3.90 \\
\hline SCR011-415 & Pl. etalloni & 48.07 & 13.61 & 3.53 \\
\hline BSY006-347 & Pl. etalloni & 56.45 & 14.70 & 3.84 \\
\hline BSY007-205 & Pl. etalloni & 60.21 & 15.41 & 3.91 \\
\hline SCR008-33 & Pl. etalloni & 55.01 & 17.76 & 3.10 \\
\hline SCR010-382 & Pl. etalloni & 49.05 & 12.82 & 3.83 \\
\hline
\end{tabular}




$\begin{array}{lllll}\text { TCH007-265 } & \text { Pl. etalloni } & 52.57 & 14.89 & 3.53 \\ \text { TCH007-505 } & \text { Pl. etalloni } & 54.88 & 14.64 & 3.75 \\ \text { BSY009-310 } & \text { Plesiochelys sp. } & 53.24 & 13.12 & 4.06 \\ \text { TCH007-272 } & \text { Plesiochelys sp. } & 48.59 & 11.64 & 4.18 \\ \text { TCH005-817 } & \text { Plesiochelys sp. } & 49.50 & 14.81 & 3.34 \\ \text { SCR010-450 } & \text { Plesiochelys sp. } & 51.98 & 11.80 & 4.40 \\ \text { SCR010-479 } & \text { Plesiochelys sp. } & 44.50 & 11.34 & 3.92 \\ \text { SCR011-525 } & \text { Plesiochelys sp. } & 47.86 & 12.81 & 3.74 \\ \text { BSY009-619 } & \text { Plesiochelys sp. } & 53.38 & 15.22 & 3.51 \\ \text { BSY008-240 } & \text { Plesiochelys sp. } & 50.52 & 10.22 & 4.95 \\ \text { SCR011-111 } & \text { Plesiochelys sp. } & 48.35 & 13.70 & 3.53 \\ \text { BSY008-484 } & \text { Plesiochelys sp. } & 57.80 & 14.77 & 3.91\end{array}$




\section{Table 4 (on next page)}

Classification of indeterminate specimens.

Comparison of the tentative classifications of indeterminate specimens (Plesiochelys sp.) based on the length/thickness scatter plot (Fig. 17A) and the discriminant analysis (Fig. 17C). All specimens are housed at the MJSN. 


\section{Specimen}

BSY009-310

TCH007-272

TCH005-817

SCR010-450

SCR010-479

SCR011-525

BSY009-619

BSY008-240

SCR011-111

BSY008-484

\section{Scatter plot}

Pl. bigleri

Pl. bigleri

Pl. etalloni

Pl. bigleri

?

Pl. etalloni

Pl. etalloni

Pl. bigleri

Pl. etalloni

Pl. etalloni

\section{Discriminant analysis}

Pl. etalloni

Pl. bigleri

Pl. etalloni

Pl. bigleri

Pl. bigleri

Pl. etalloni

Pl. etalloni

Pl. bigleri

Pl. etalloni

Pl. etalloni

1 